\title{
Biphenyl Cyclobutenone Photoelectrocyclizations
}

Changhang Dai, Xuchen Zhao, Changqing Song, Zach Schwartz, and Jon D. Rainier* Department of Chemistry

University of Utah

315 South, 1400 East

Salt Lake City, UT 84112

Email: rainier@chem.utah.edu

\begin{tabular}{|c|c|}
\hline Compound & page \\
\hline 1. 4 ( ${ }^{1} \mathrm{H}$ NMR) & S2 \\
\hline 2. $4\left({ }^{13} \mathrm{C}\right.$ NMR $)$ & S3 \\
\hline 3. 10 ( ${ }^{1} \mathrm{H}$ NMR $)$ & S4 \\
\hline 4. $10\left({ }^{13} \mathrm{C} N M R\right)$ & S5 \\
\hline 5. $14\left({ }^{1} \mathrm{H}\right.$ NMR $)$ & S6 \\
\hline 6. $14\left({ }^{13} \mathrm{C}\right.$ NMR $)$ & S7 \\
\hline 7.27 ( ${ }^{1} \mathrm{H}$ NMR) & S8 \\
\hline 8. $27\left({ }^{13} \mathrm{C}\right.$ NMR) & SS \\
\hline 9. S3 ( $\left.{ }^{1} \mathrm{H} N M R\right)$ & $\mathrm{S} 10$ \\
\hline 10. S3 ( ${ }^{13} \mathrm{C}$ NMR) & \\
\hline 11. $32\left({ }^{1} \mathrm{H}\right.$ NMR) & $\mathrm{S} 12$ \\
\hline 12. $32\left({ }^{13} \mathrm{C}\right.$ NMR $)$ & $\mathrm{S} 13$ \\
\hline 13. $34\left({ }^{1} \mathrm{H}\right.$ NMR) & S \\
\hline 14. $34\left({ }^{13} \mathrm{C}\right.$ NMR) & \\
\hline 15. 35 ( ${ }^{1} \mathrm{H}$ NMR) & \\
\hline 16. $35\left({ }^{13} \mathrm{C}\right.$ NMR) & S17 \\
\hline 17. 36 ( ${ }^{1} \mathrm{H}$ NMR) & $\mathrm{S}$ \\
\hline 18. $36\left({ }^{13} \mathrm{C}\right.$ NMR $)$ & $S$ \\
\hline 19. $37\left({ }^{1} \mathrm{H}\right.$ NMR) & S2 \\
\hline 20. $37\left({ }^{13} \mathrm{C}\right.$ NMR) & S2 \\
\hline 21. $38\left({ }^{1} \mathrm{H}\right.$ NMR) & S2 \\
\hline 22. $38\left({ }^{13} \mathrm{C}\right.$ NMR $)$ & S2 \\
\hline 23. 39 ( ${ }^{1} \mathrm{H}$ NMR) & \\
\hline 24. $39\left({ }^{13} \mathrm{C}\right.$ NMR $)$ & St \\
\hline $25.40\left({ }^{1} \mathrm{H}\right.$ NMR) & S? \\
\hline 26. $40\left({ }^{13} \mathrm{C}\right.$ NMR) & S2 \\
\hline $27.41\left({ }^{1} \mathrm{H}\right.$ NMR) & S? \\
\hline 28. 41 ( ${ }^{13} \mathrm{C}$ NMR) & S2 \\
\hline 29. S22 ( ${ }^{1} \mathrm{H}$ NMR) & S3 \\
\hline 30. S22 ( ${ }^{13} \mathrm{C}$ NMR) & \\
\hline 31. 42 ( ${ }^{1} \mathrm{H}$ NMR) & S32 \\
\hline 32. $42\left({ }^{13} \mathrm{C}\right.$ NMR) & \\
\hline
\end{tabular}

${ }^{1} \mathrm{H}$ NMR $\&{ }^{13} \mathrm{C}$ Spectra

$$
\begin{aligned}
& \text { Compound page } \\
& \text { 33. } \mathrm{S} 24\left({ }^{1} \mathrm{H} \text { NMR) } \quad \mathrm{S} 34\right. \\
& \text { 34. S24 }\left({ }^{13} \mathrm{C} \text { NMR) } \quad \mathrm{S} 35\right. \\
& \text { 35. } 43\left({ }^{1} \mathrm{H} \text { NMR }\right) \quad \text { S36 } \\
& \text { 36. } 43\left({ }^{13} \mathrm{C} \text { NMR) } \quad \mathrm{S} 37\right. \\
& \text { 37. } 44\left({ }^{1} \mathrm{H} \text { NMR }\right) \quad \text { S38 } \\
& \text { 37. } 44\left({ }^{13} \mathrm{C} \text { NMR) } \quad\right. \text { S39 } \\
& \text { 38. } 46\left({ }^{1} \mathrm{H} \text { NMR }\right) \quad \mathrm{S} 40 \\
& 39.46\left({ }^{13} \mathrm{C} \text { NMR }\right) \quad \mathrm{S} 41 \\
& \text { 40. } 47 \text { ( }{ }^{1} \mathrm{H} \text { NMR) } \quad \mathrm{S} 42 \\
& \text { 41. } 47\left({ }^{13} \mathrm{C} \text { NMR) } \quad \mathrm{S} 43\right. \\
& \text { 42. } 48 \text { ( }{ }^{1} \mathrm{H} \text { NMR) } \quad \mathrm{S} 44 \\
& \text { 43. } 48\left({ }^{13} \mathrm{C} \text { NMR) } \quad \mathrm{S} 45\right. \\
& \text { 44. } 52\left({ }^{1} \mathrm{H} \text { NMR) } \quad \mathrm{S} 46\right. \\
& \text { 45. } 52\left({ }^{13} \mathrm{C} \text { NMR }\right) \quad \mathrm{S} 47 \\
& \text { 46. } 53\left({ }^{1} \mathrm{H} \text { NMR }\right) \quad \mathrm{S} 48 \\
& \text { 47. } 53\left({ }^{13} \mathrm{C} \text { NMR }\right) \quad S 49 \\
& \text { 48. } 54 \text { ( }{ }^{1} \mathrm{H} \text { NMR) } \quad \mathrm{S} 50 \\
& \text { 49. } 54\left({ }^{13} \mathrm{C} \text { NMR) } \mathrm{S} 51\right. \\
& \text { 50. } 55\left({ }^{1} \mathrm{H} \mathrm{NMR}\right) \quad \mathrm{S} 52 \\
& 51.55\left({ }^{13} \mathrm{C} N M R\right) \quad \mathrm{S} 53 \\
& 52,56 / S 25\left({ }^{1} H\right. \text { NMR) S54 } \\
& \text { 53. 56/S25 ( }{ }^{13} \mathrm{C} \text { NMR) S55 } \\
& \text { 54. } 58\left({ }^{1} \mathrm{H} \text { NMR) } \quad \mathrm{S} 56\right. \\
& \text { 55. } 58\left({ }^{13} \mathrm{C} \text { NMR) } \quad \mathrm{S} 57\right. \\
& \text { 56. } 59\left({ }^{1} \mathrm{H} \text { NMR) } \quad \mathrm{S} 58\right. \\
& \text { 57. } 59\left({ }^{13} \mathrm{C} \text { NMR }\right) \quad \text { S59 } \\
& \text { 58. } 60\left({ }^{1} \mathrm{H} \text { NMR }\right) \quad S 60 \\
& \text { 59. } 60\left({ }^{13} \mathrm{C} \text { NMR) } \quad \mathrm{S} 61\right. \\
& \text { 60. } 61\left({ }^{1} \mathrm{H} \text { NMR) } \quad \mathrm{S} 62\right. \\
& 61.61\left({ }^{13} \mathrm{C} \text { NMR) } \quad \mathrm{S} 63\right. \\
& \text { 62. } 62\left({ }^{1} \mathrm{H} \text { NMR) } \quad \mathrm{S} 64\right. \\
& \text { 63. } 62\left({ }^{13} \mathrm{C} N M R\right) \quad S 65
\end{aligned}
$$

64. Fig S1. Spectral distribution and intensity of RPR-3500 lamp 


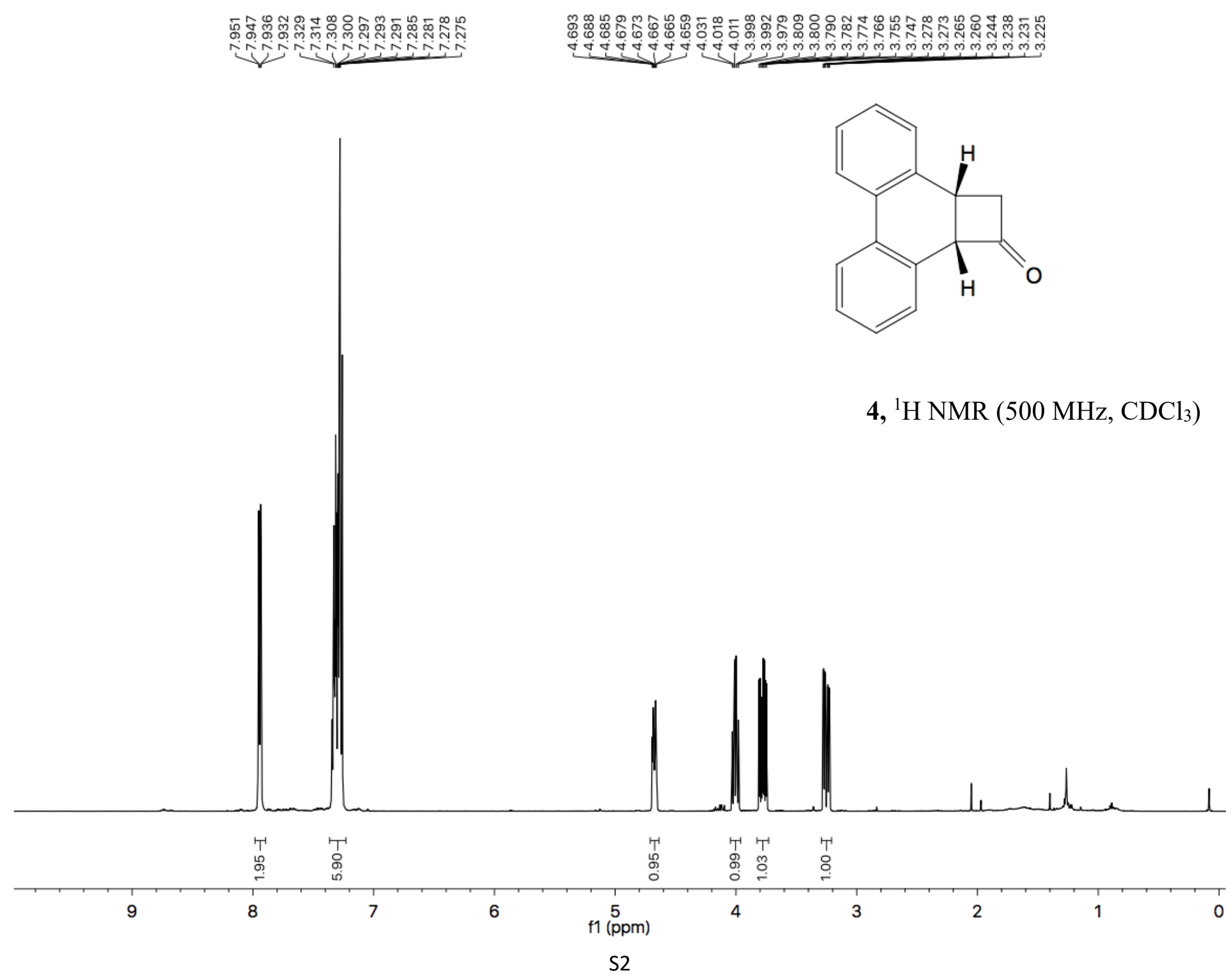




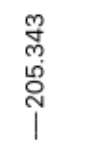

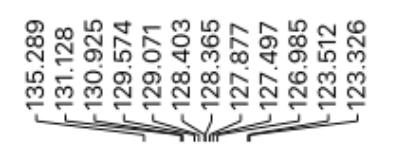

4, ${ }^{13} \mathrm{C}\left\{{ }^{1} \mathrm{H}\right\} \mathrm{NMR}\left(126 \mathrm{MHz}, \mathrm{CDCl}_{3}\right)$
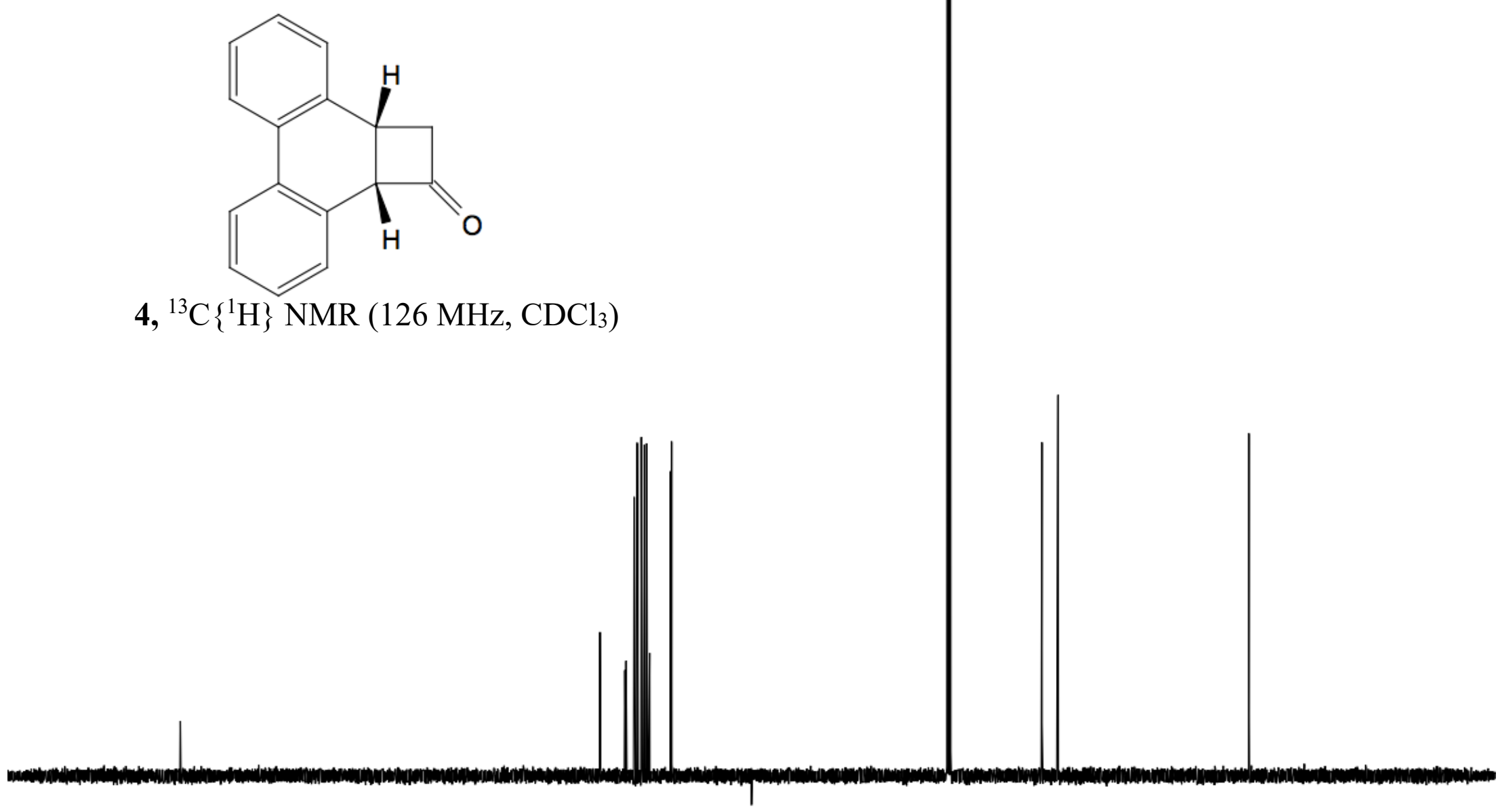


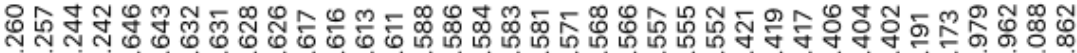

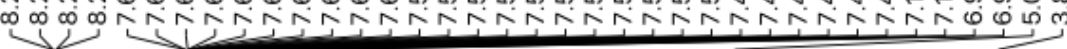

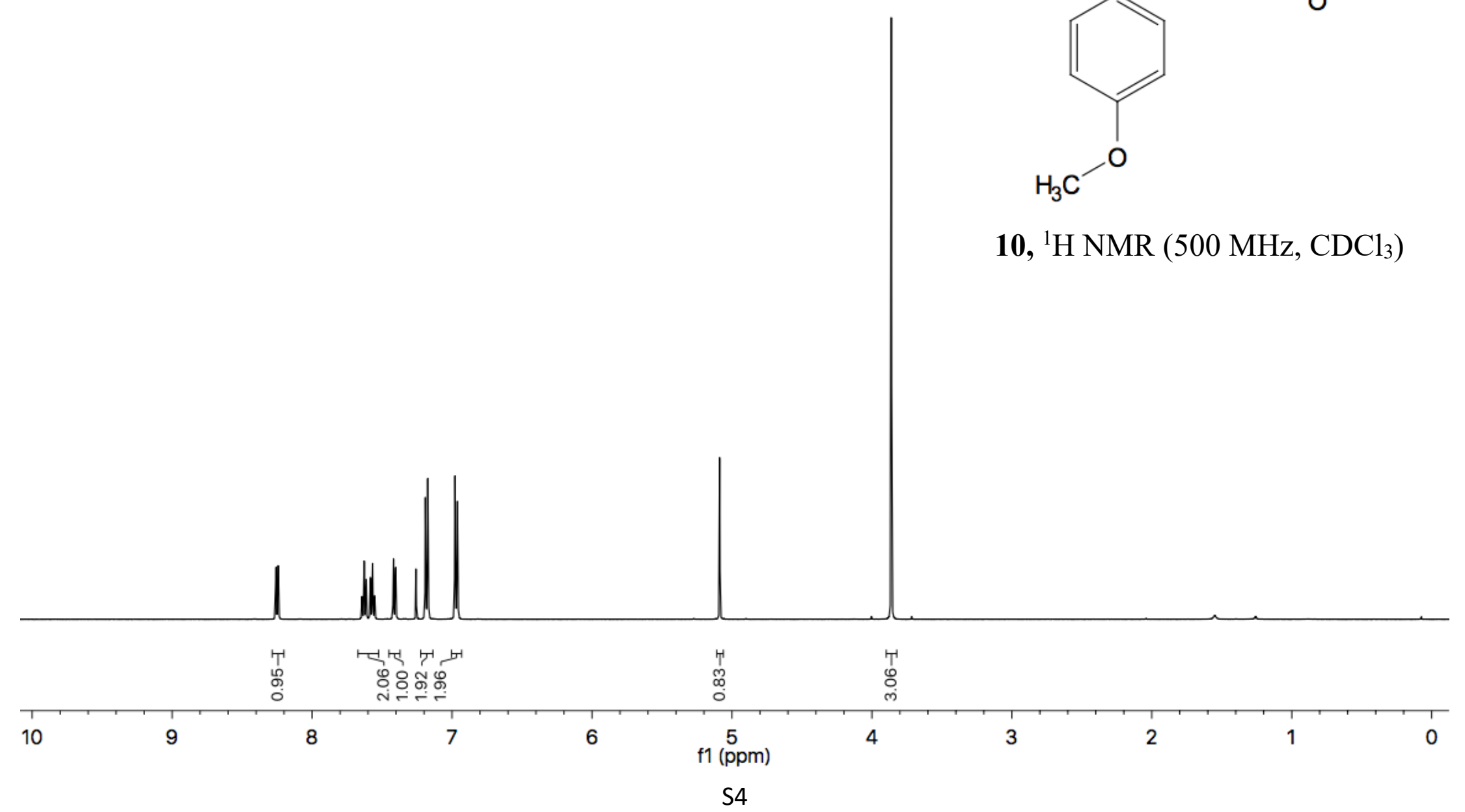

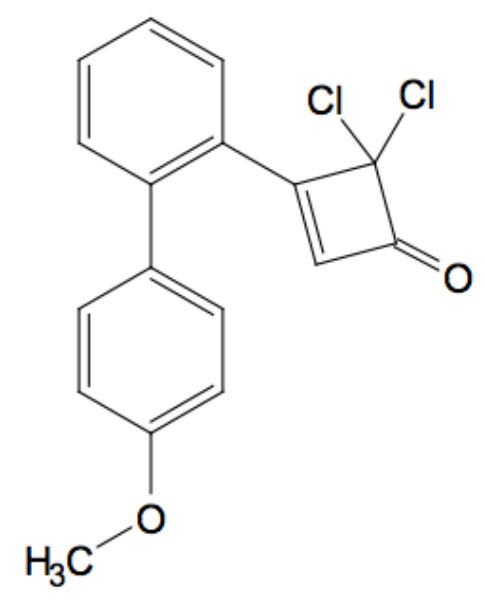

10, ${ }^{1} \mathrm{H}$ NMR $\left(500 \mathrm{MHz}, \mathrm{CDCl}_{3}\right)$ 


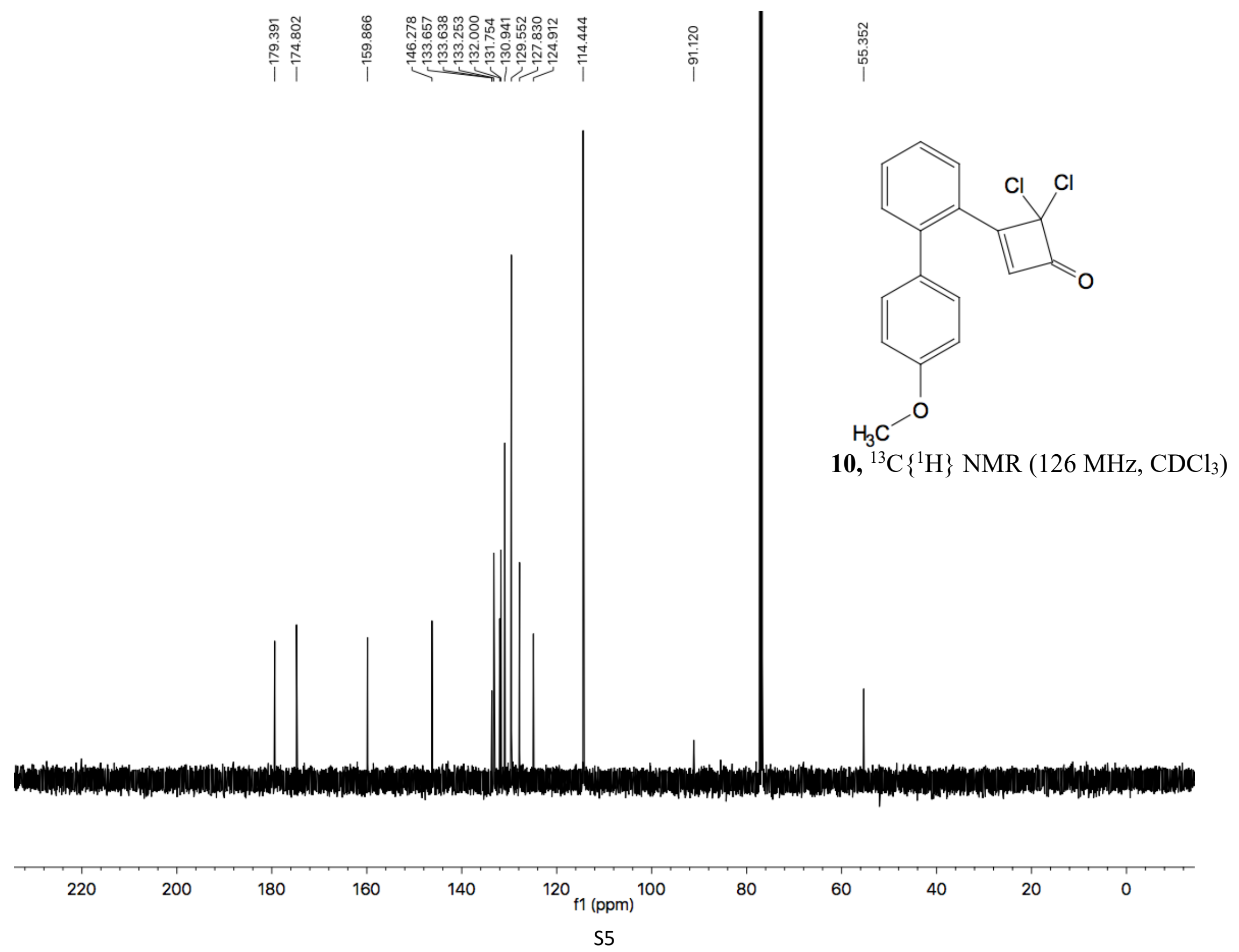




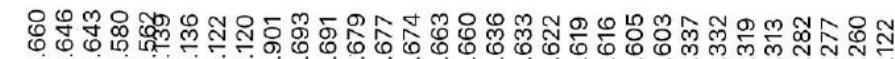

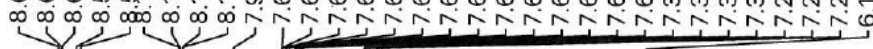

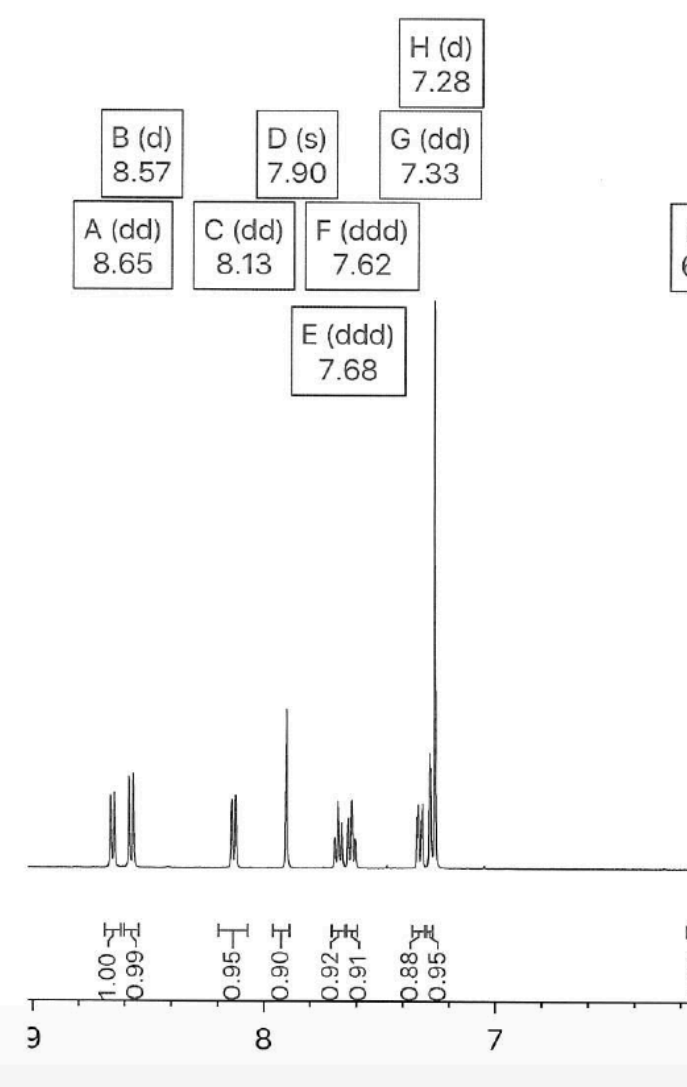

\begin{tabular}{l|} 
I (s) \\
6.12
\end{tabular}

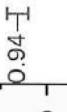

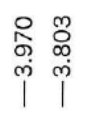

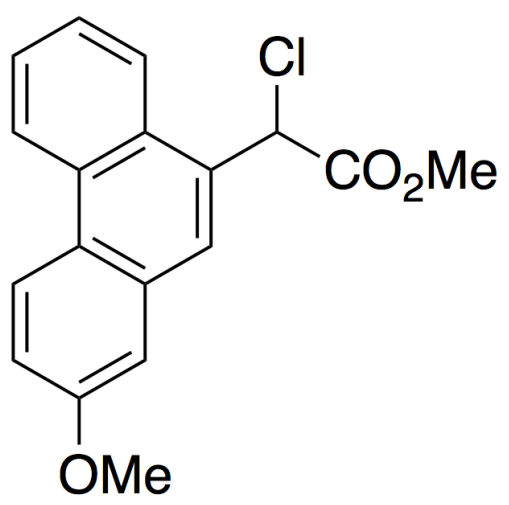

14, ${ }^{1} \mathrm{H}$ NMR $\left(500 \mathrm{MHz}, \mathrm{CDCl}_{3}\right)$
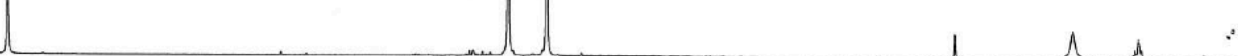

8 我

$6+\frac{1}{4}+\frac{1}{4}$

f1 (ppm) 


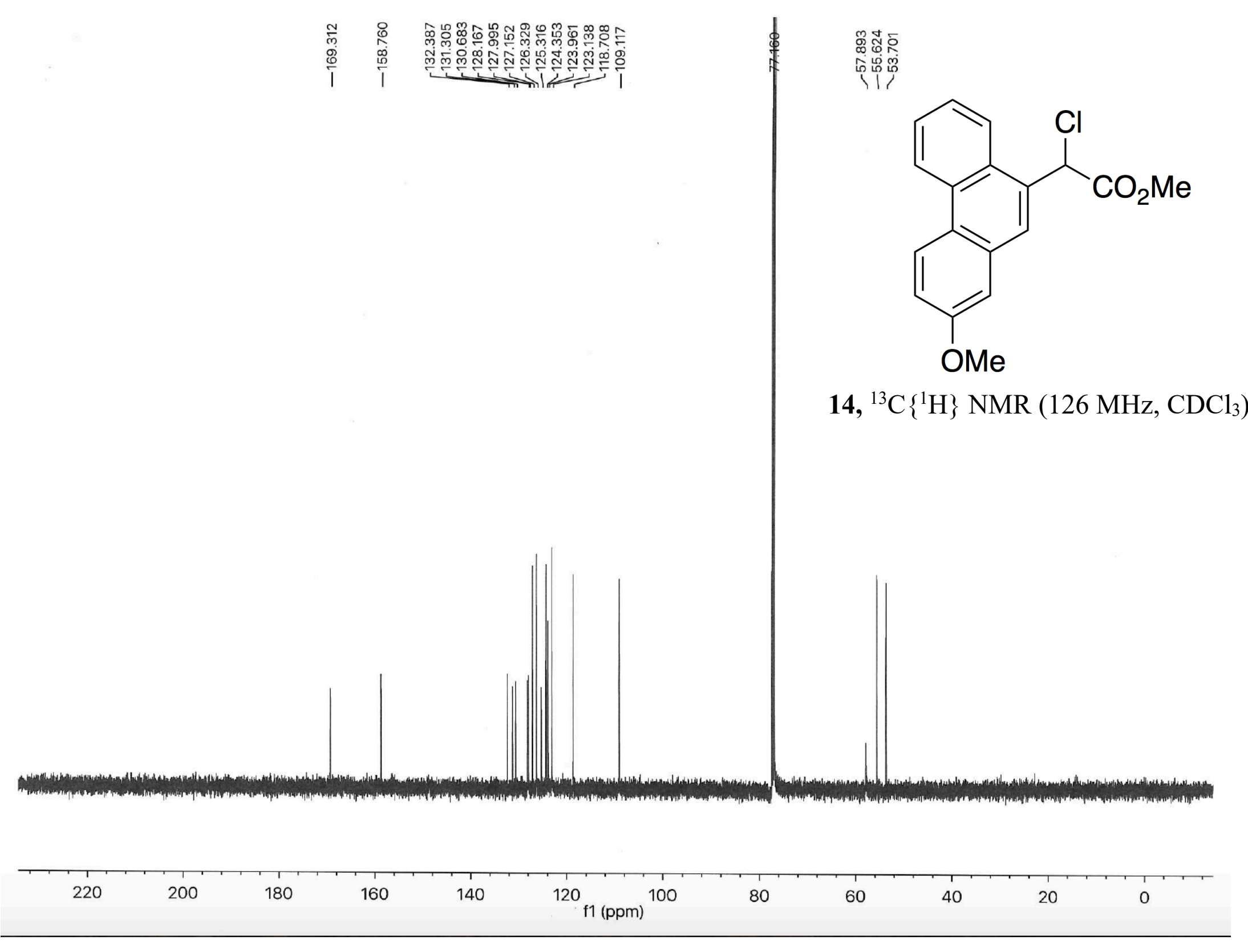




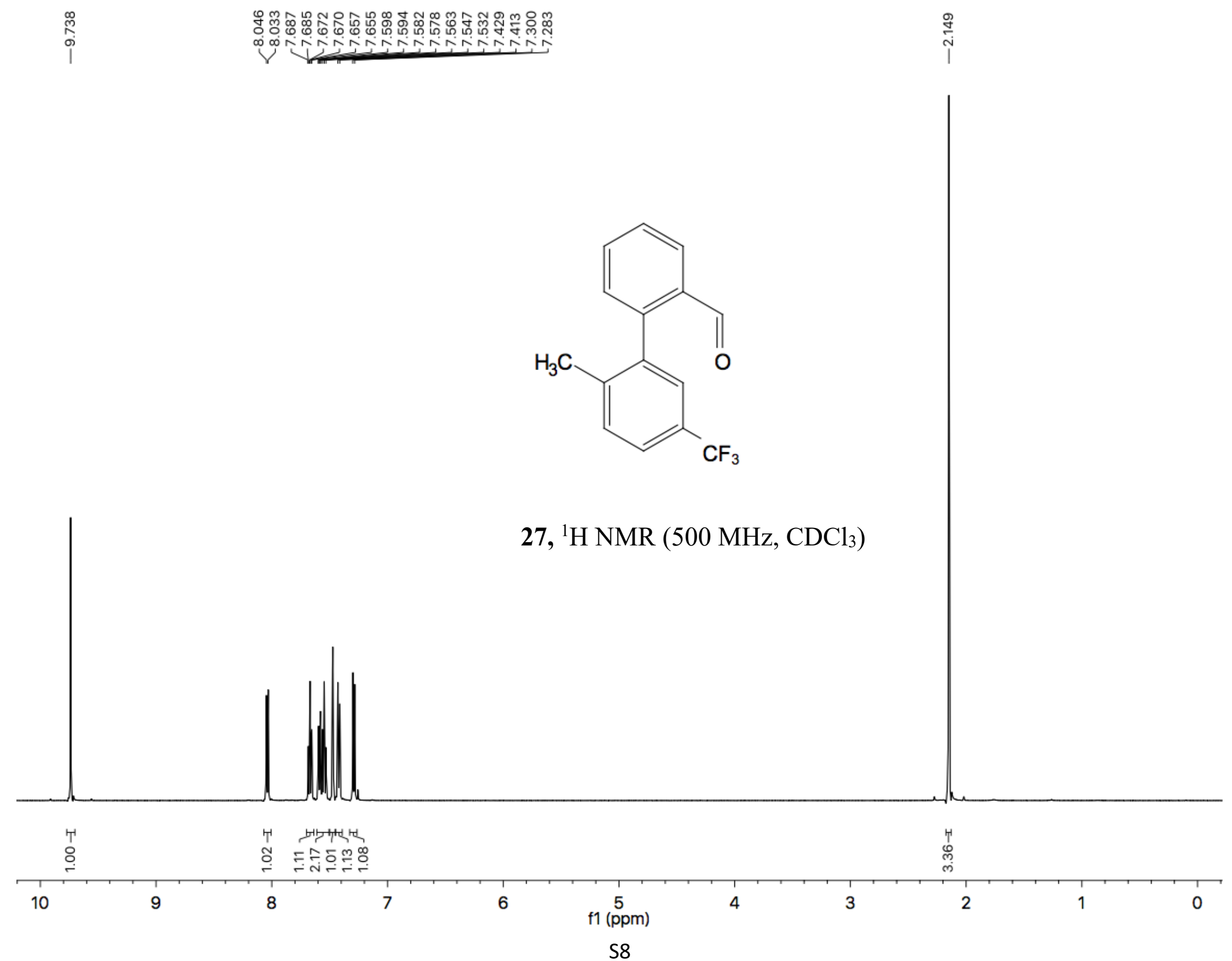




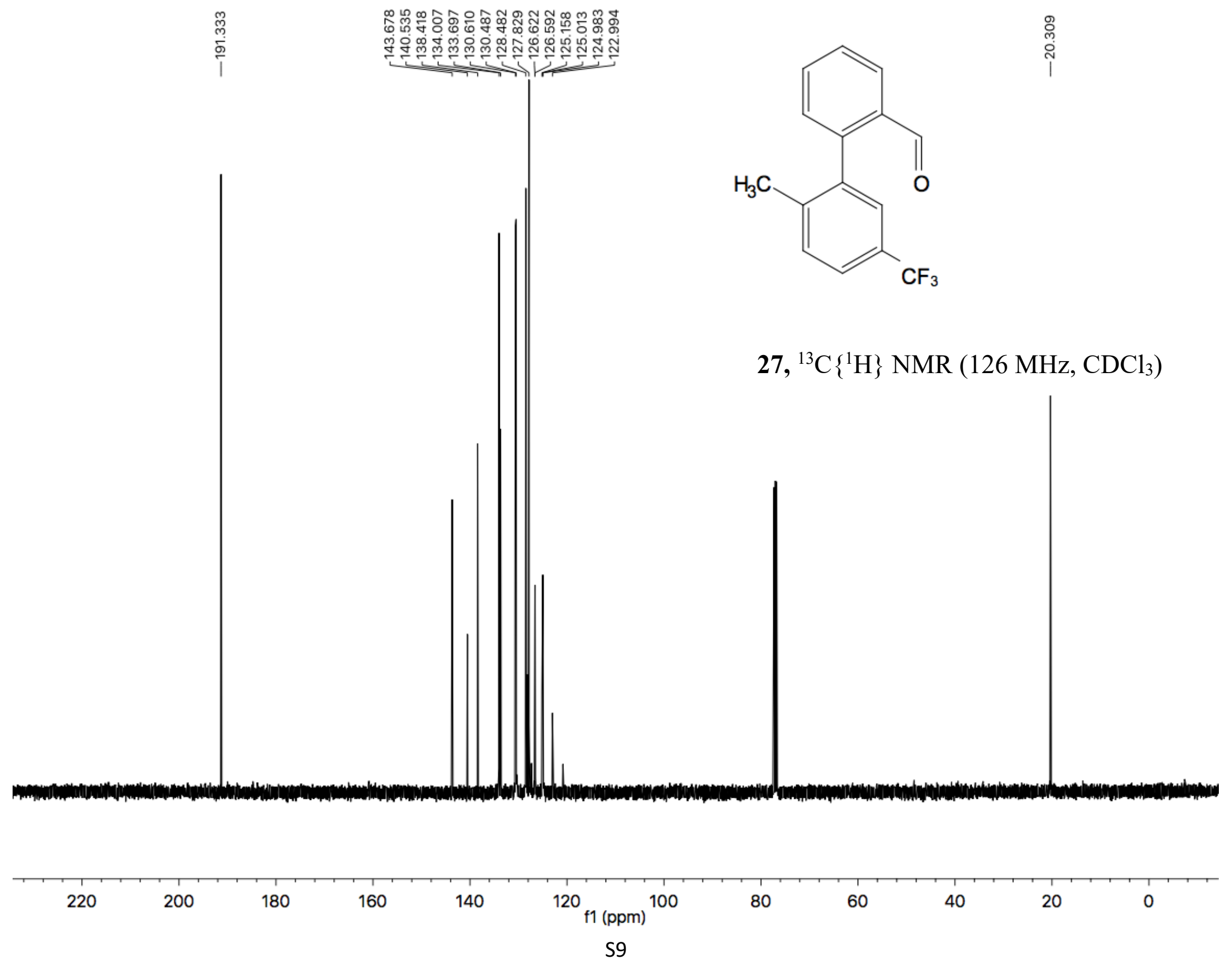




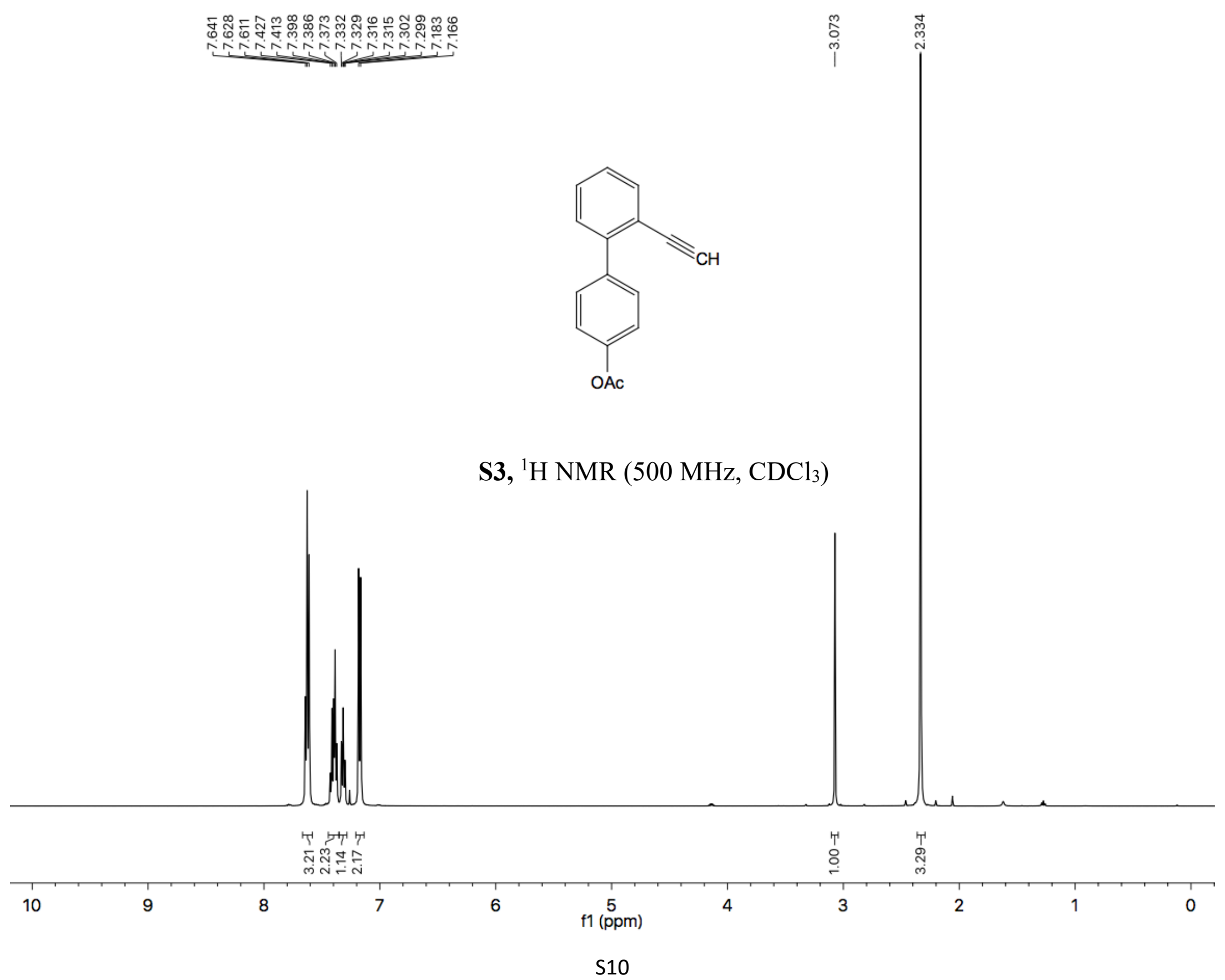




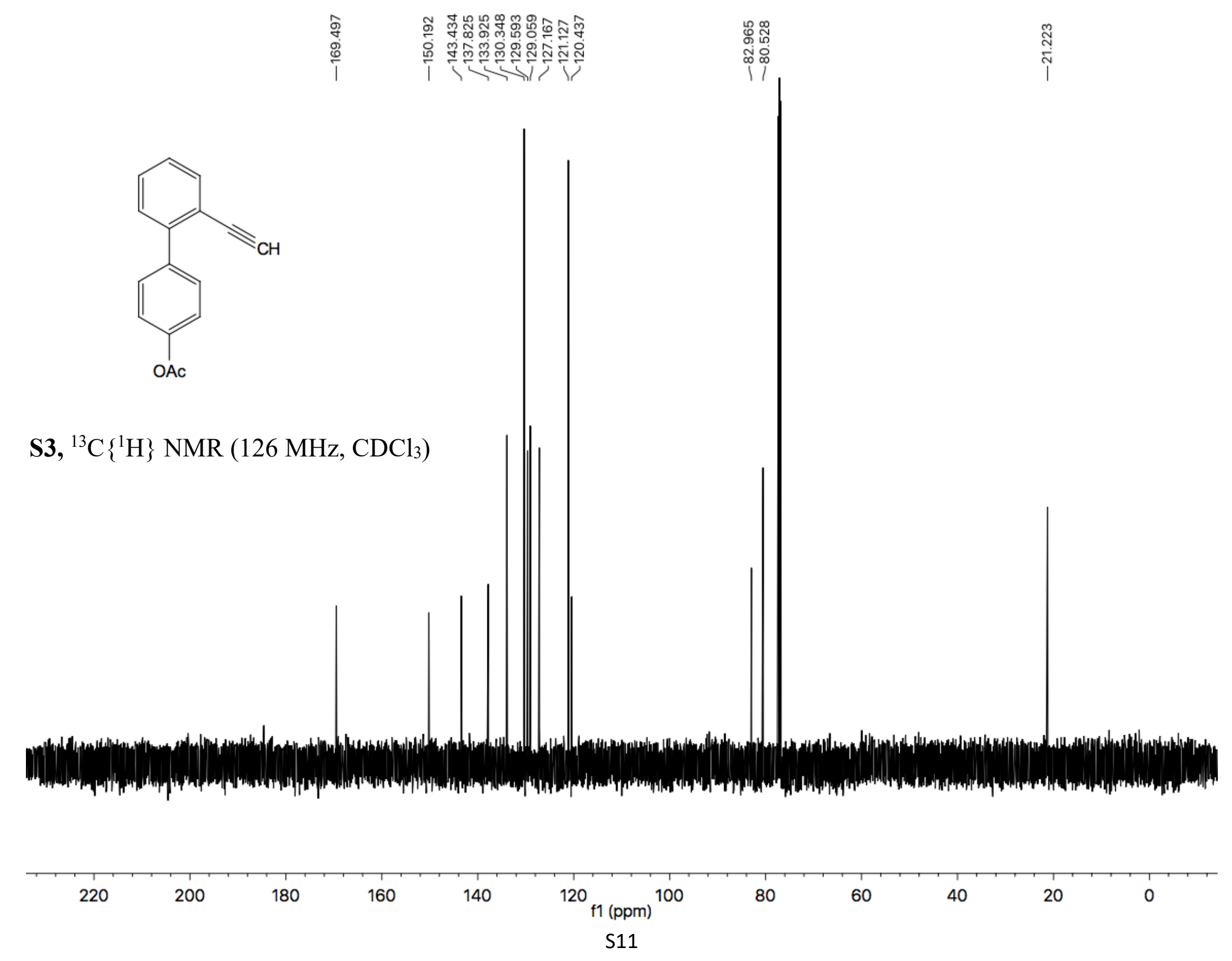




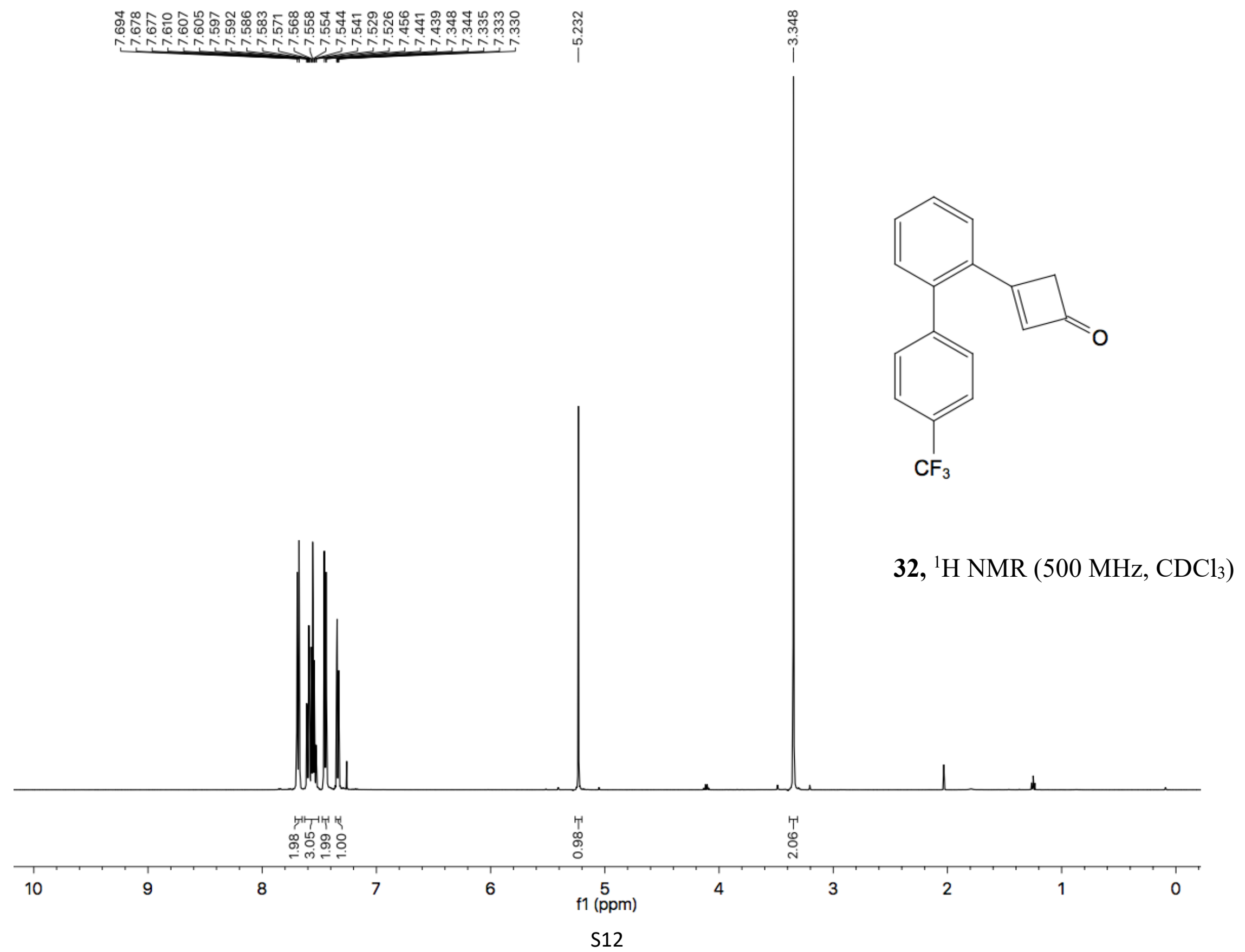




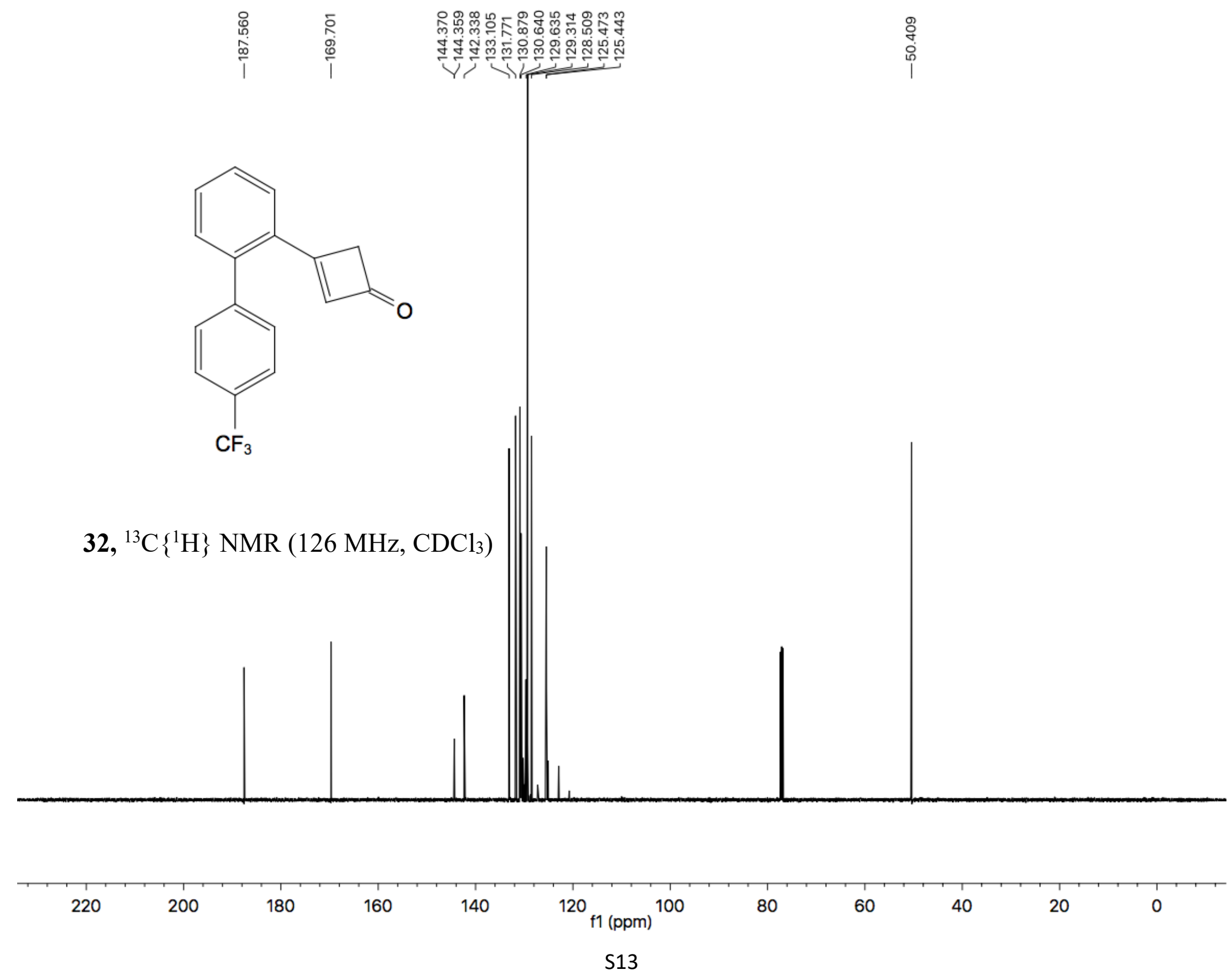




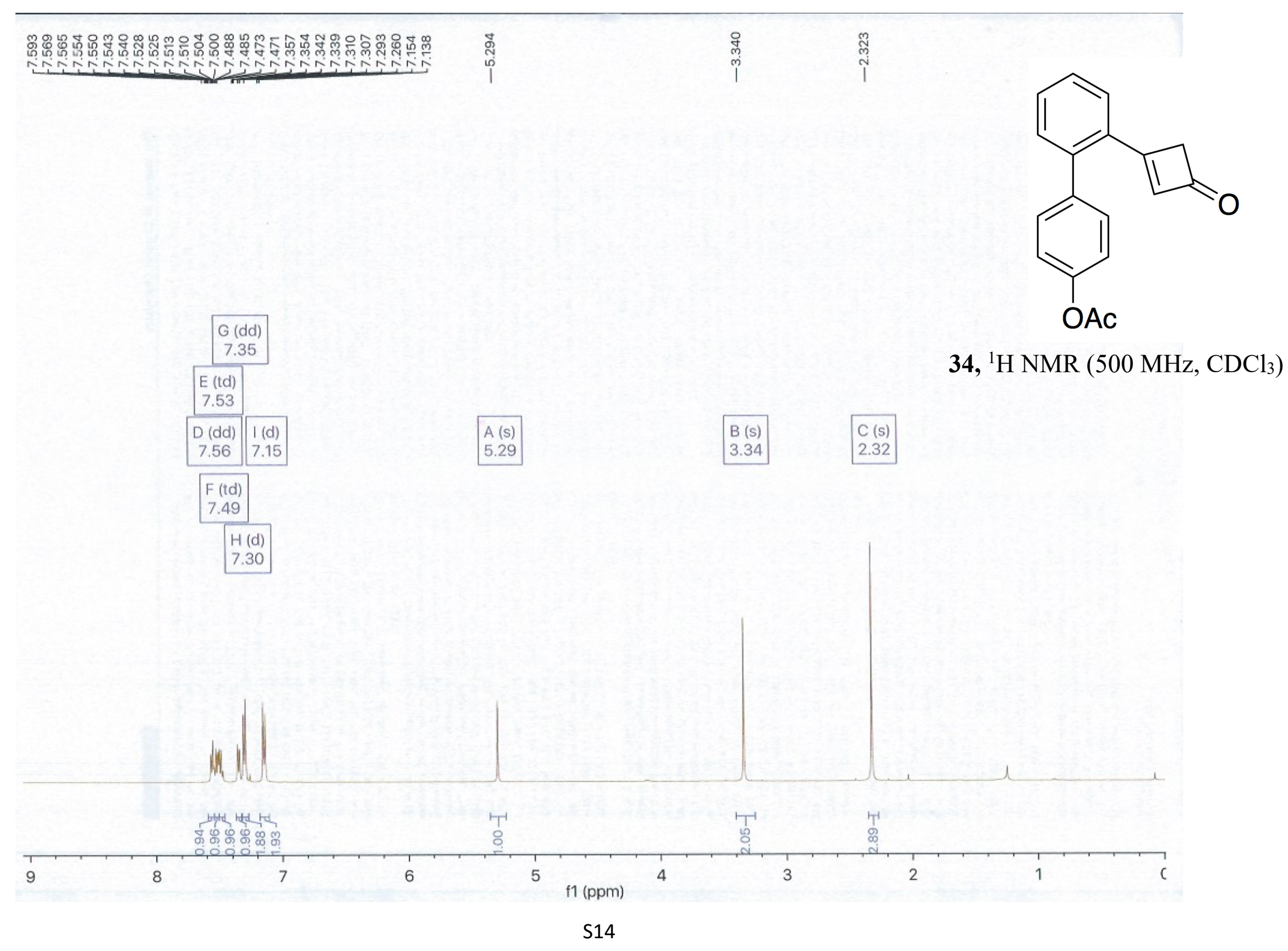




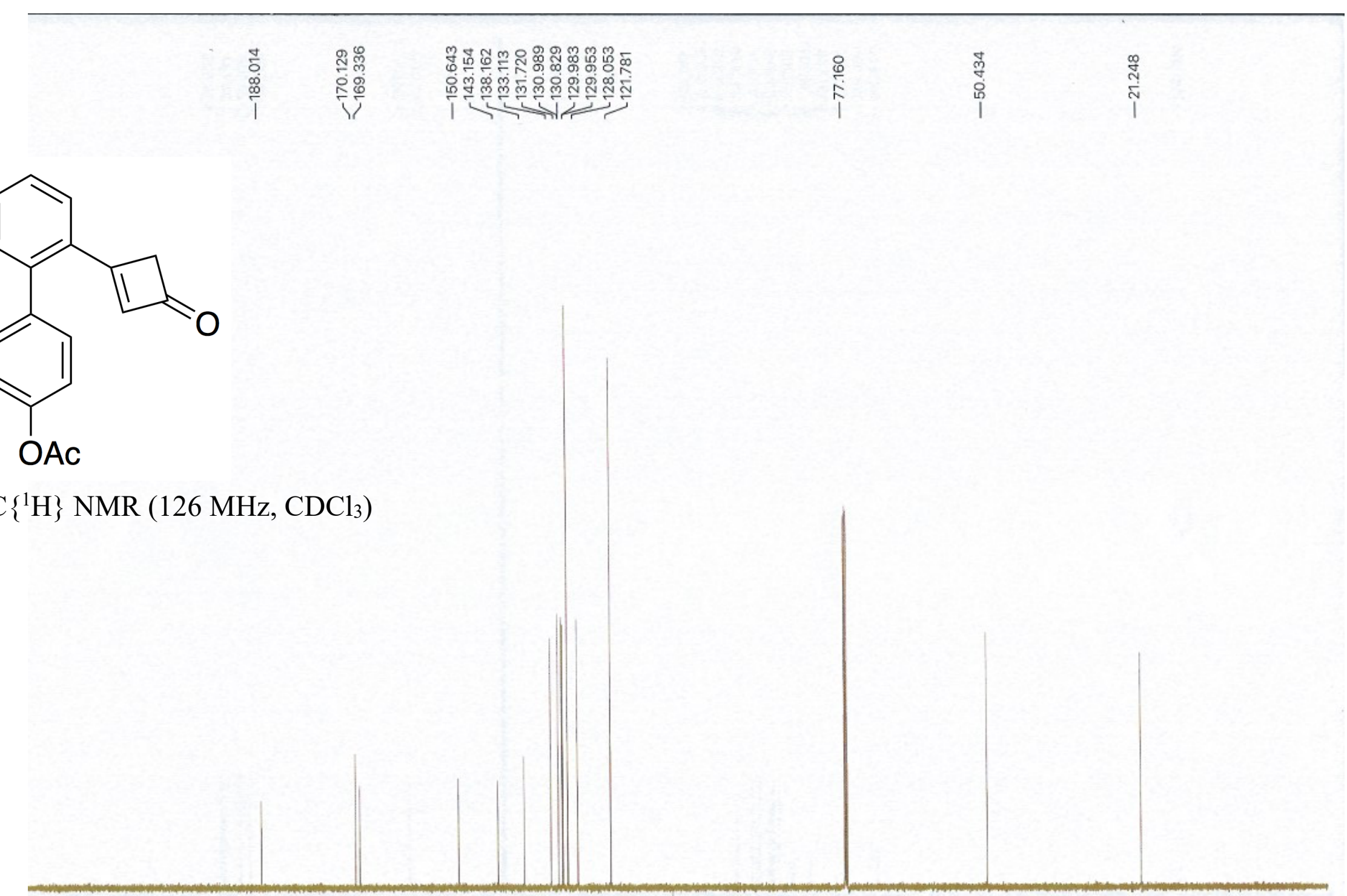

34, ${ }^{13} \mathrm{C}\left\{{ }^{1} \mathrm{H}\right\}$ NMR $\left(126 \mathrm{MHz}, \mathrm{CDCl}_{3}\right)$

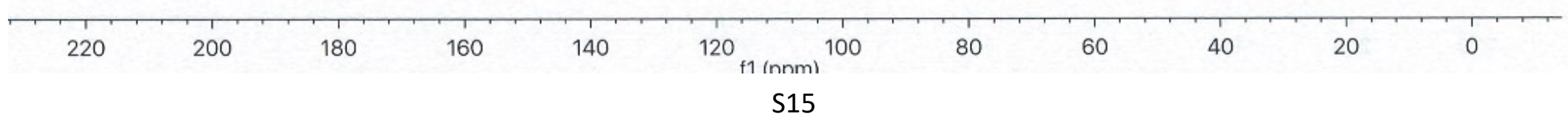




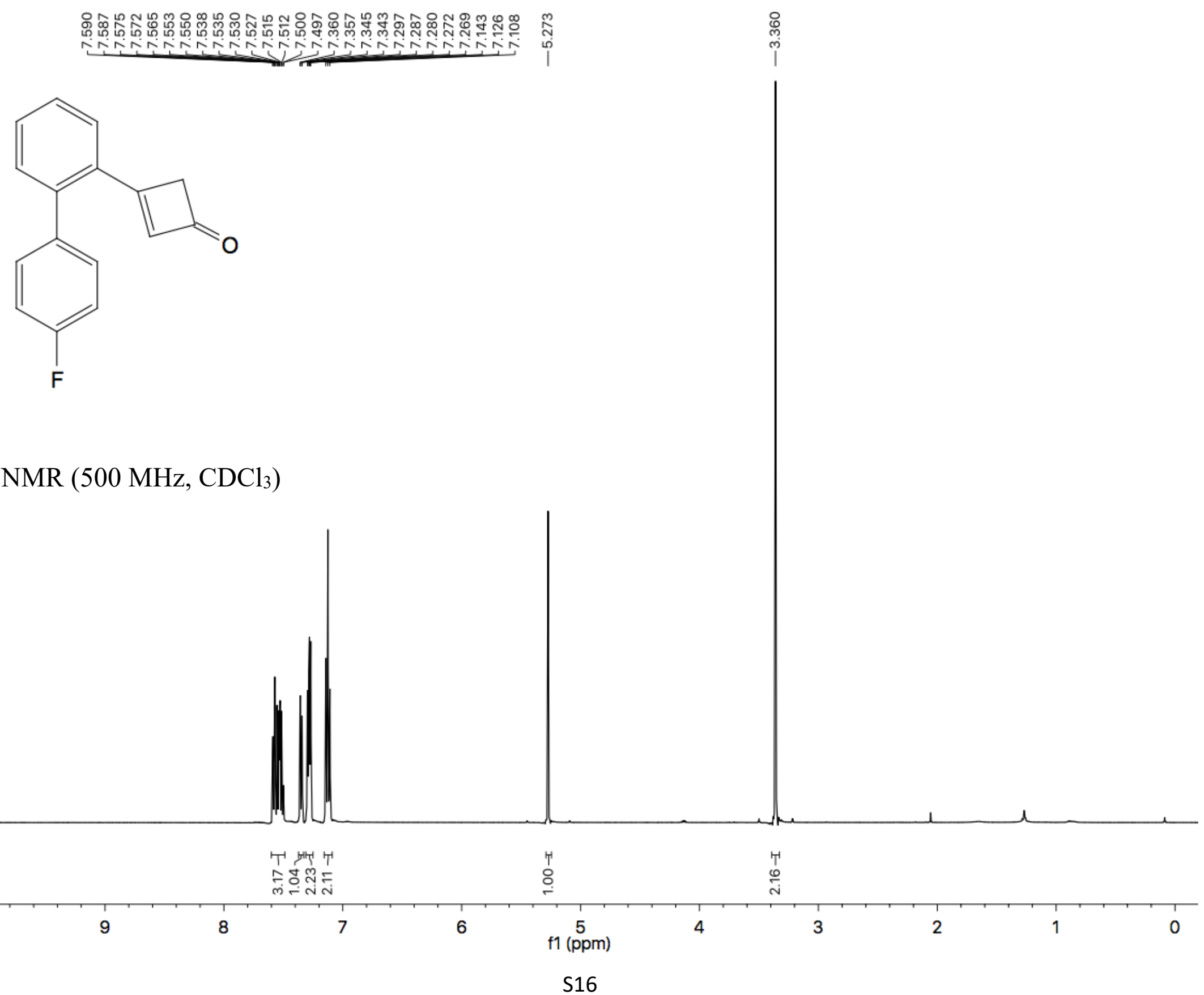




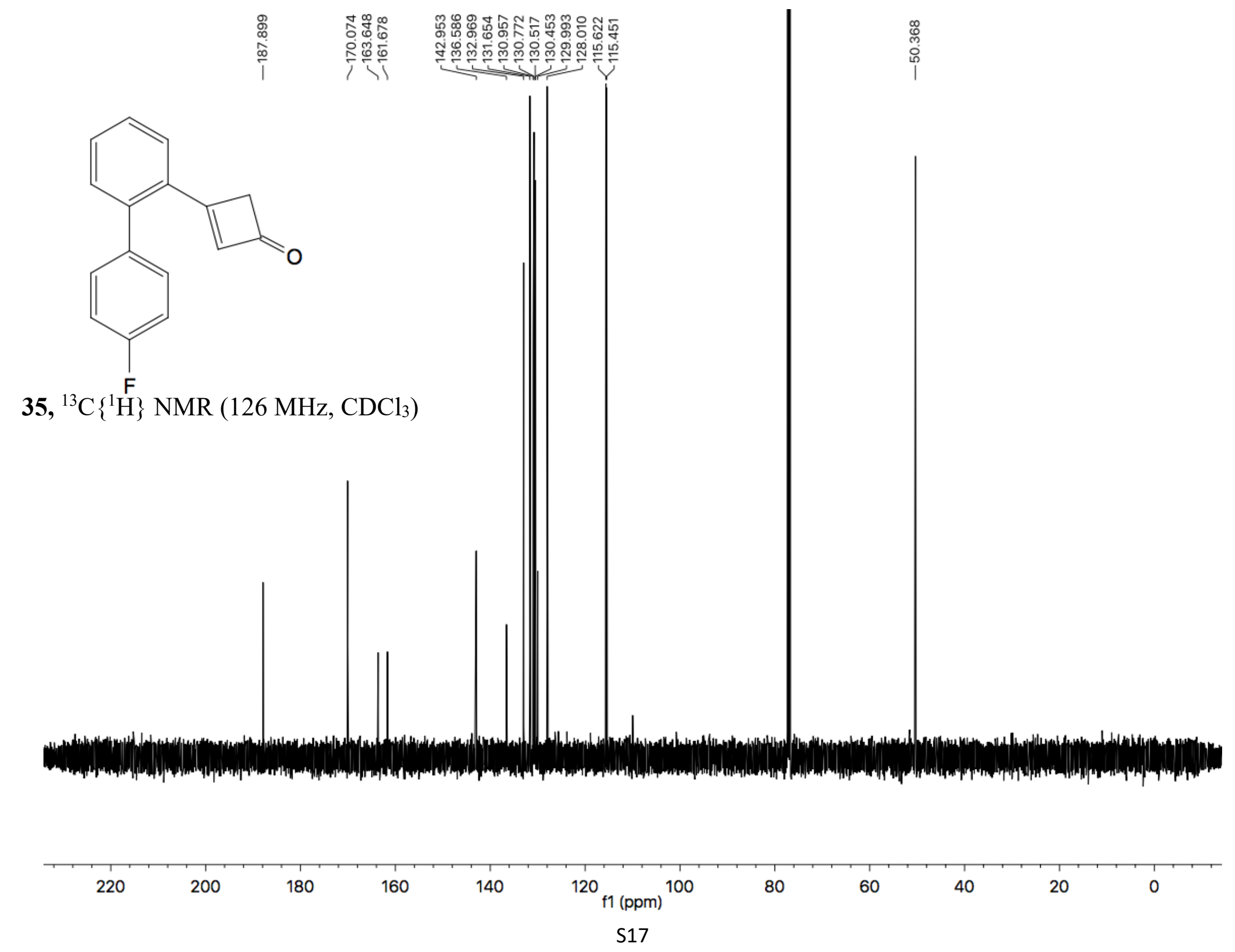




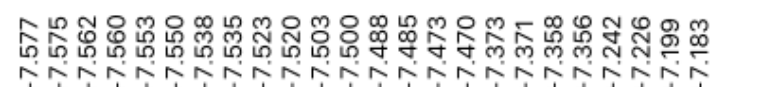

iָ

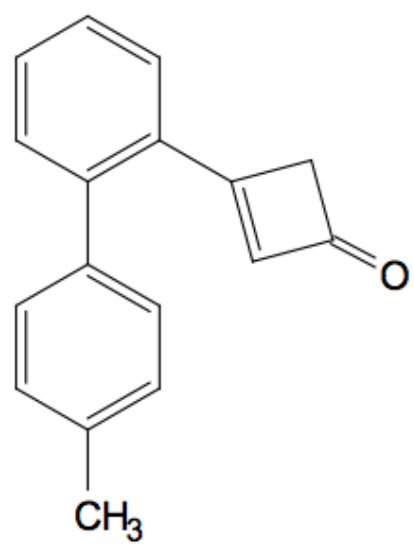

36, ${ }^{1} \mathrm{H}$ NMR $\left(500 \mathrm{MHz}, \mathrm{CDCl}_{3}\right)$

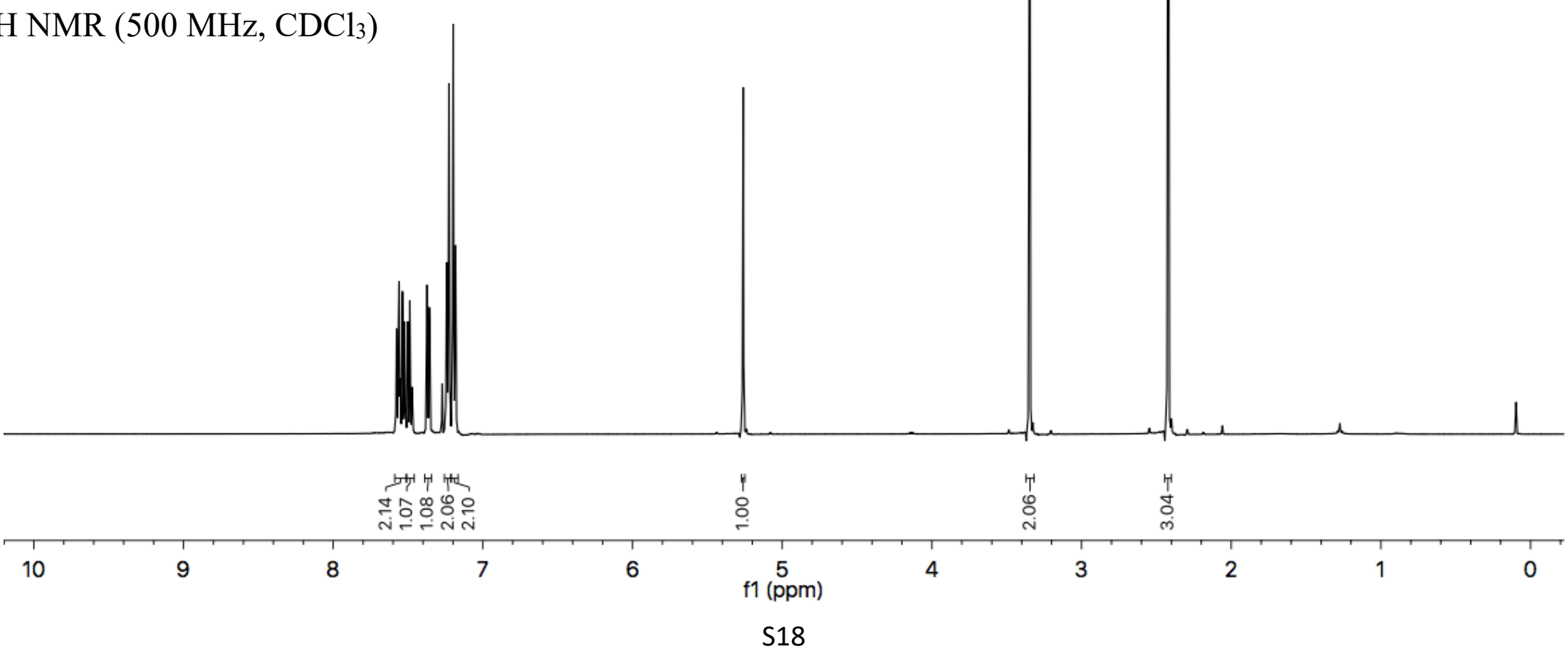




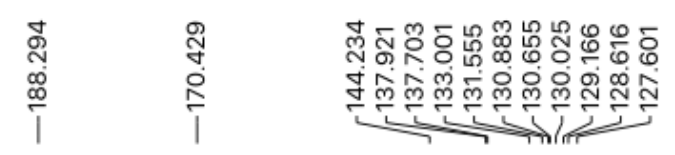

오ำ

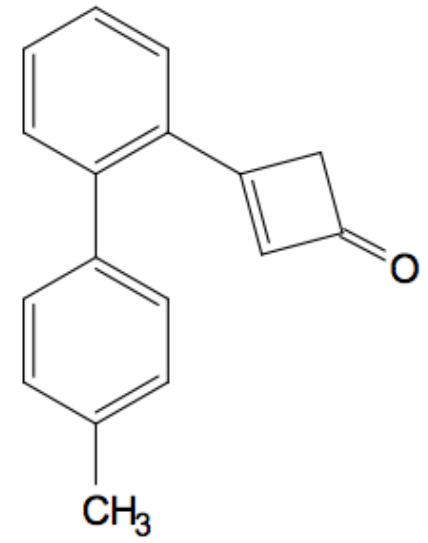

36, ${ }^{13} \mathrm{C}\left\{{ }^{1} \mathrm{H}\right\} \mathrm{NMR}\left(126 \mathrm{MHz}, \mathrm{CDCl}_{3}\right)$

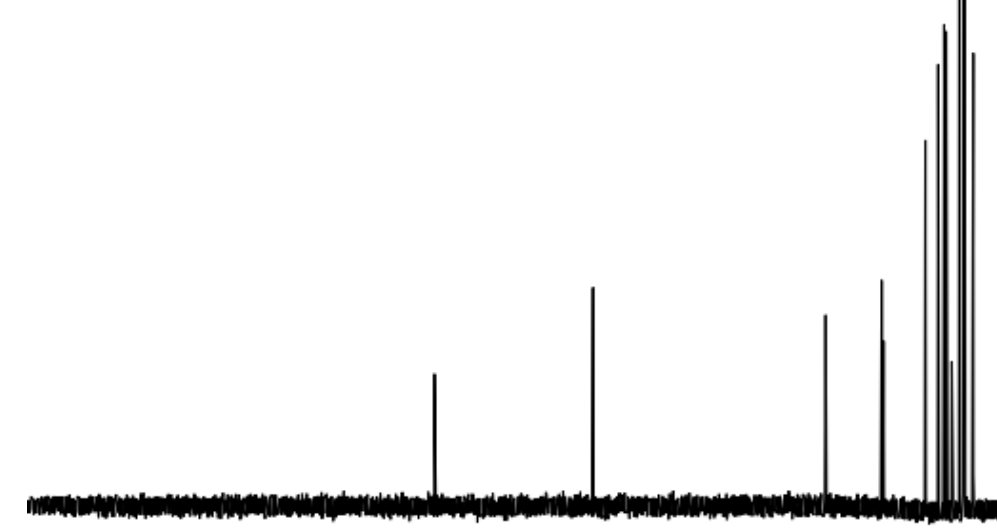

220

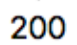

180

160

140

120

100

S19

60

40

20 


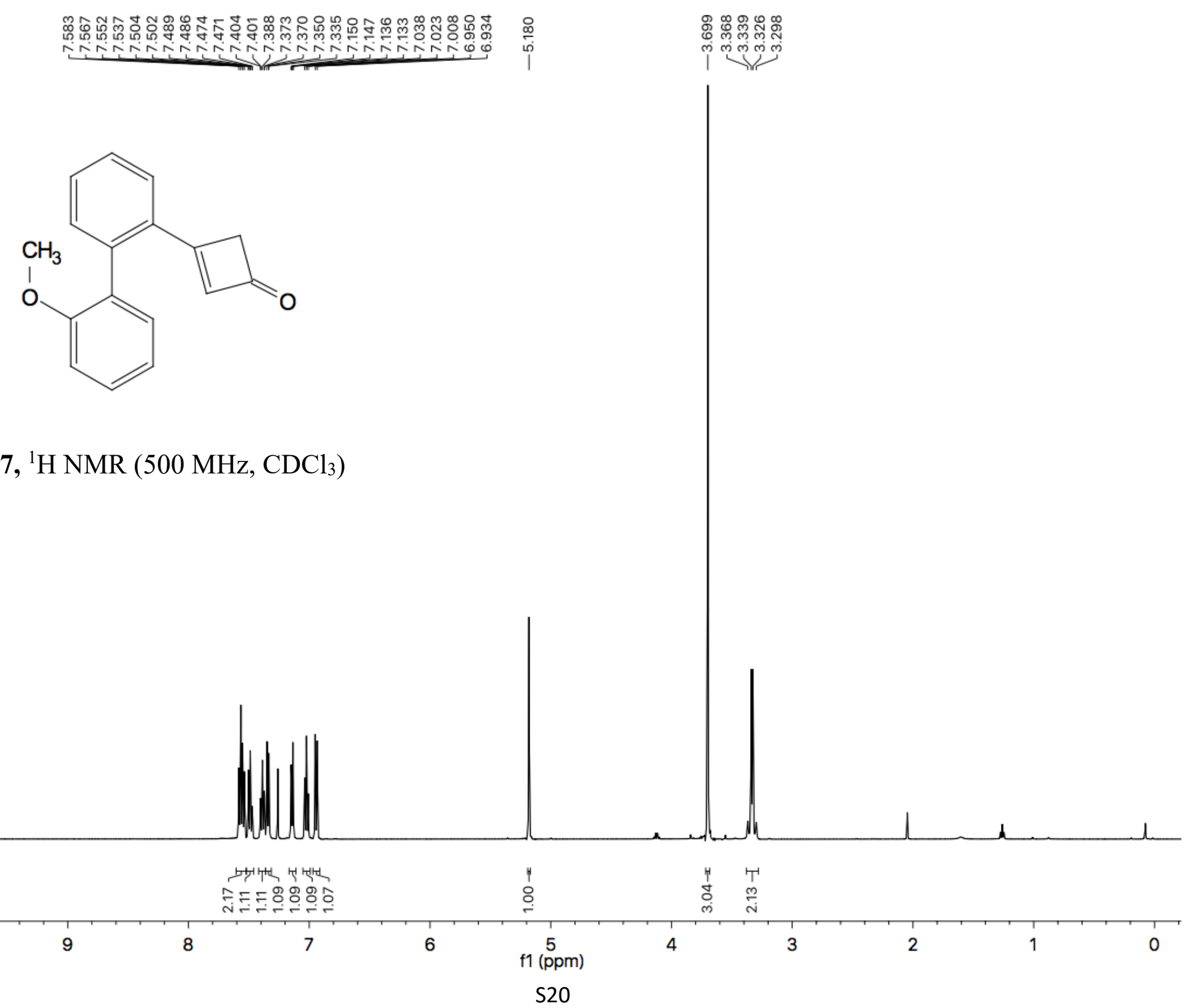




$$
1
$$




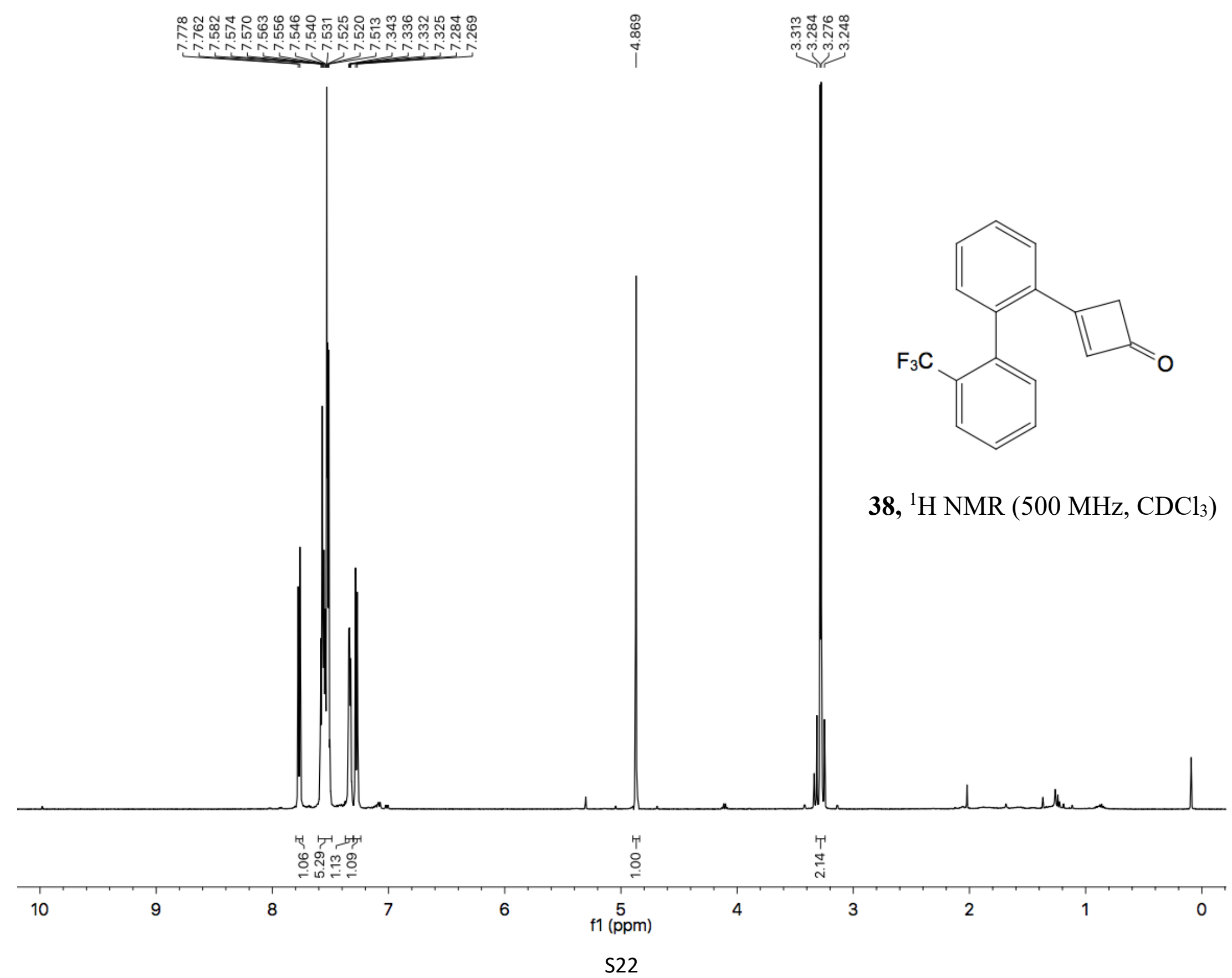




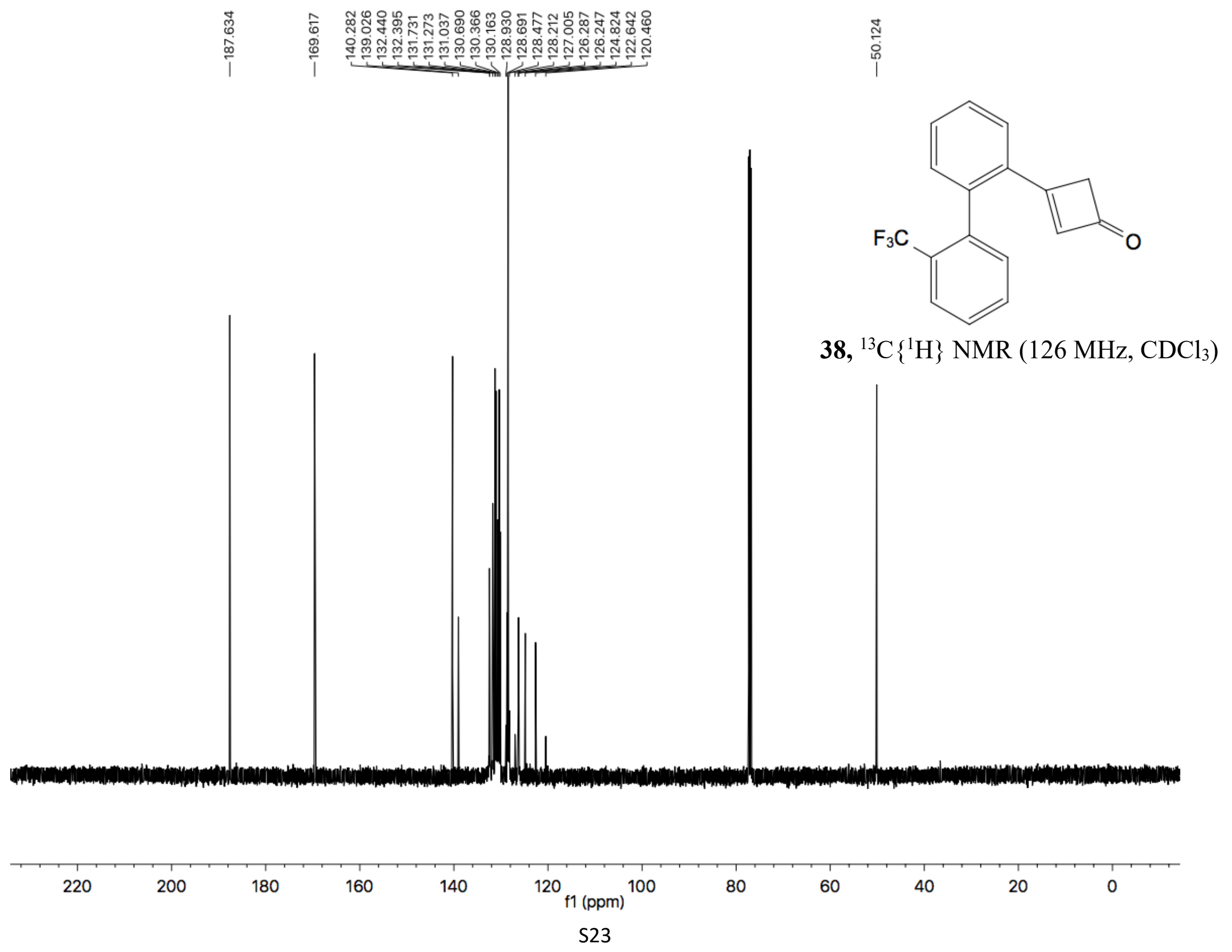


<smiles>Cc1ccc(C(F)(F)F)cc1-c1ccccc1C1=CC(=O)C1</smiles>

39, ${ }^{1} \mathrm{H}$ NMR $\left(500 \mathrm{MHz}, \mathrm{CDCl}_{3}\right)$

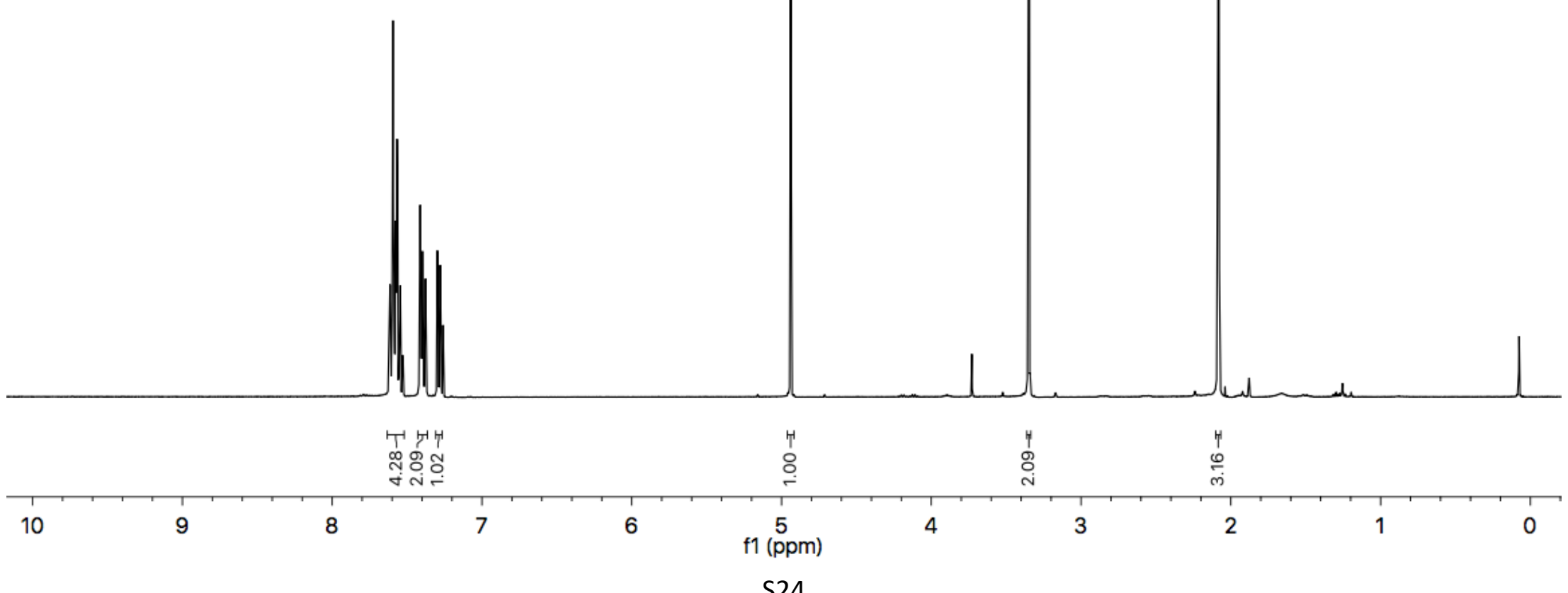

S24 


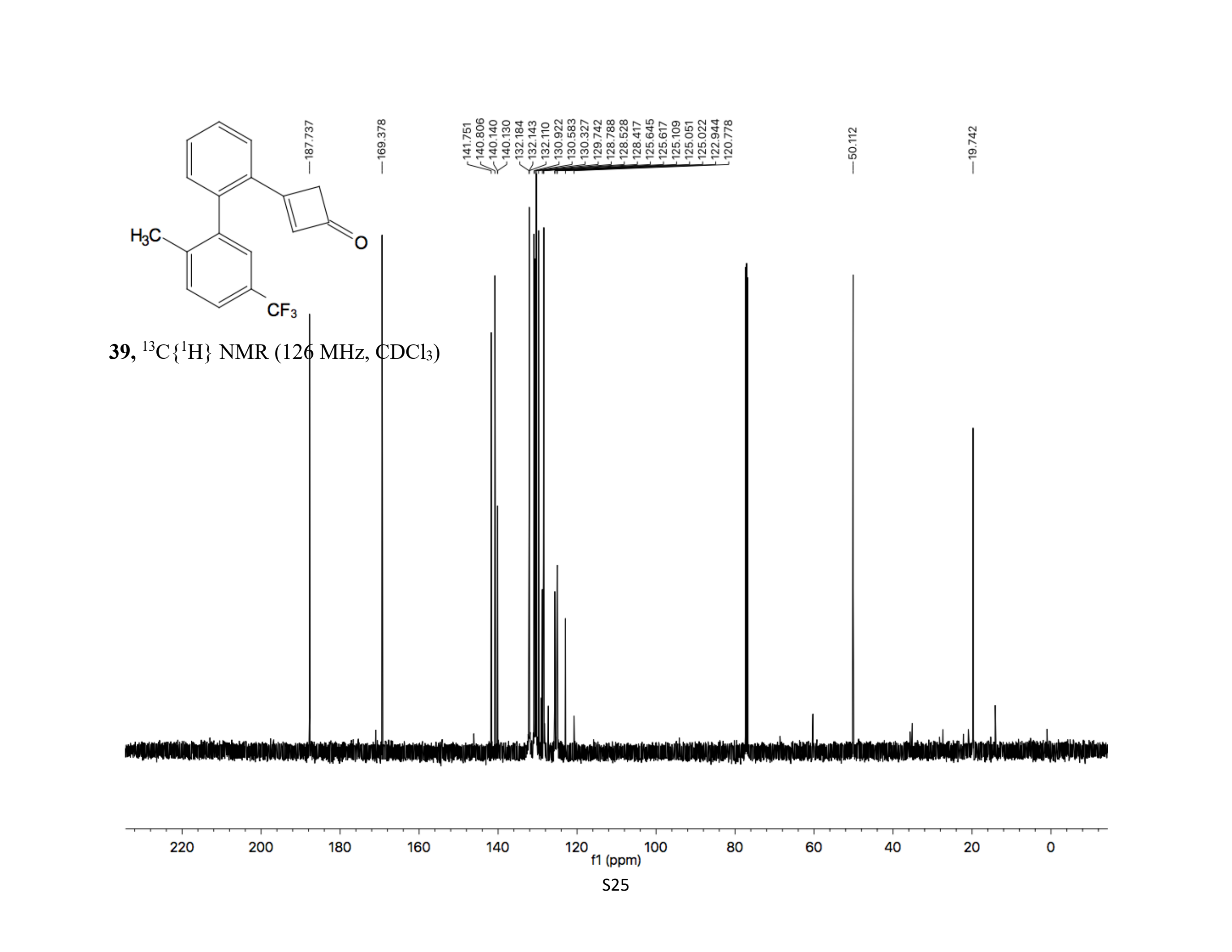




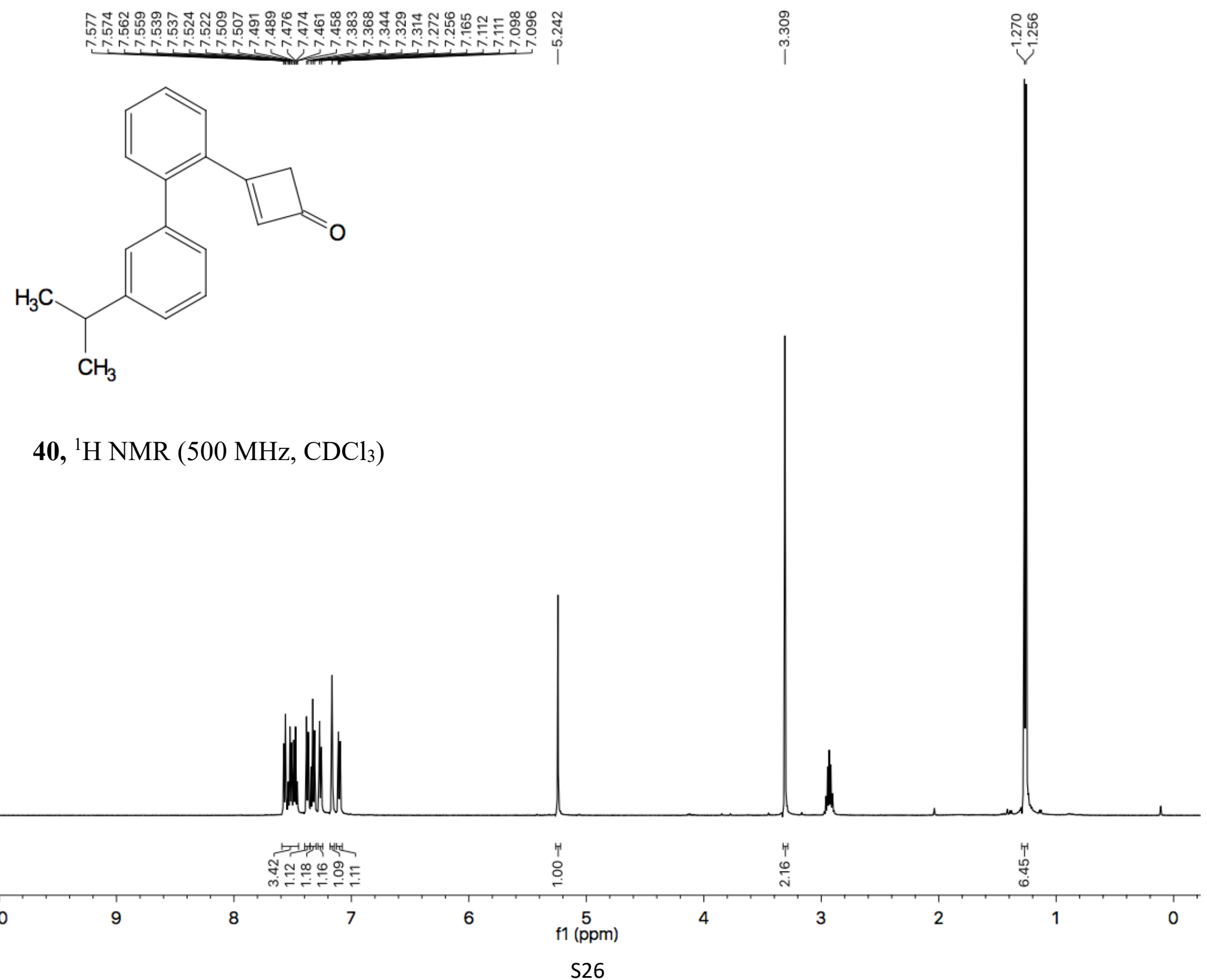




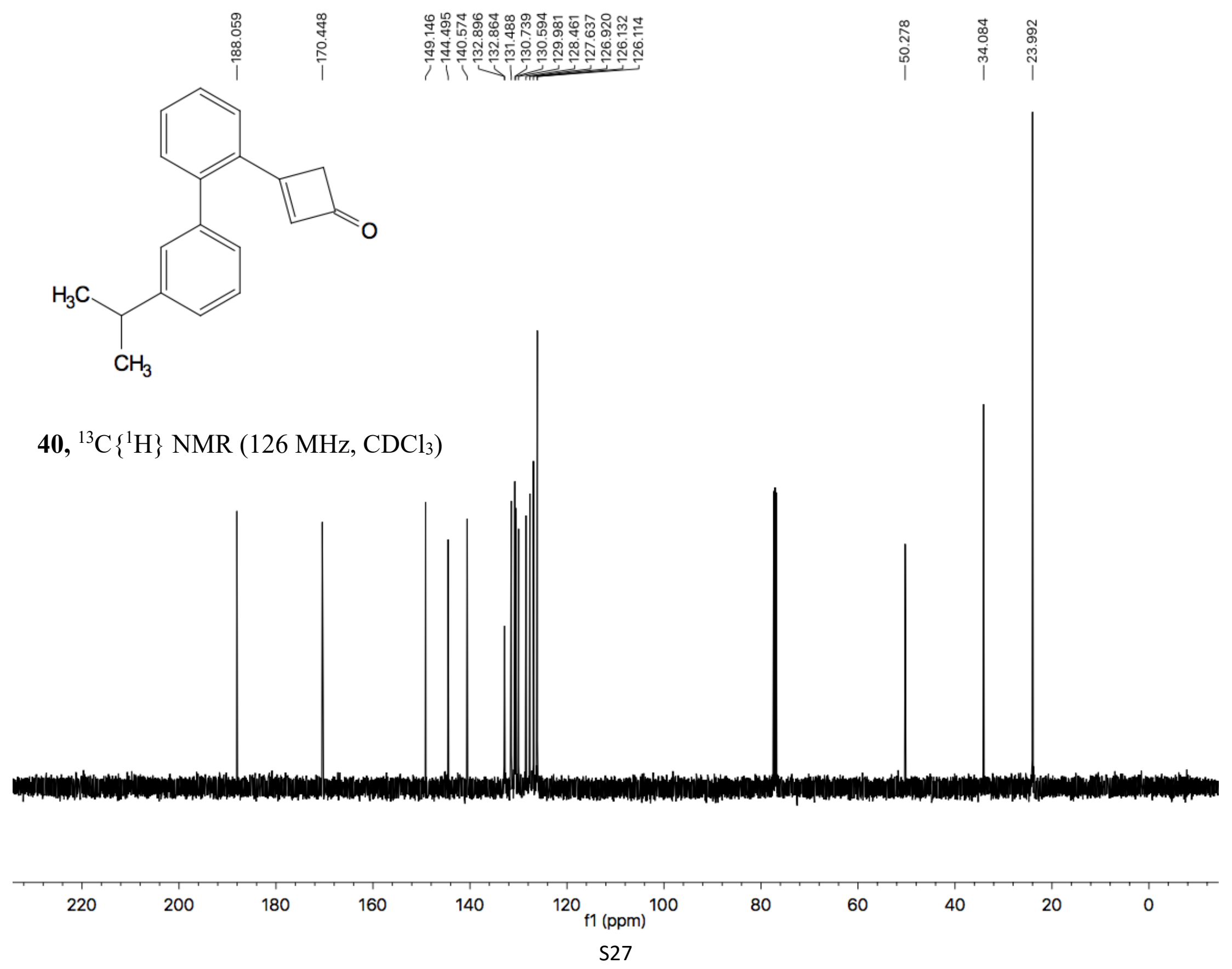




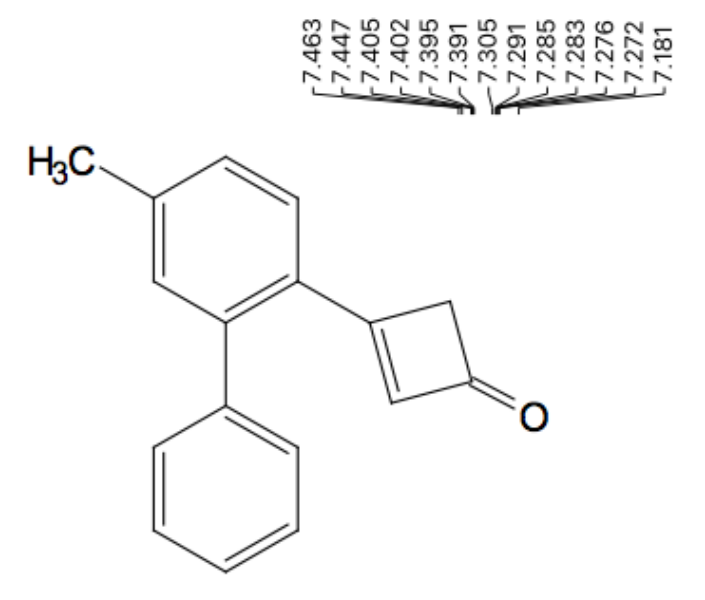

$\stackrel{\stackrel{2}{\infty}}{\stackrel{0}{\omega}}$

$\stackrel{\substack{i \\ \infty}}{i}$

41, ${ }^{1} \mathrm{H}$ NMR $\left(500 \mathrm{MHz}, \mathrm{CDCl}_{3}\right)$

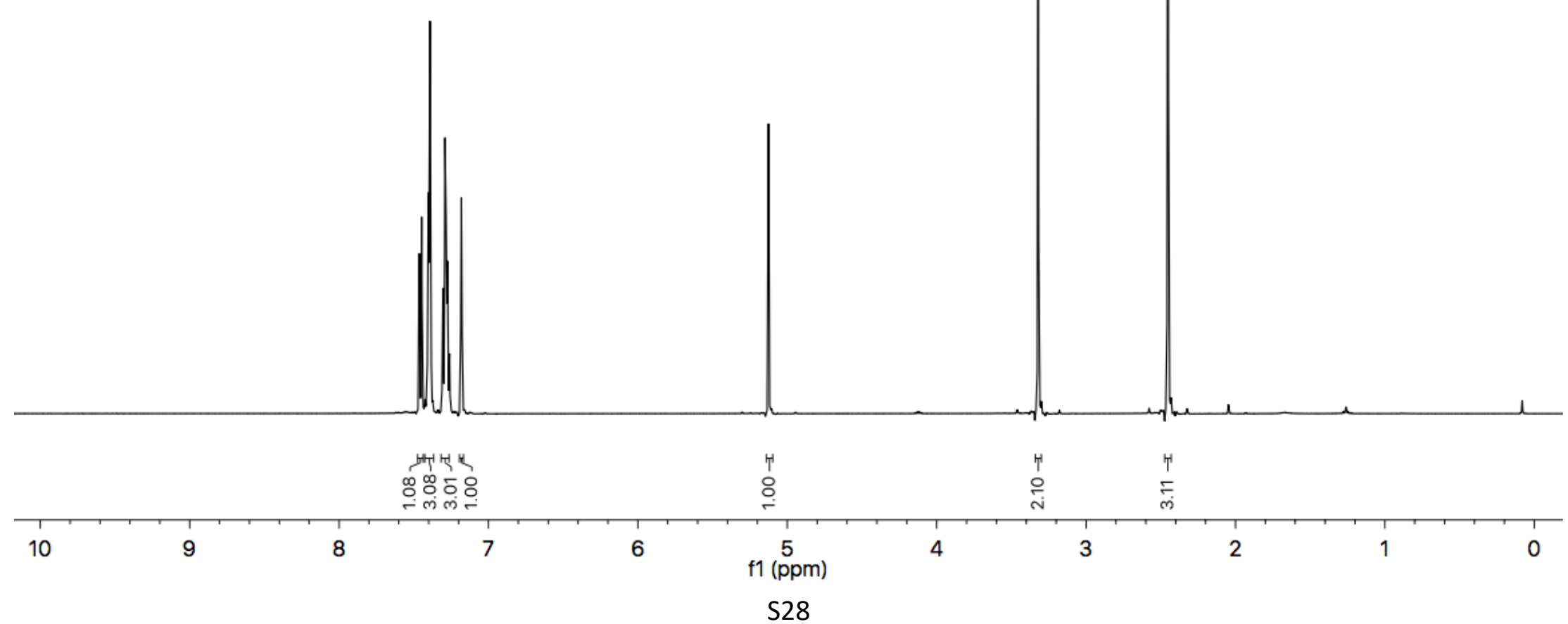




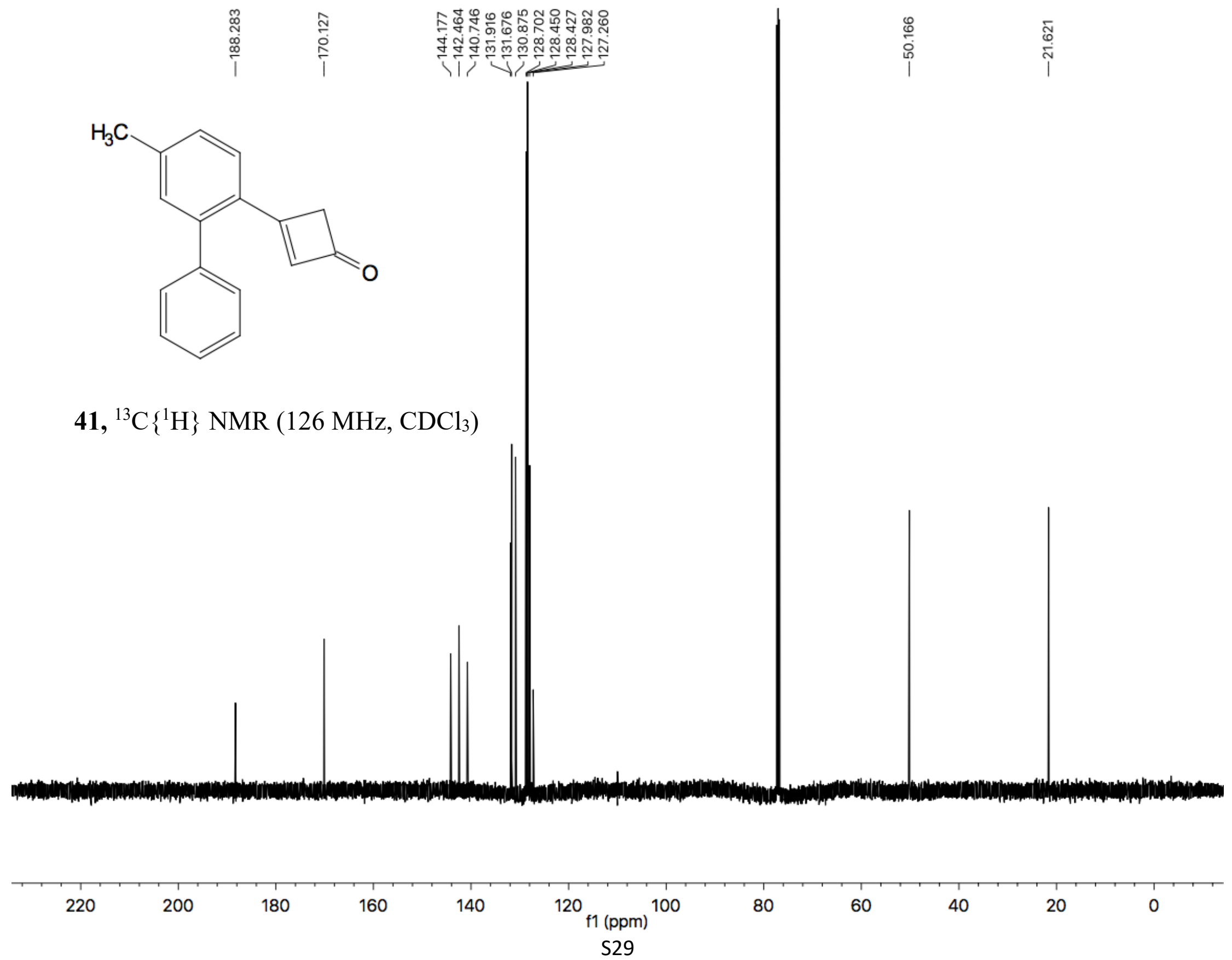




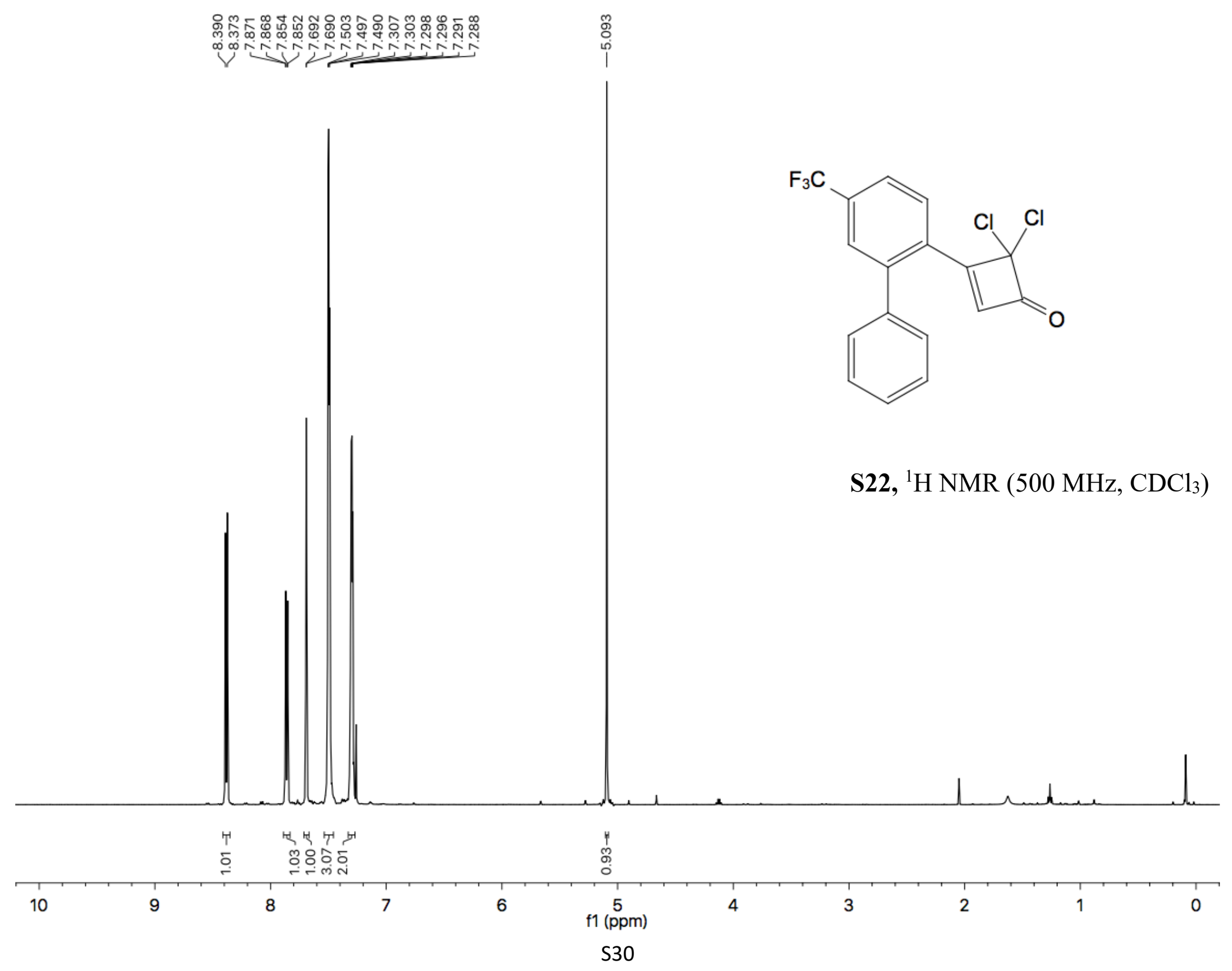




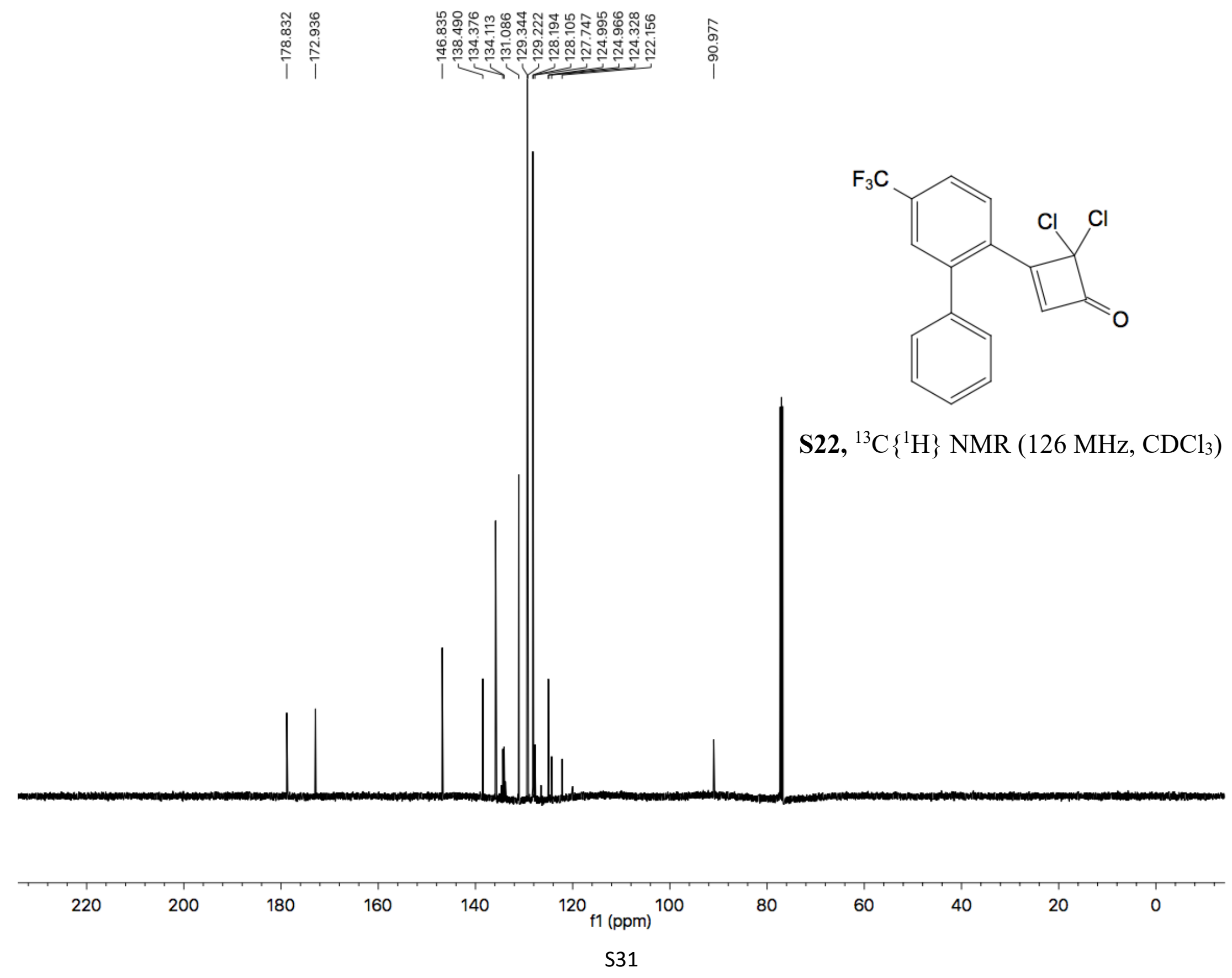




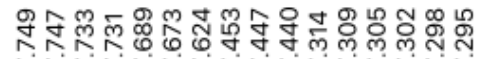

insinisinisin

趈

$\mathrm{F}_{3} \mathrm{C}$

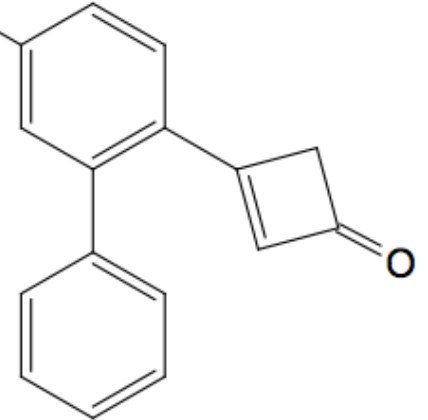

42, ${ }^{1} \mathrm{H} \mathrm{NMR}\left(500 \mathrm{MHz}, \mathrm{CDCl}_{3}\right)$

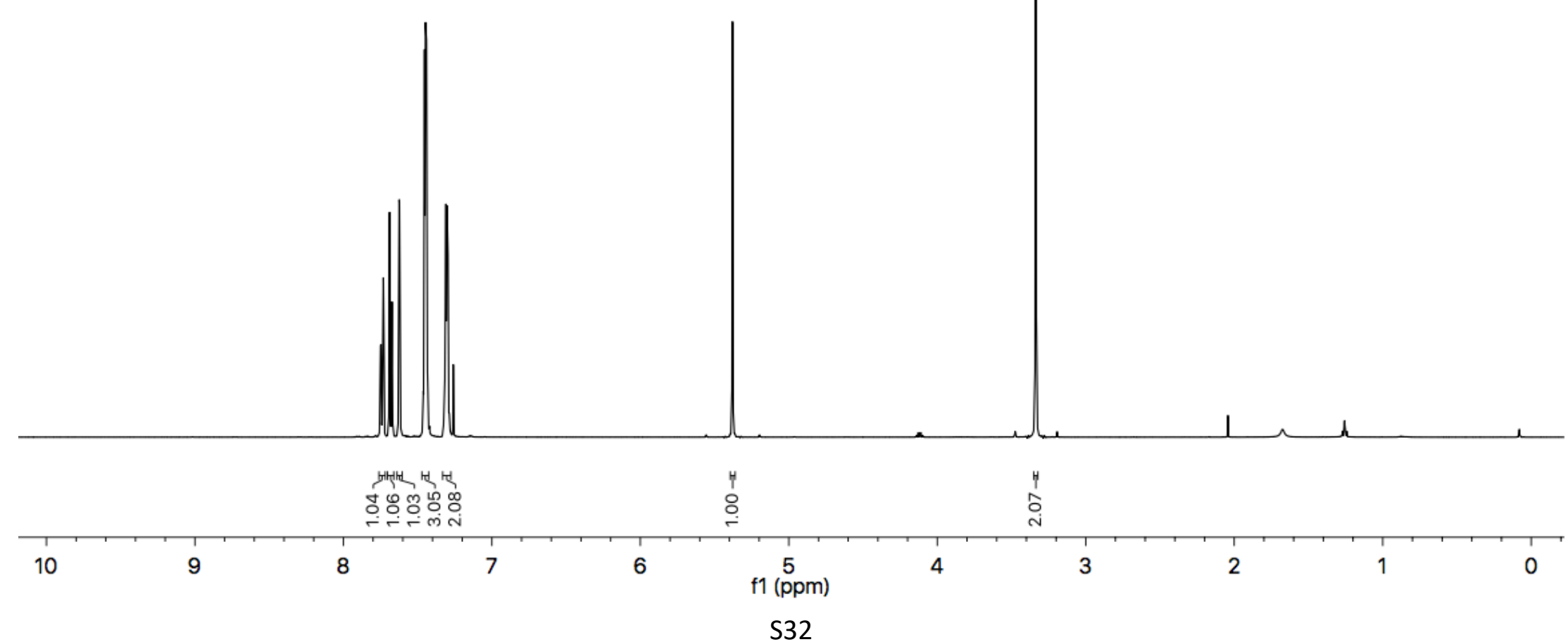




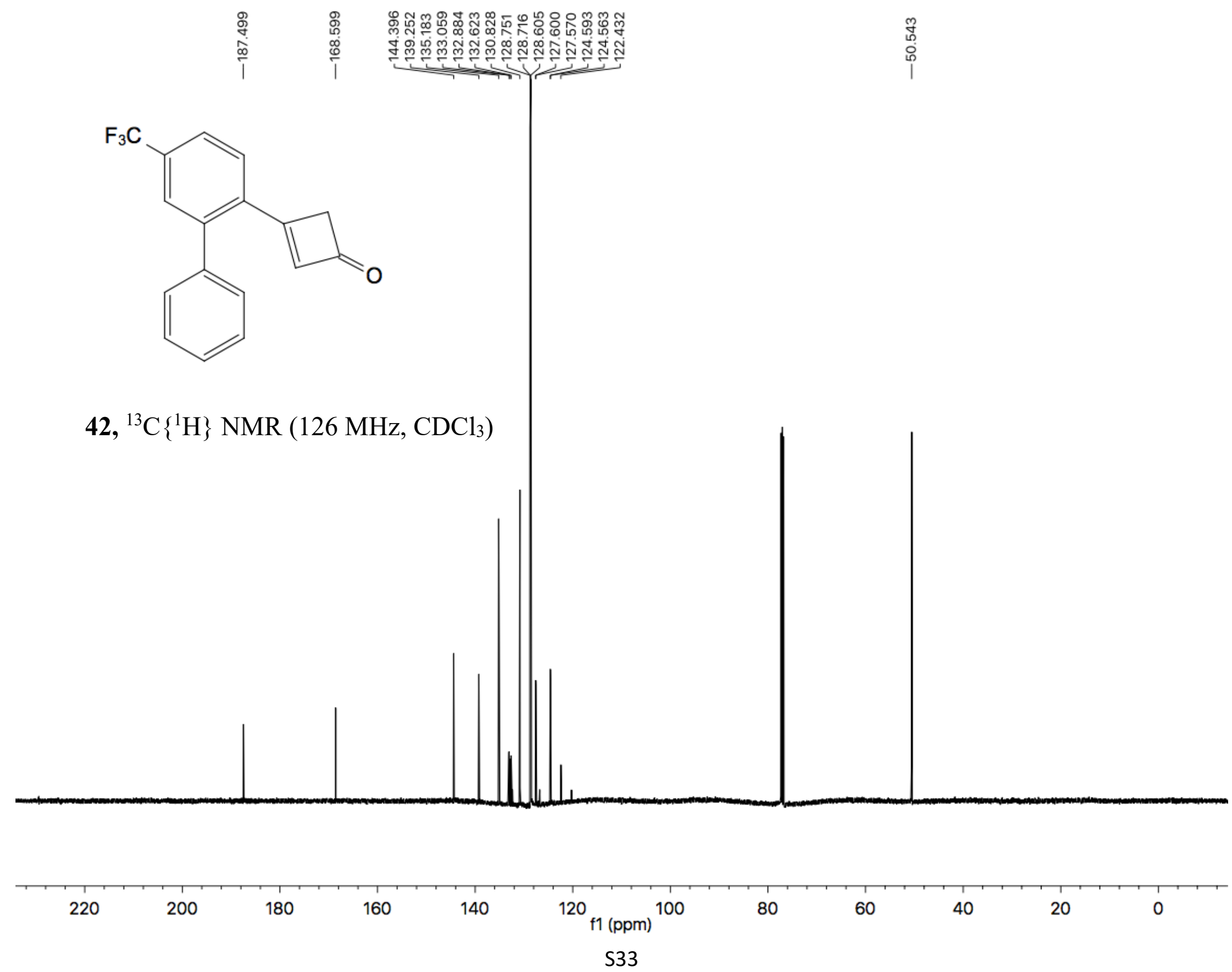




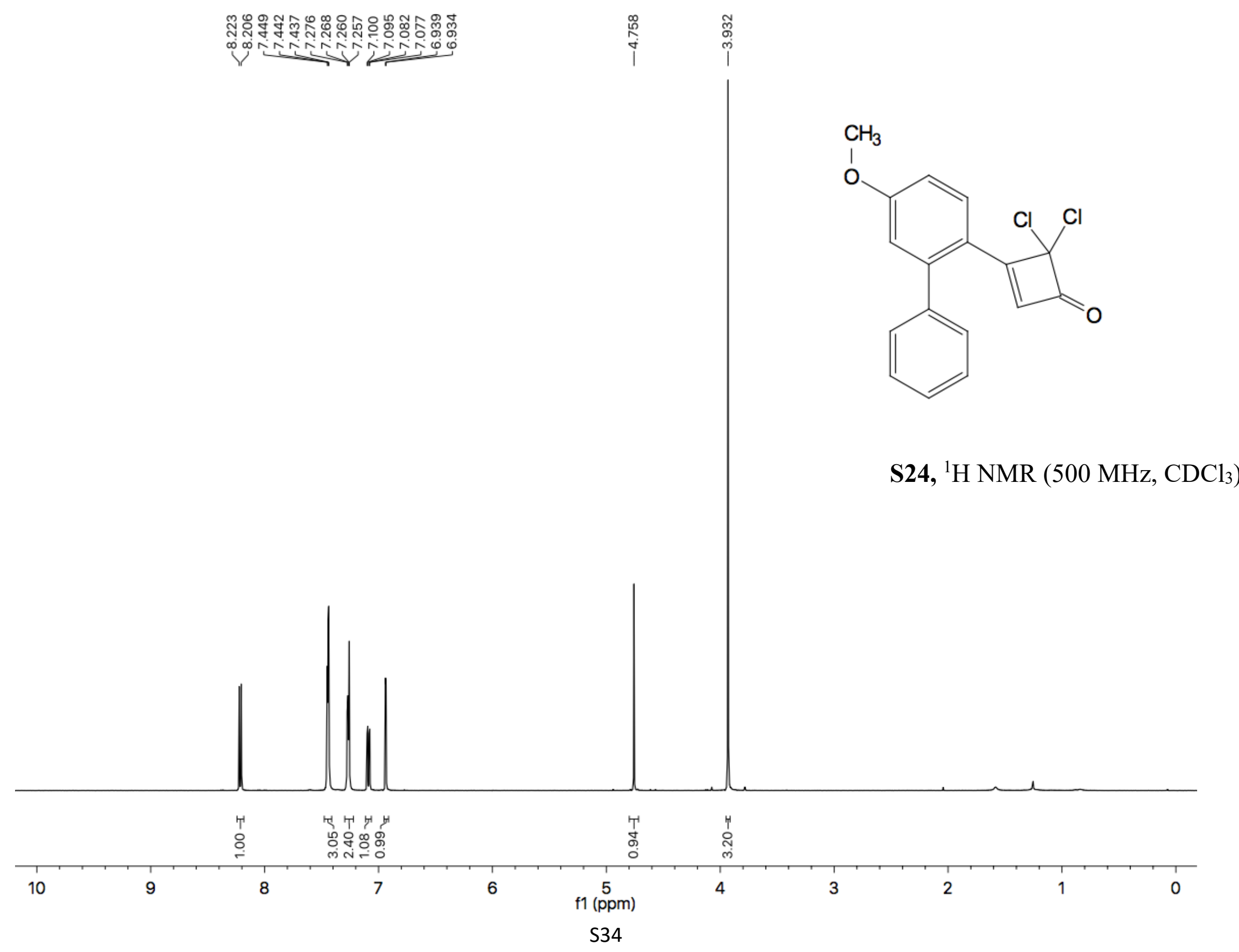




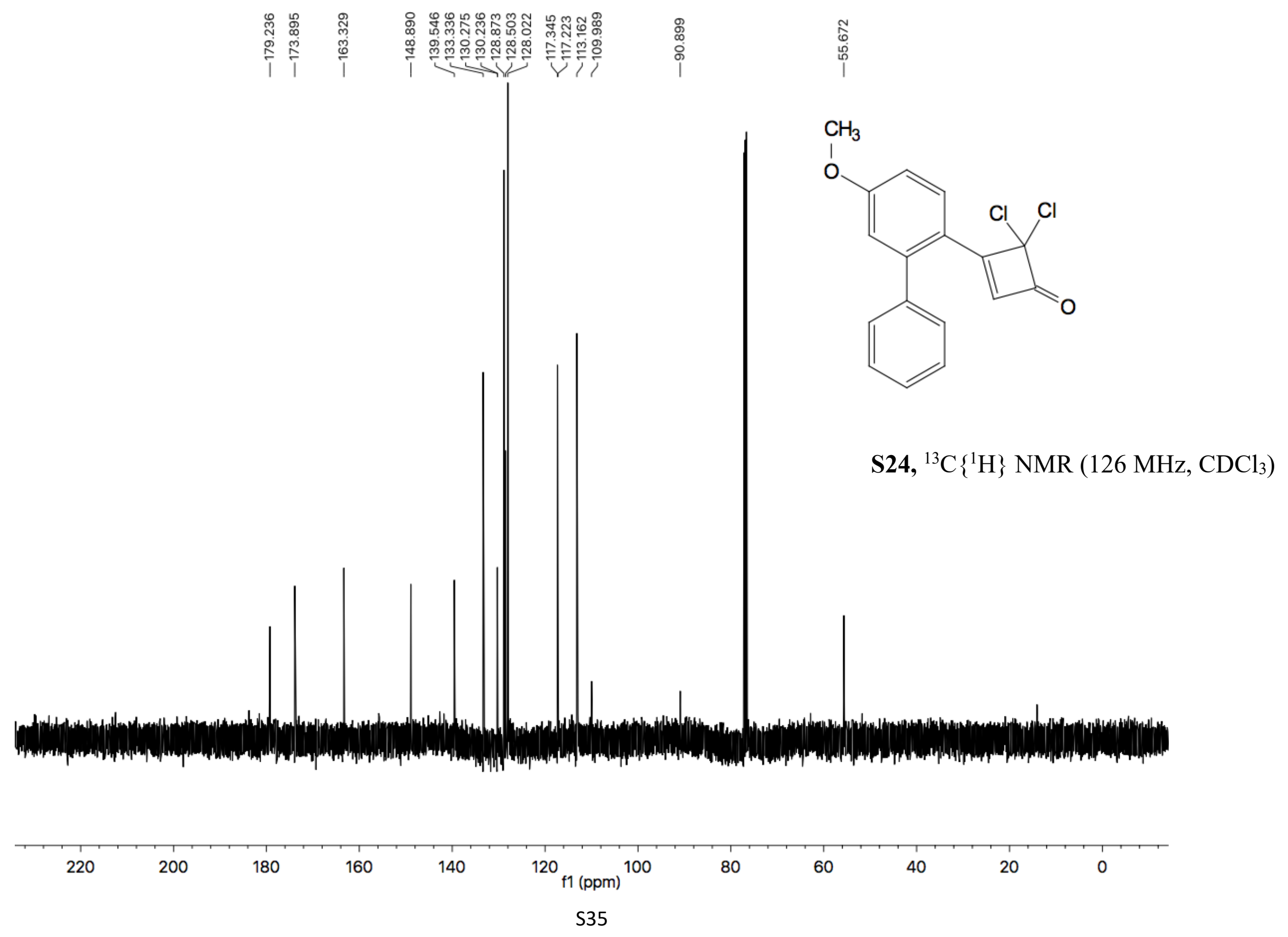




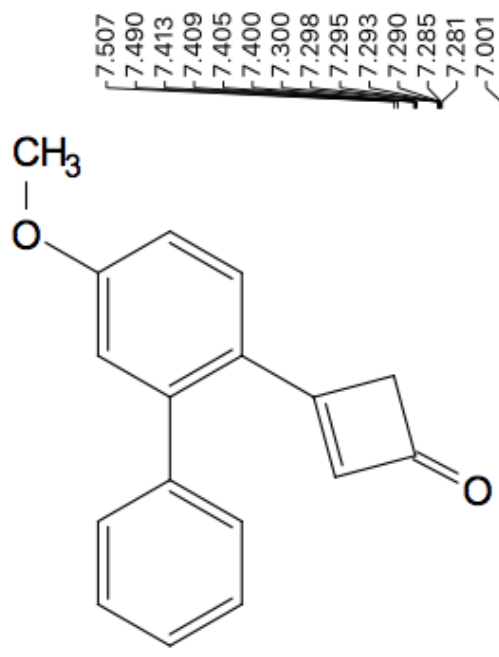

43, ${ }^{1} \mathrm{H}$ NMR $\left(500 \mathrm{MHz}, \mathrm{CDCl}_{3}\right)$

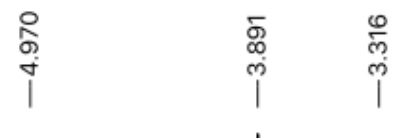

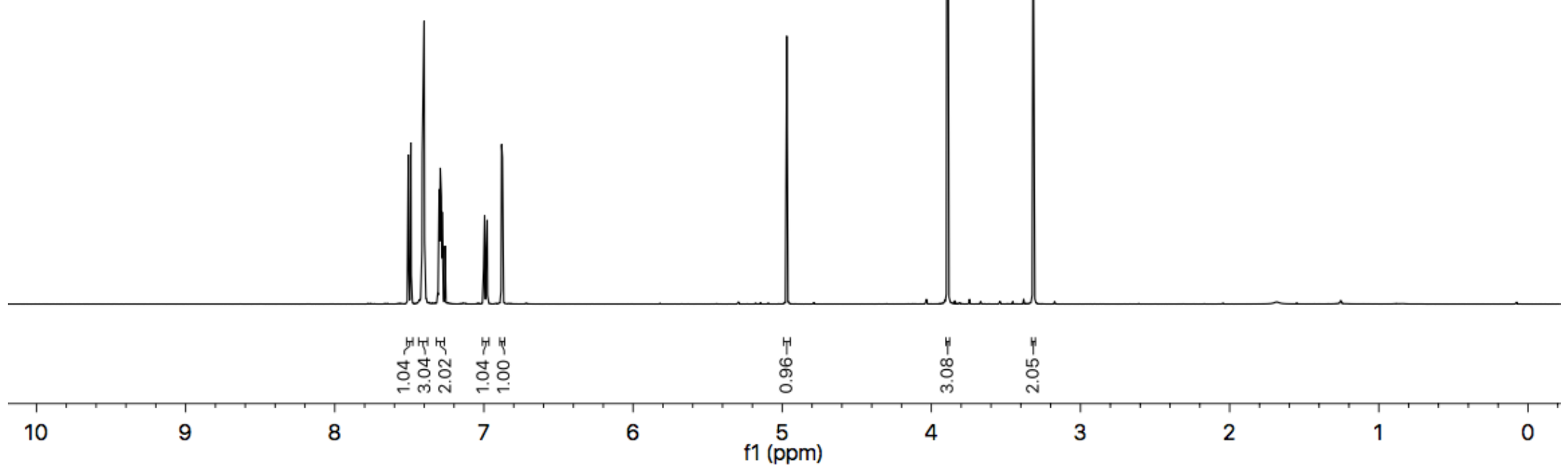

S36 


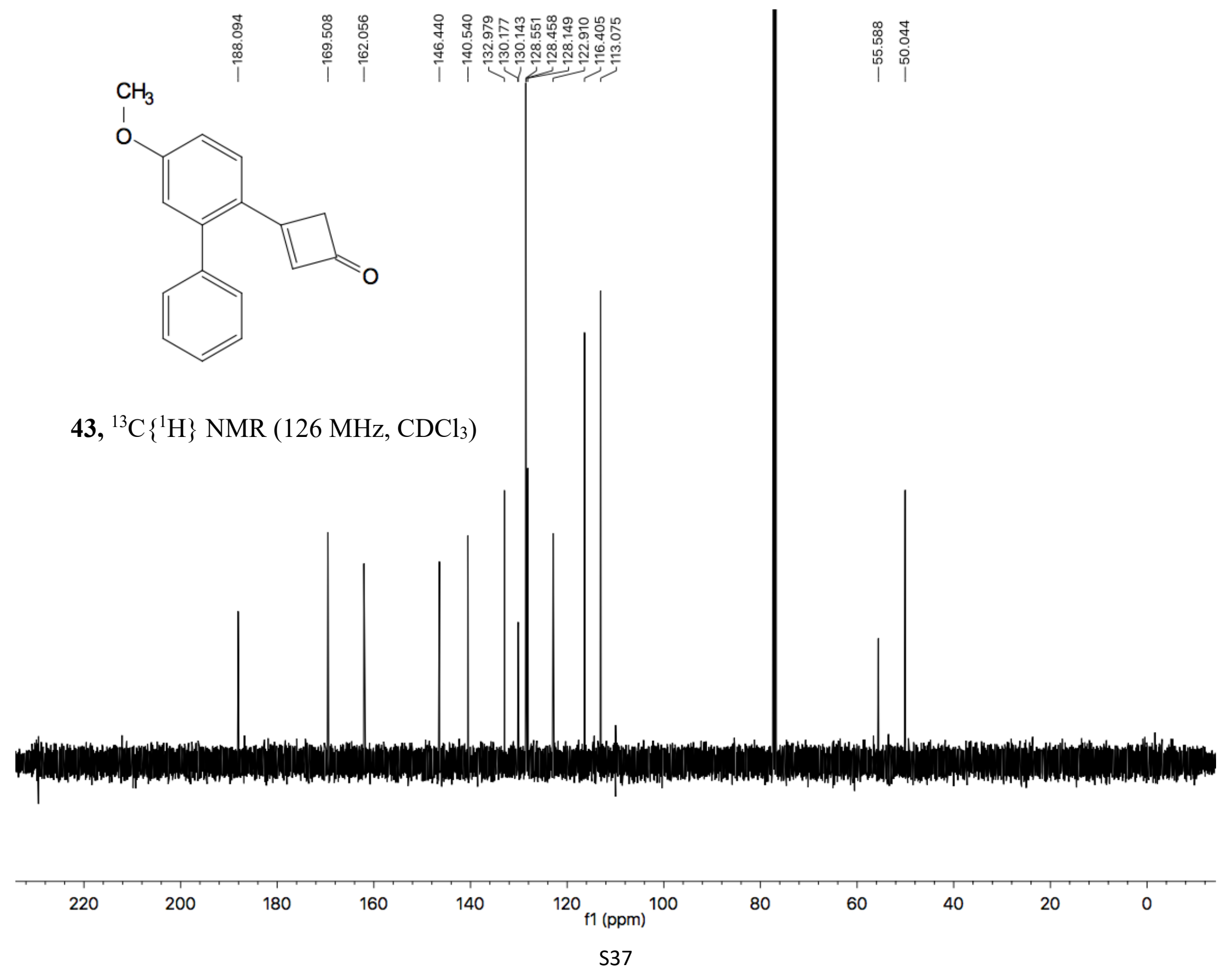




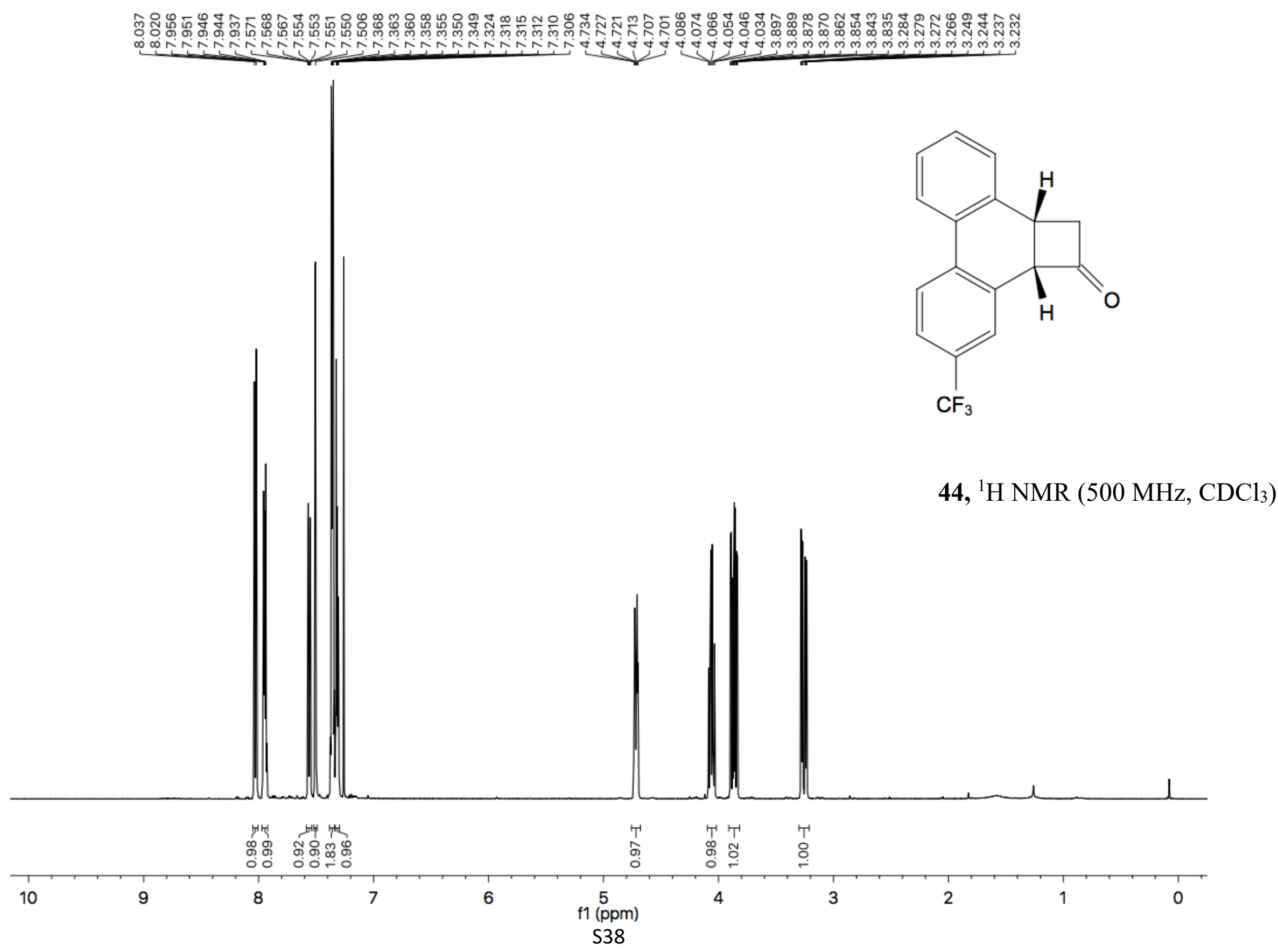




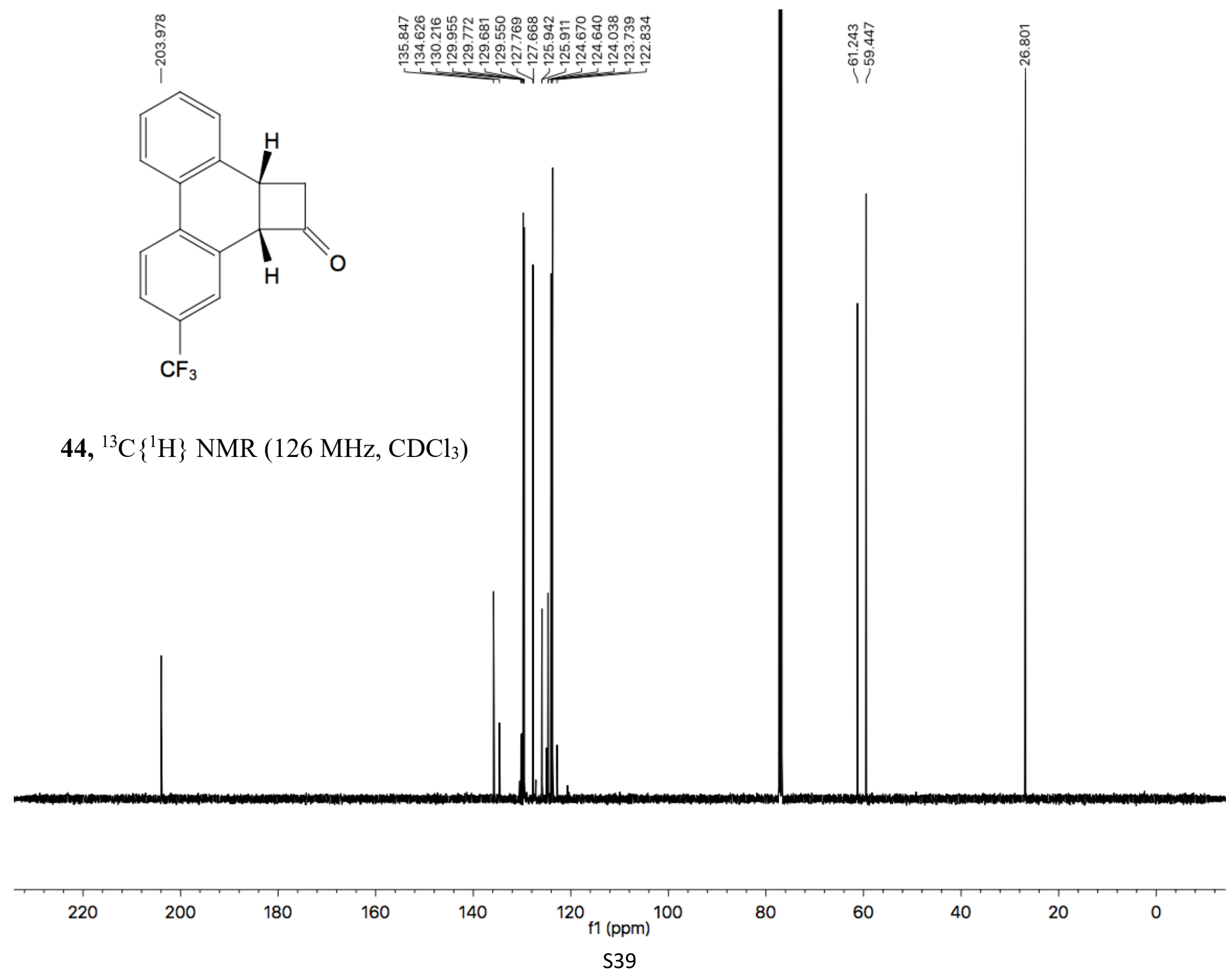




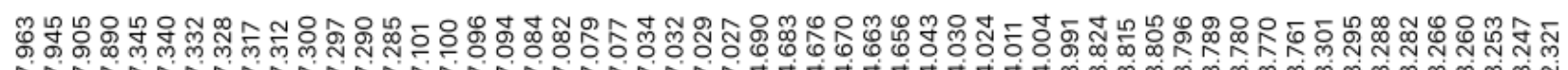

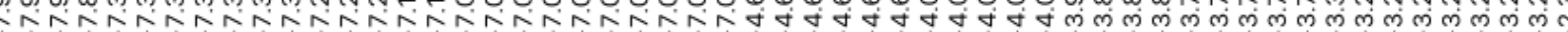

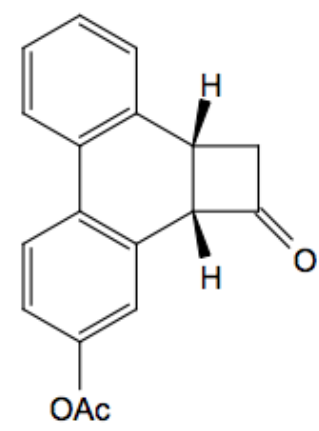

46, ${ }^{1} \mathrm{H}$ NMR $\left(500 \mathrm{MHz}, \mathrm{CDCl}_{3}\right)$

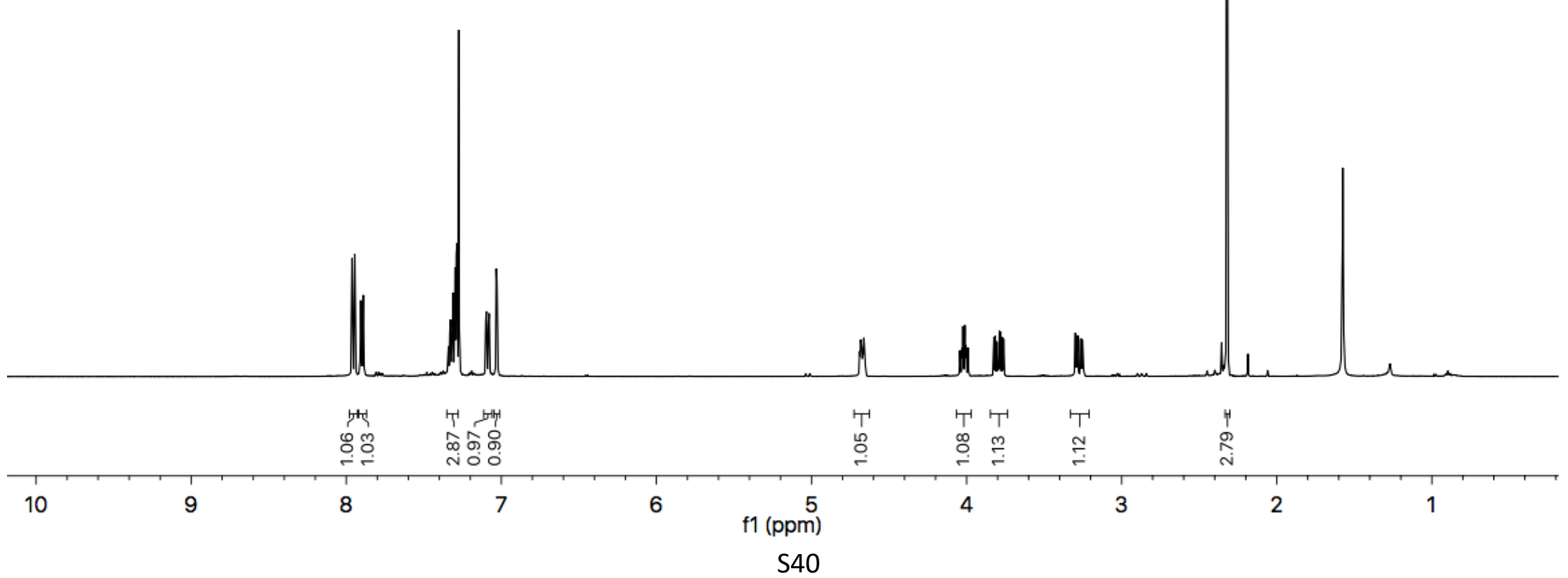



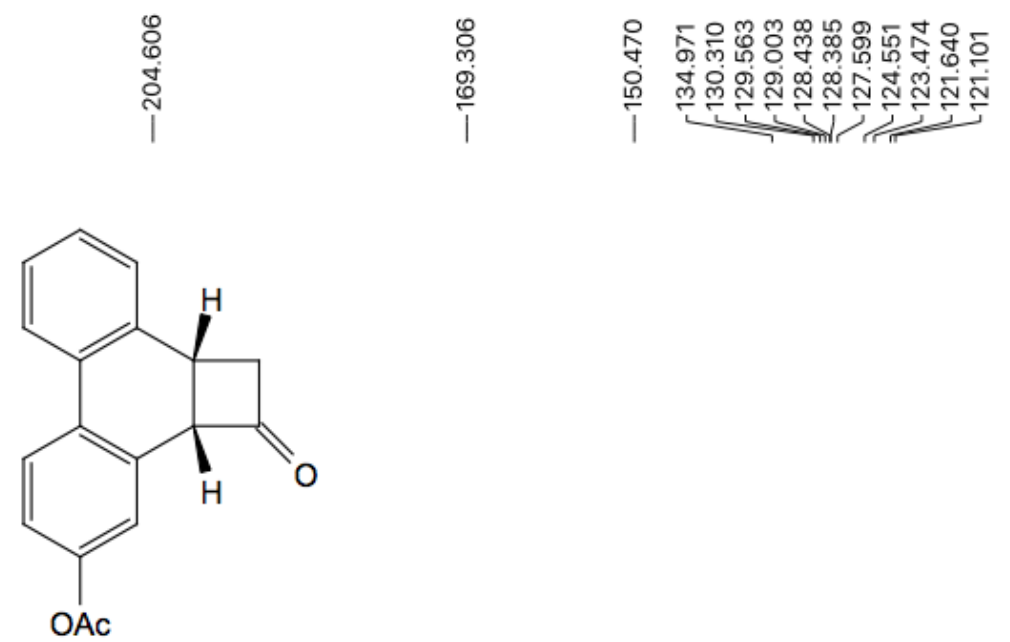

46, ${ }^{13} \mathrm{C}\left\{{ }^{1} \mathrm{H}\right\}$ NMR $\left(126 \mathrm{MHz}, \mathrm{CDCl}_{3}\right)$

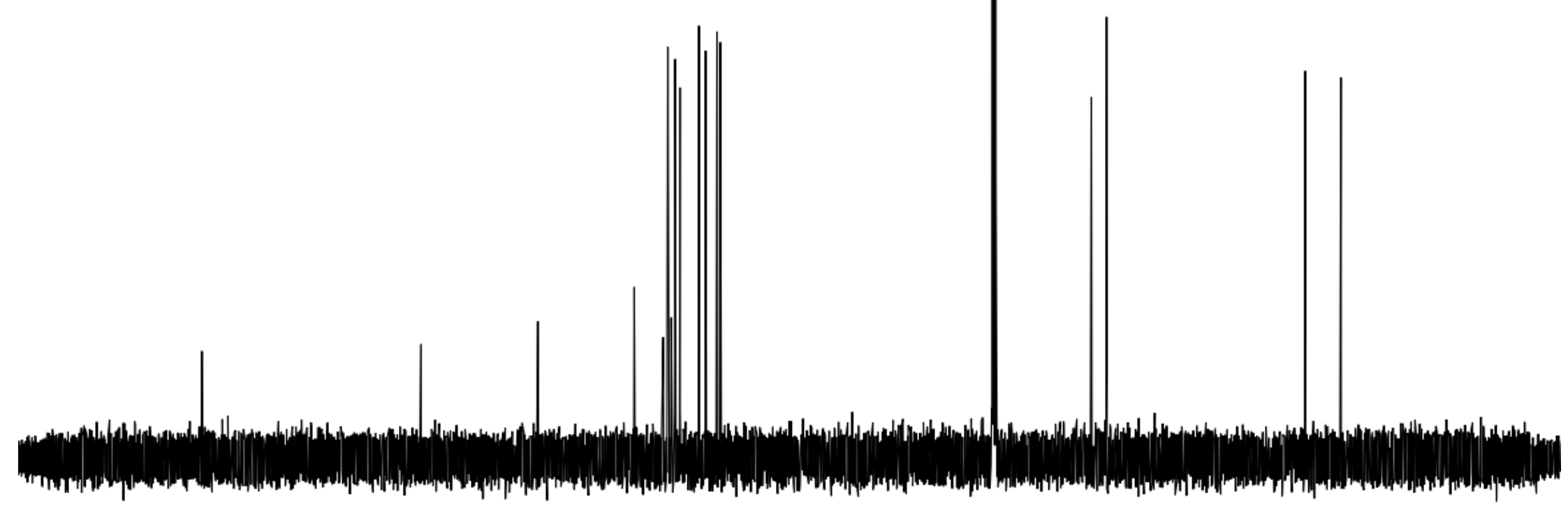

220

200

180

160

140

$120_{\mathrm{f} 1(\mathrm{ppm})} 100$

80

60

40

20

0 


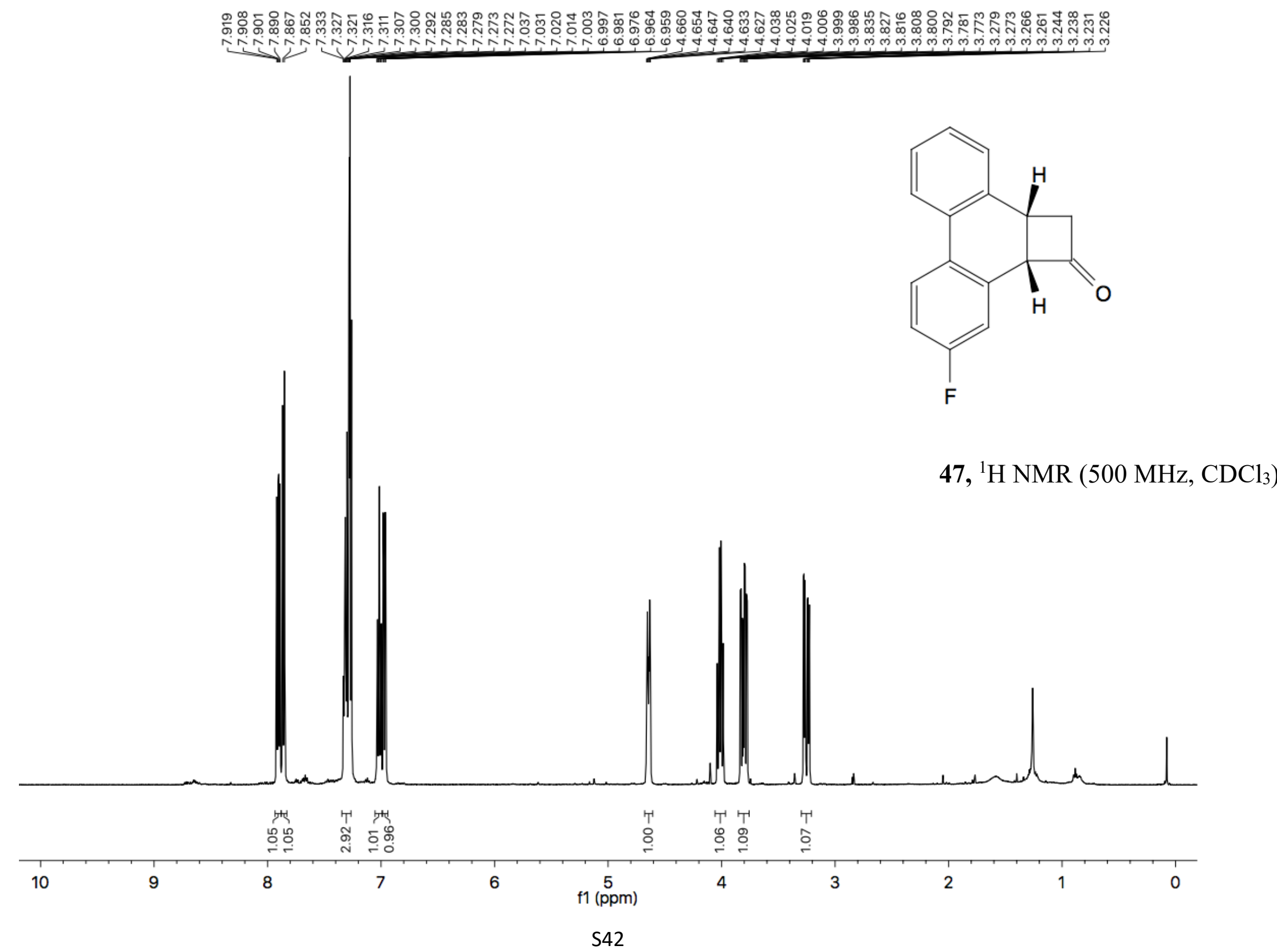




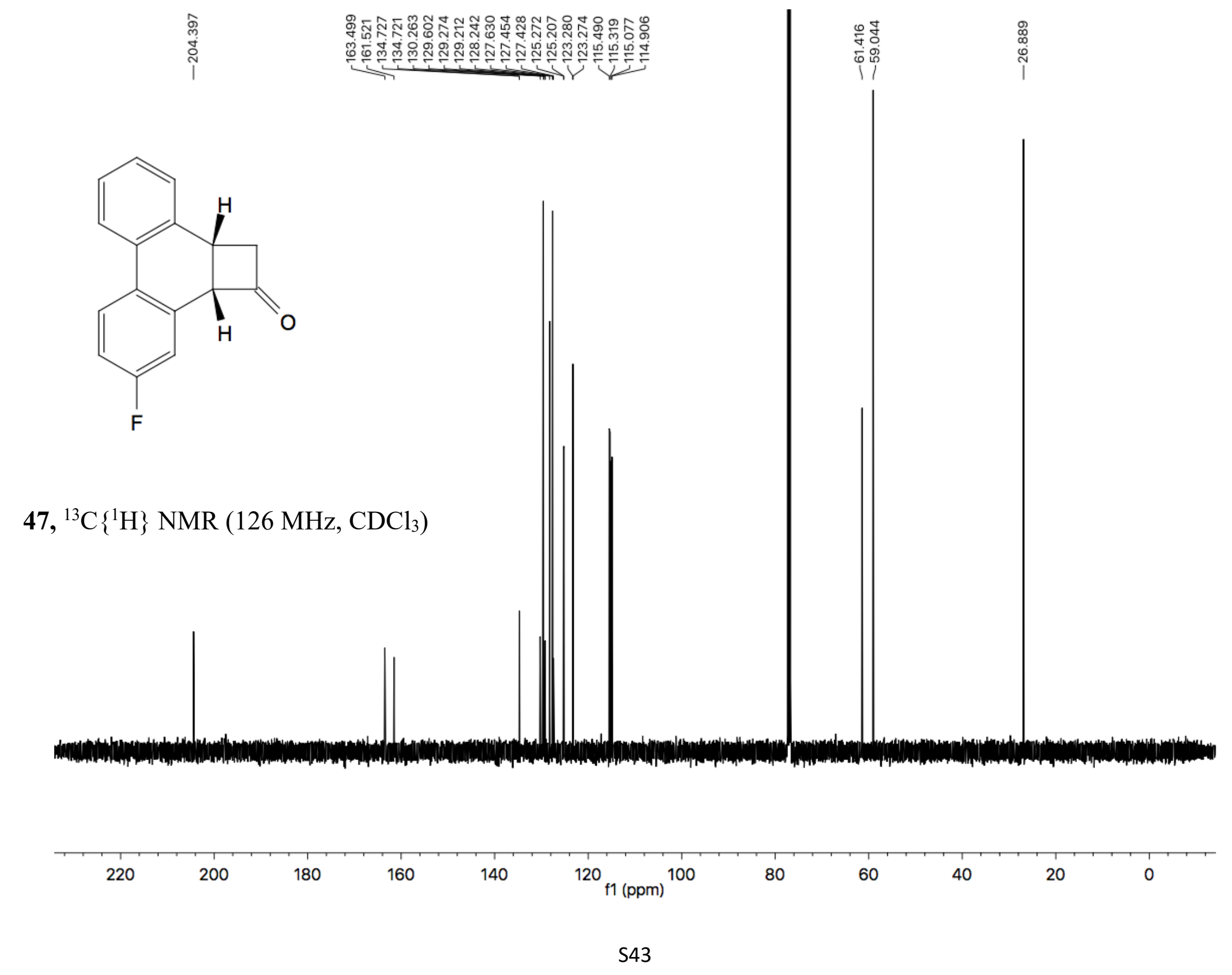




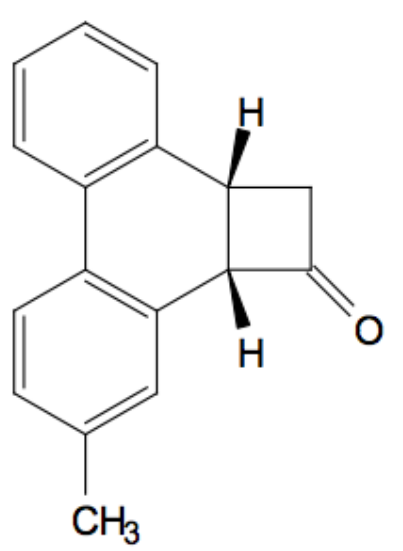

48, ${ }^{1} \mathrm{H}$ NMR $\left(500 \mathrm{MHz}, \mathrm{CDCl}_{3}\right)$

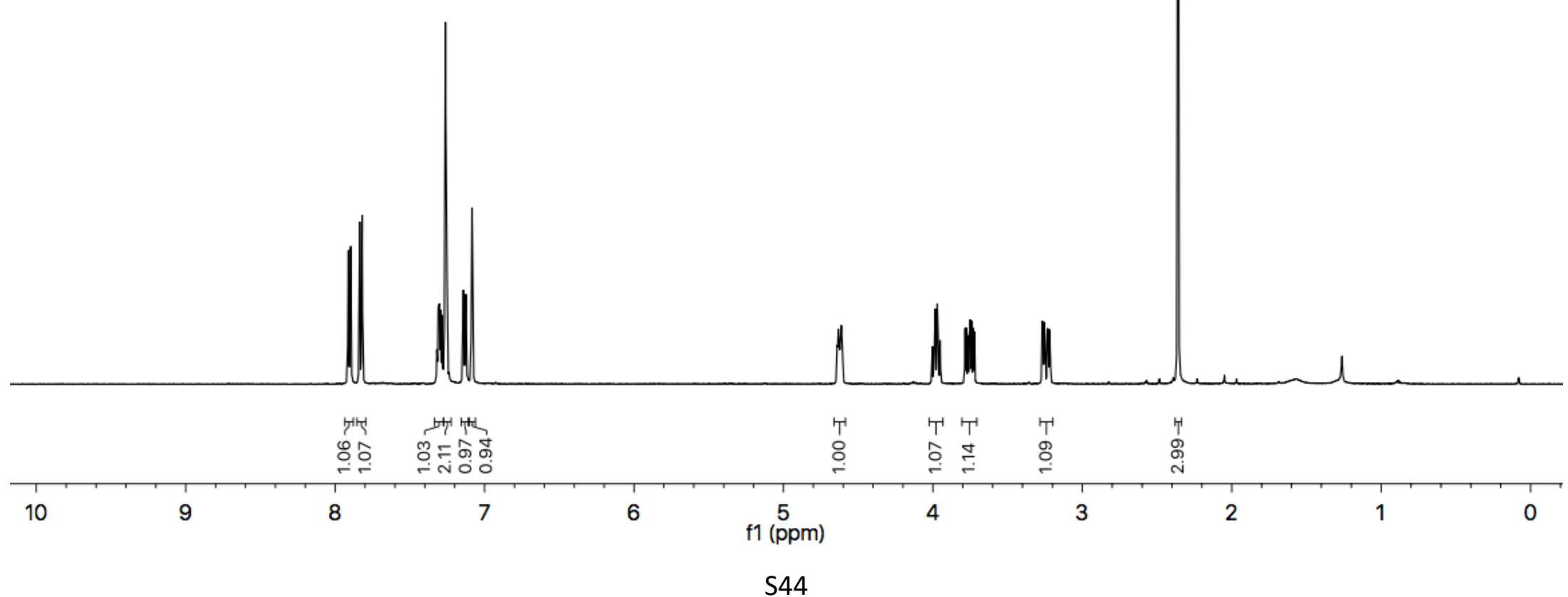



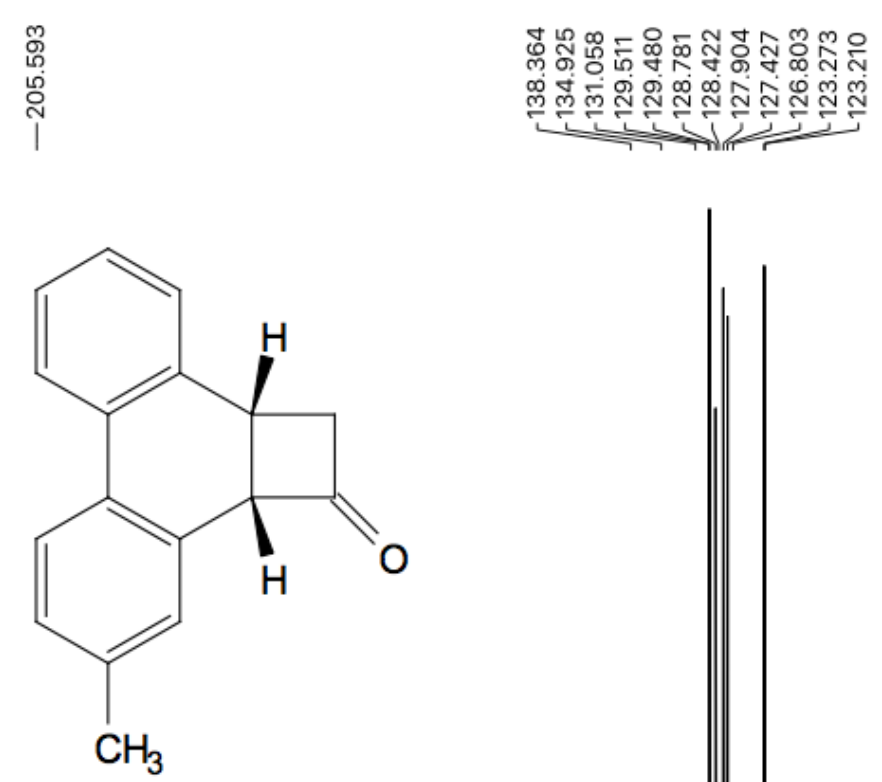

48, ${ }^{13} \mathrm{C}\left\{{ }^{1} \mathrm{H}\right\}$ NMR (126 MHz, $\left.\mathrm{CDCl}_{3}\right)$

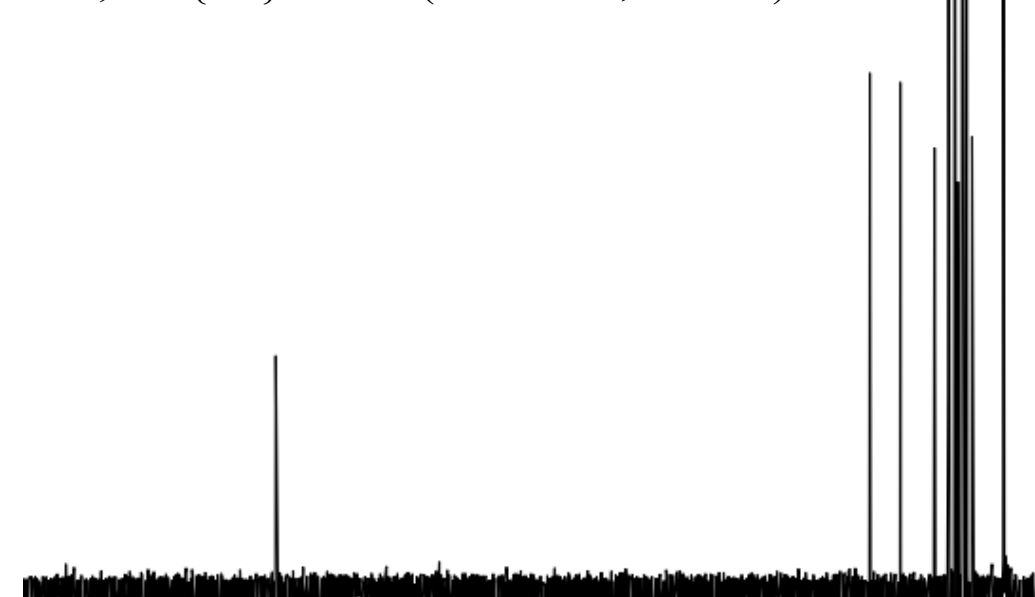




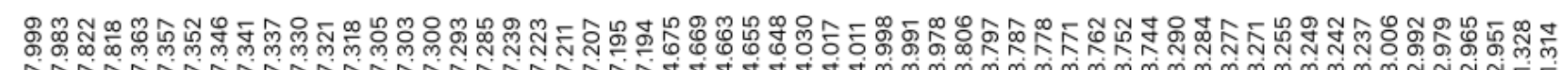

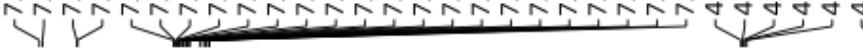

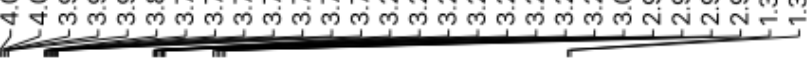

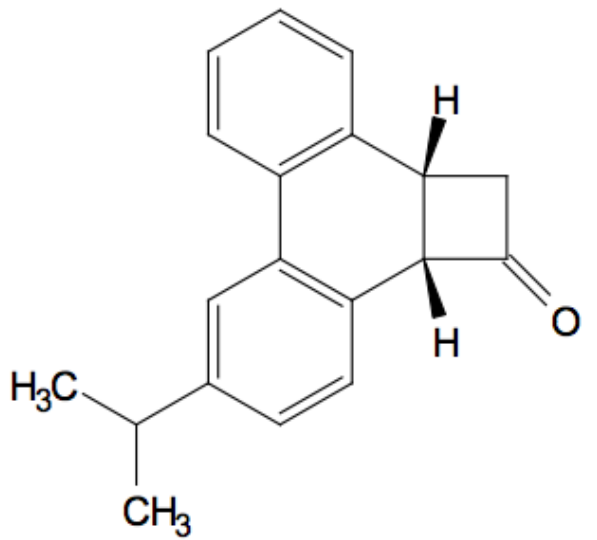

52, ${ }^{1} \mathrm{H}$ NMR $\left(500 \mathrm{MHz}, \mathrm{CDCl}_{3}\right)$

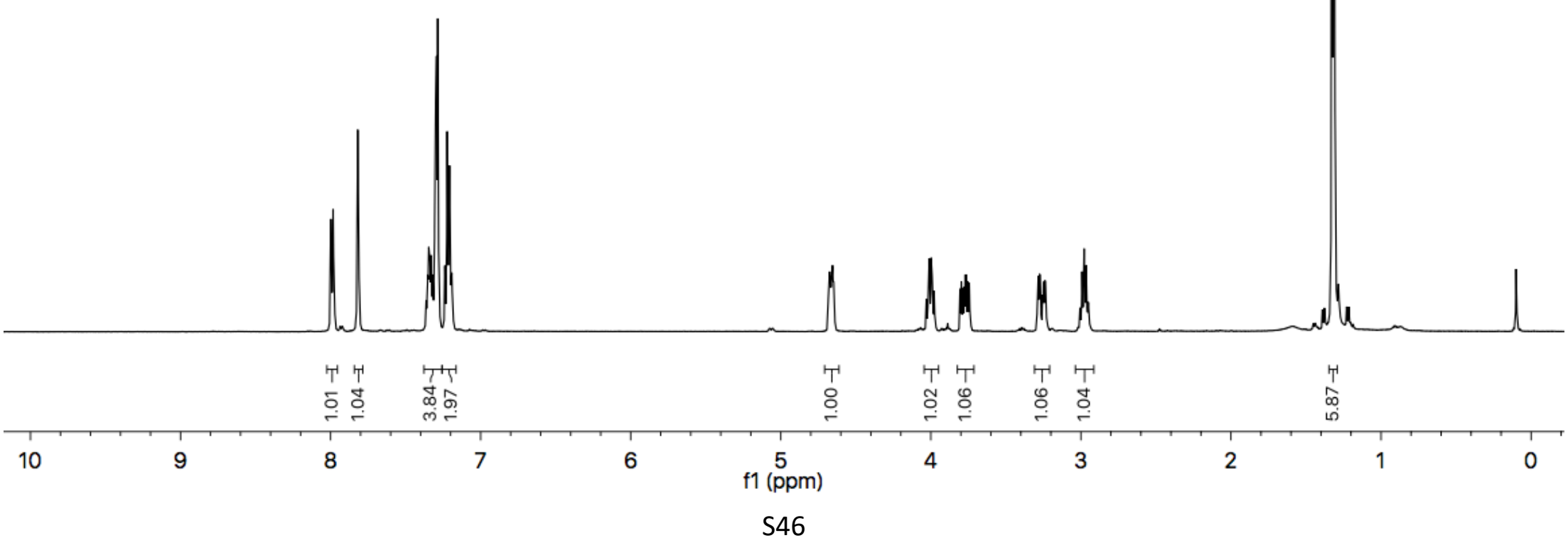




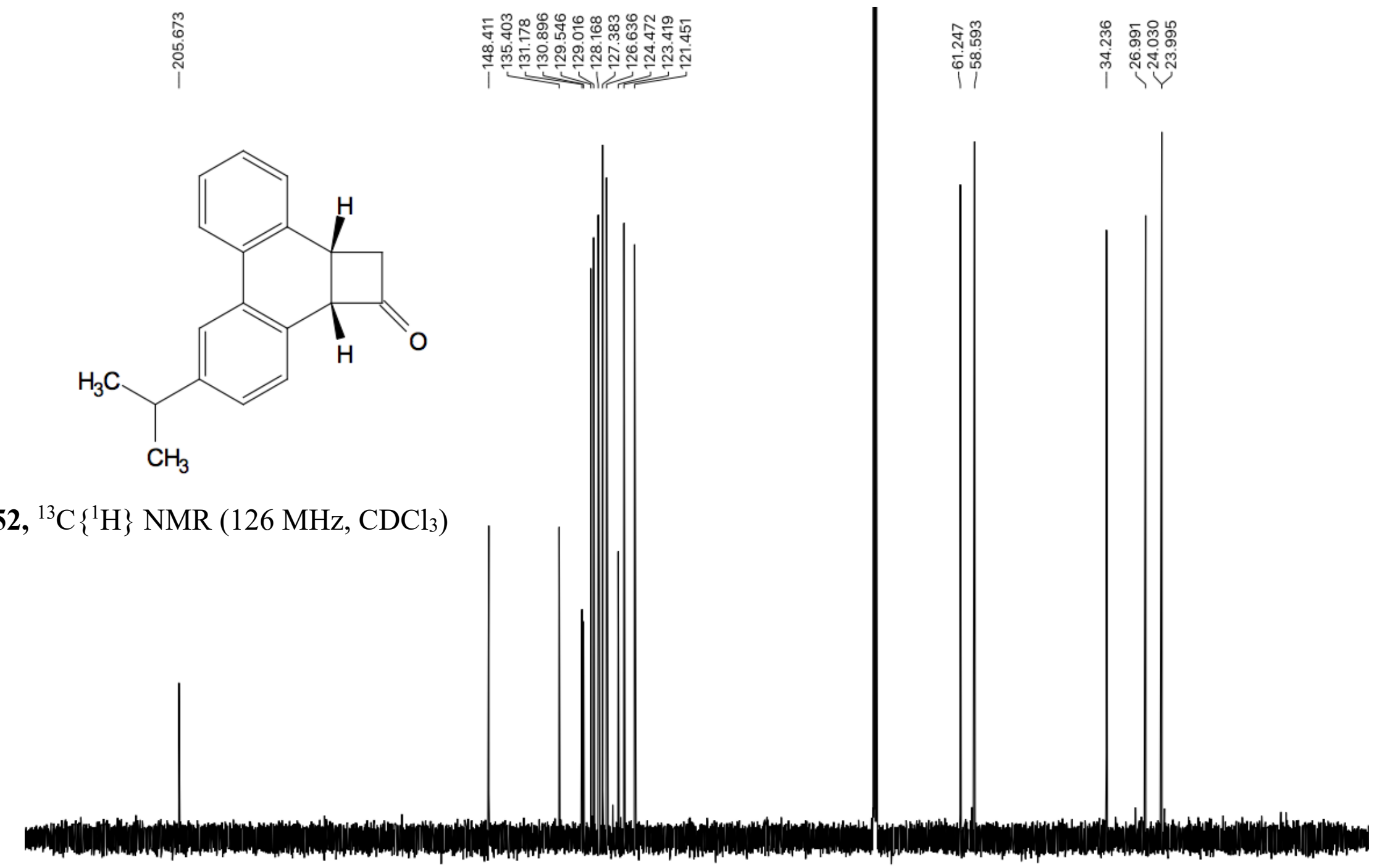

52, ${ }^{13} \mathrm{C}\left\{{ }^{1} \mathrm{H}\right\}$ NMR (126 MHz, $\left.\mathrm{CDCl}_{3}\right)$

220

200

180

160

140

120

$\mathrm{f1}(\mathrm{ppm})$

80

60

40

20

S47 


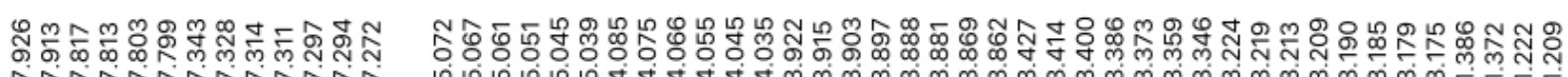

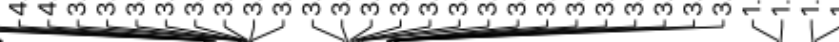

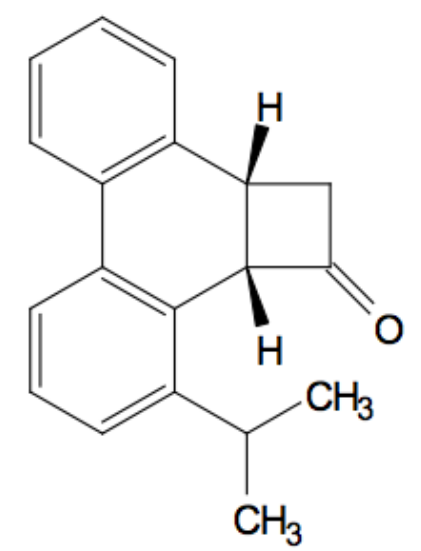

53, ${ }^{1} \mathrm{H}$ NMR $\left(500 \mathrm{MHz}, \mathrm{CDCl}_{3}\right)$

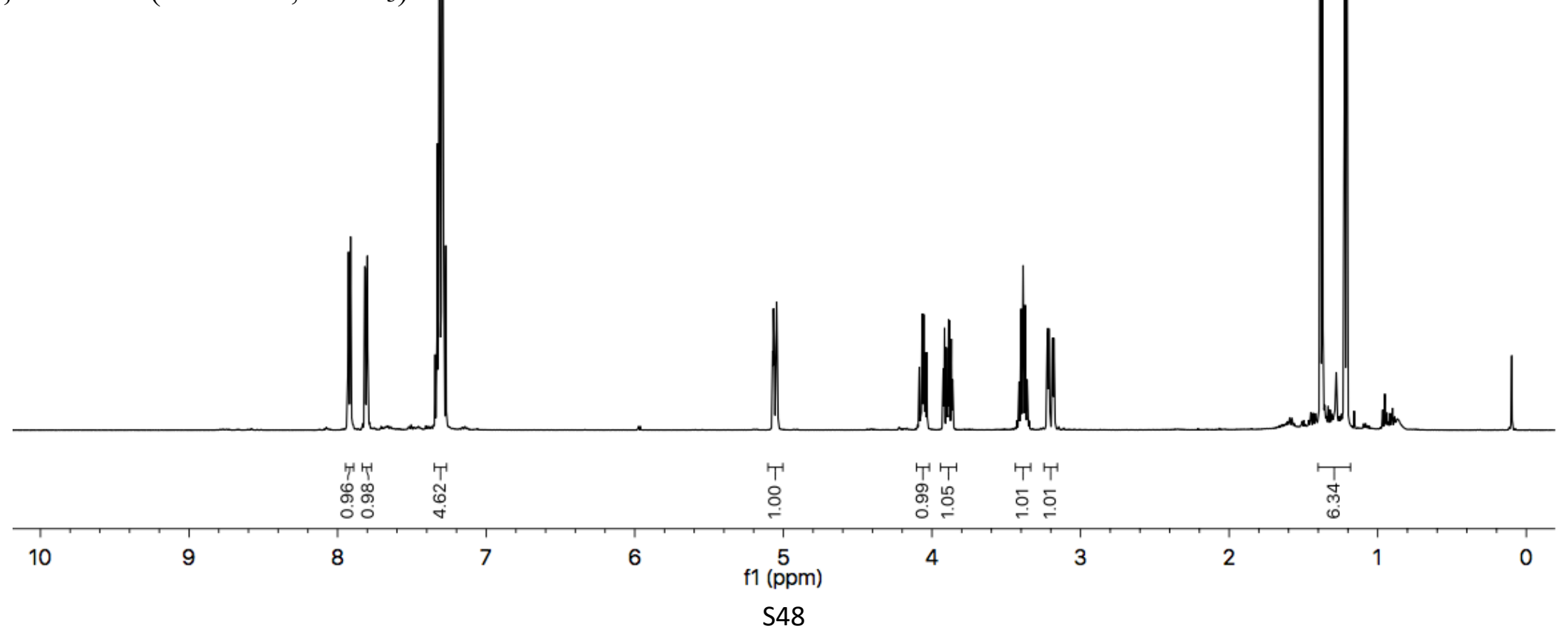




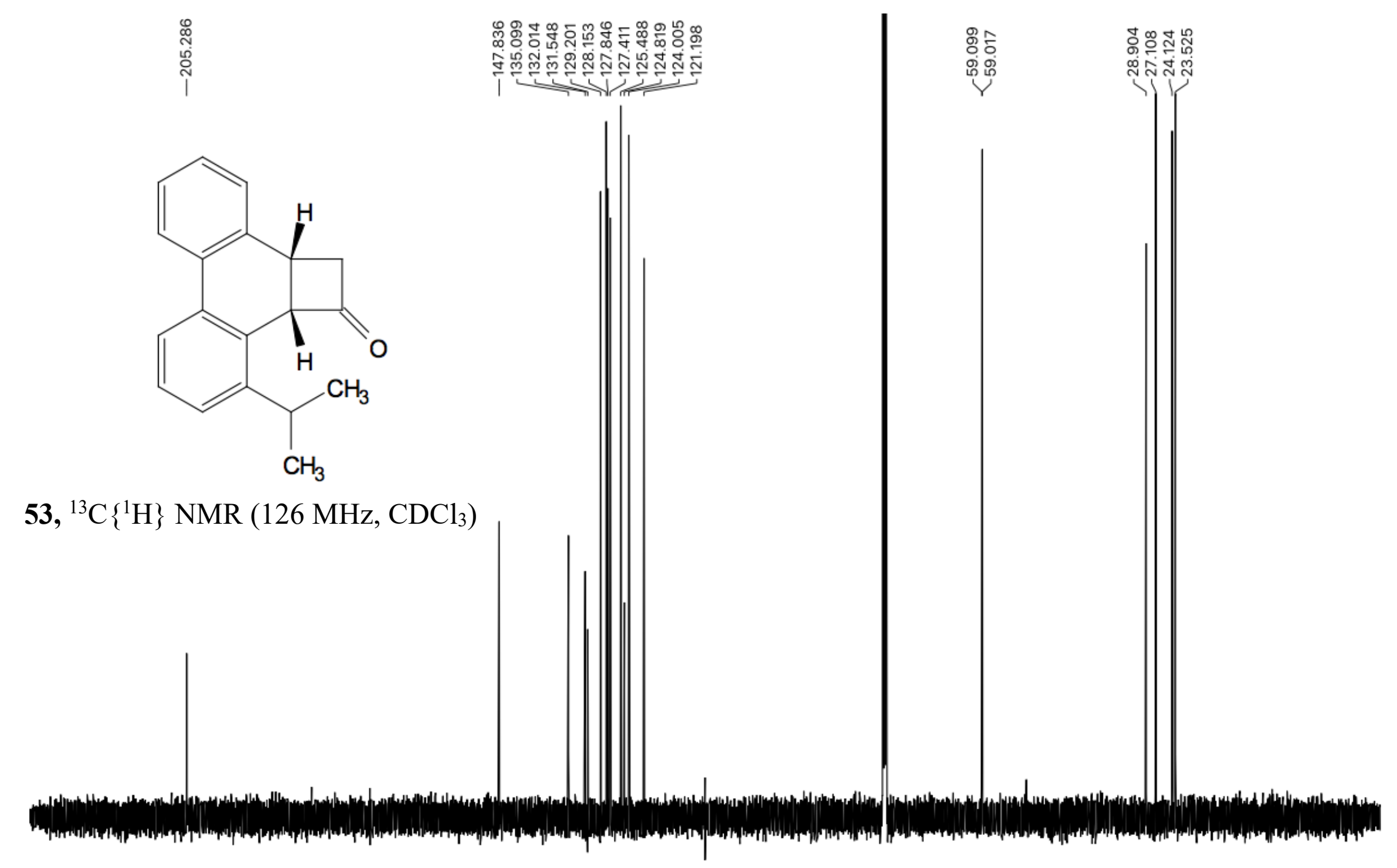

220

200

180

160

140

120

$100 \quad 80$

60

40

20

0

S49 


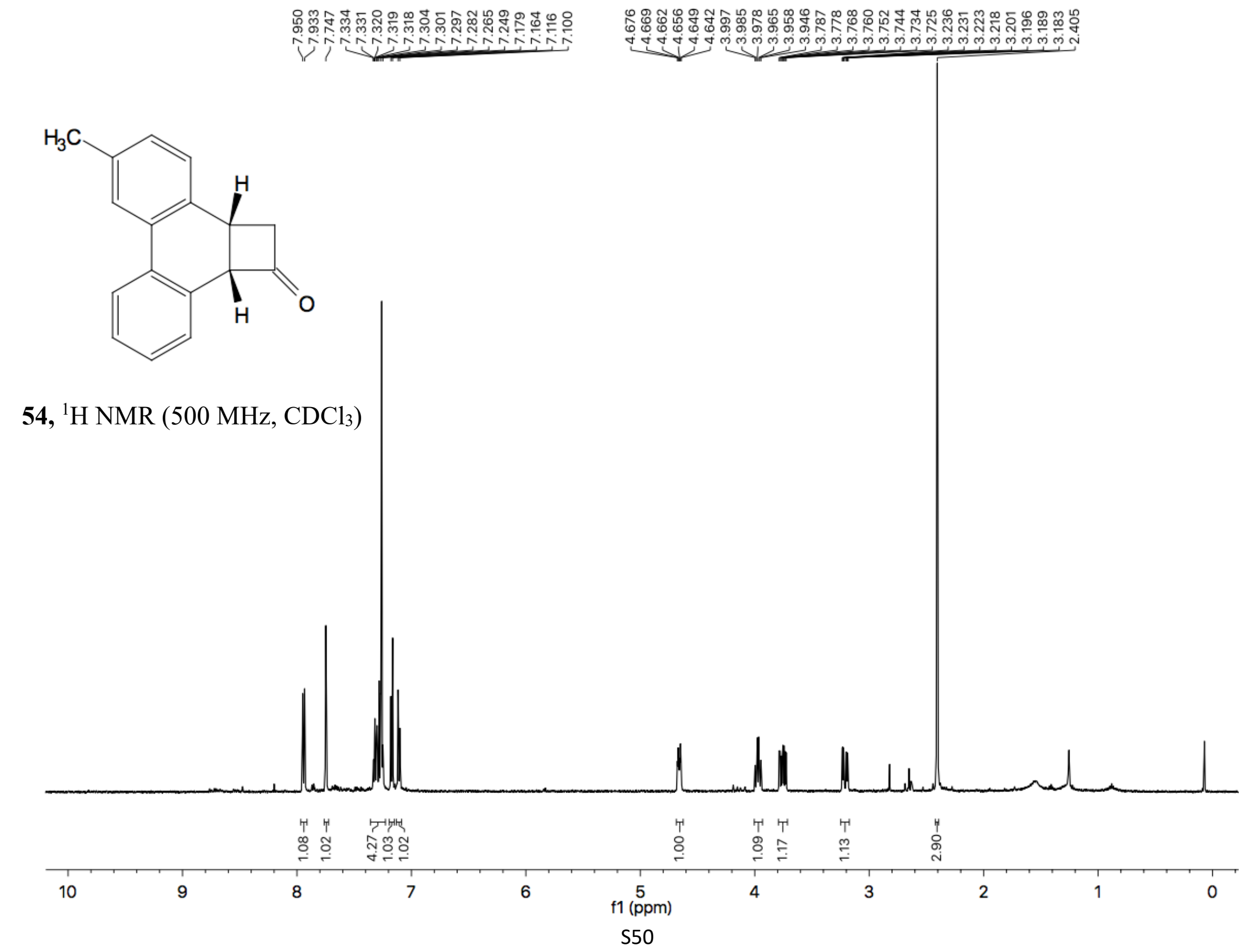




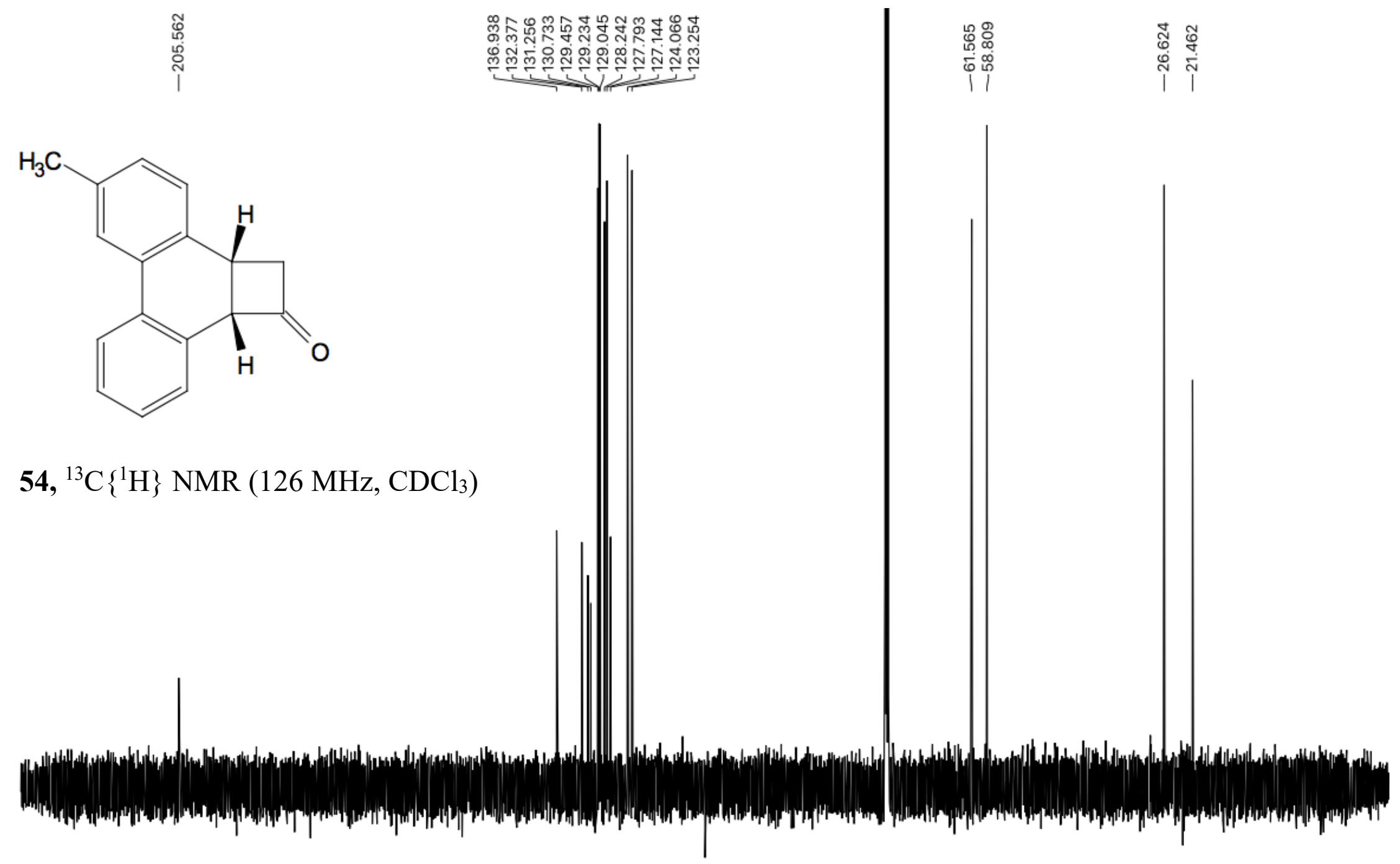

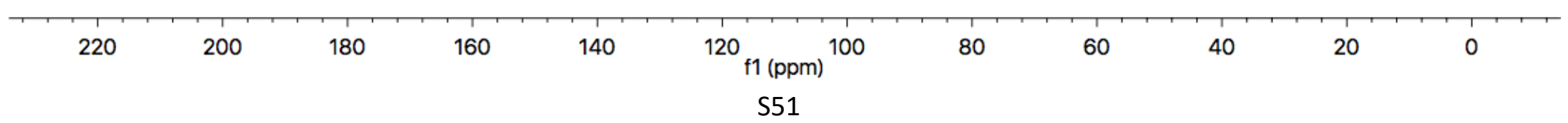




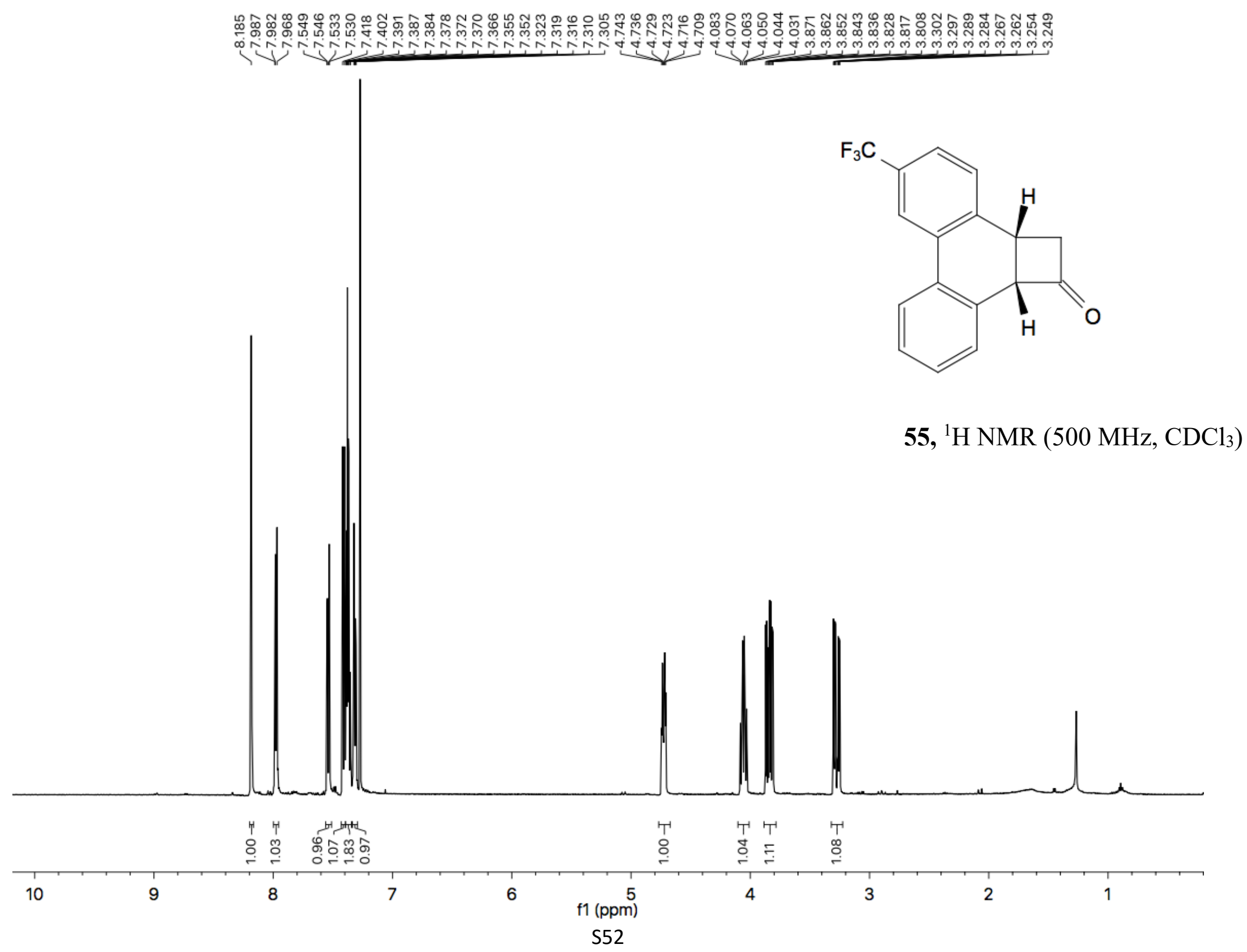



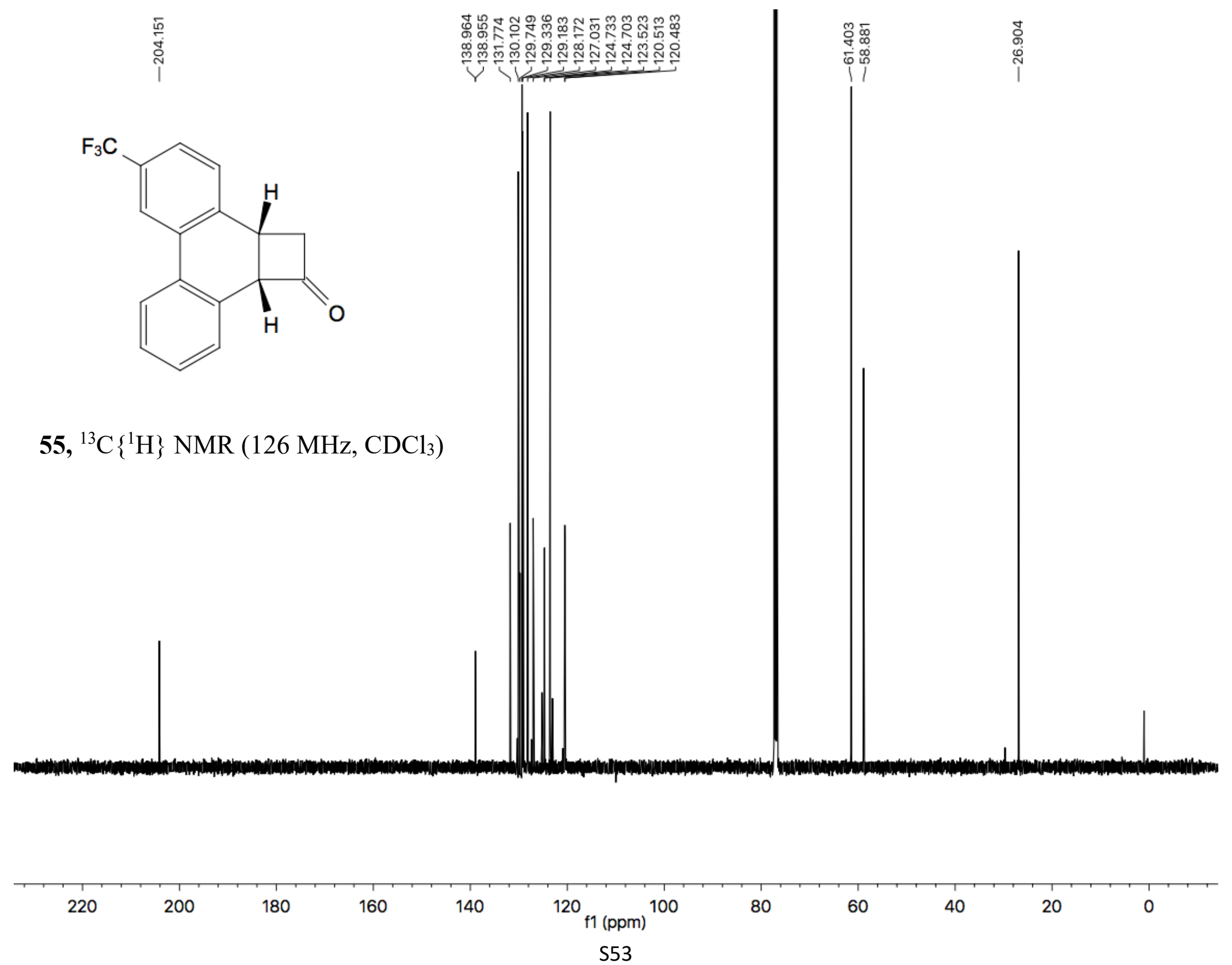


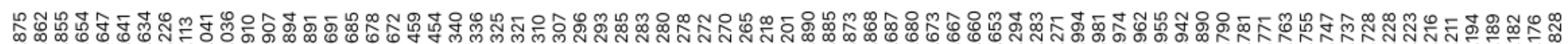

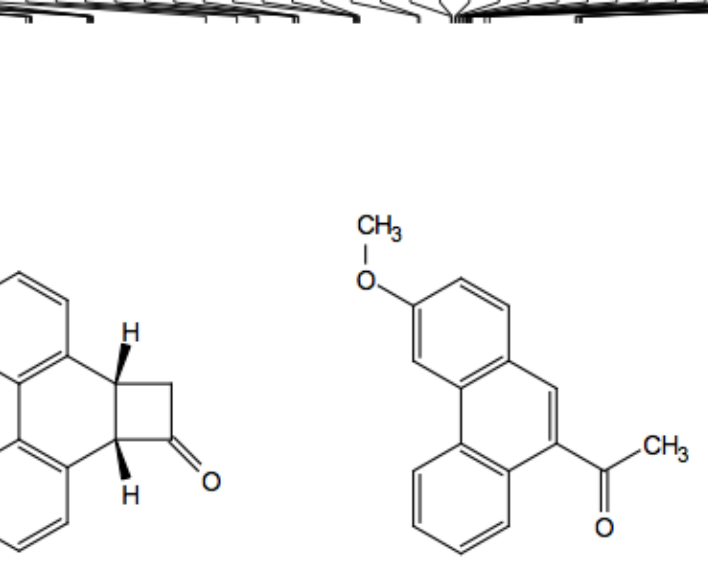

56 and S25, 10:1, ${ }^{1} \mathrm{H}$ NMR $\left(500 \mathrm{MHz}, \mathrm{CDCl}_{3}\right)$

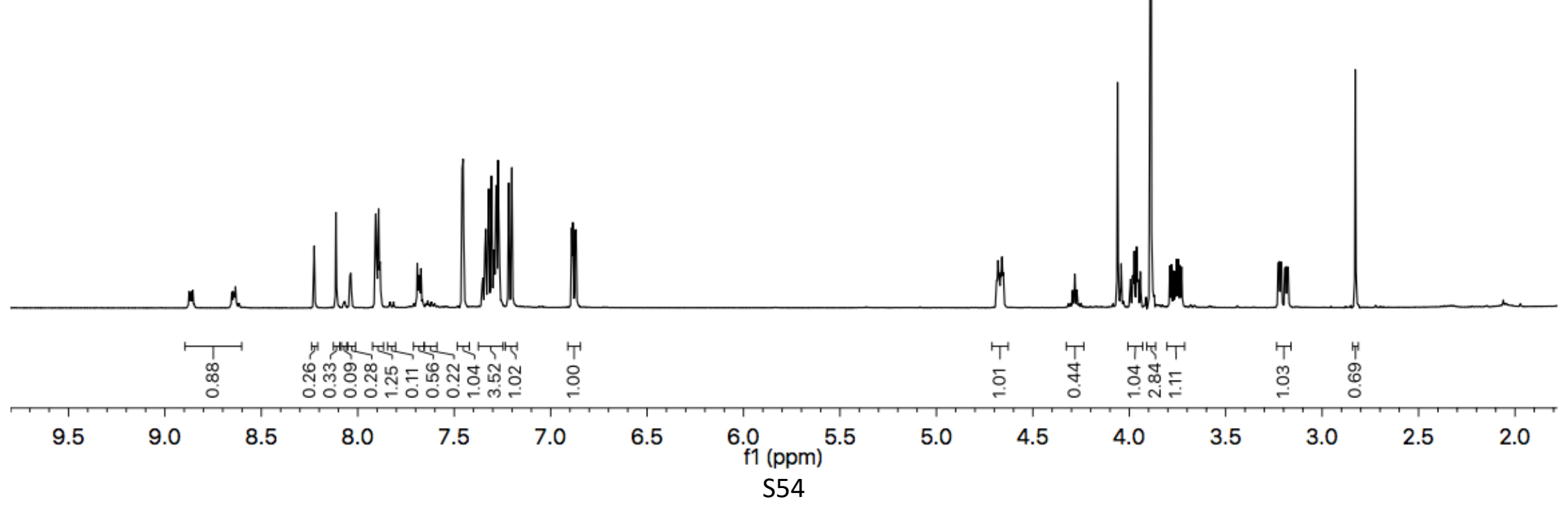


ํㅠ |

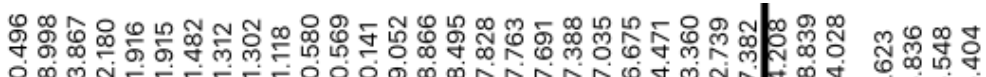

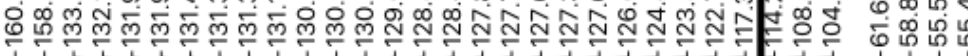
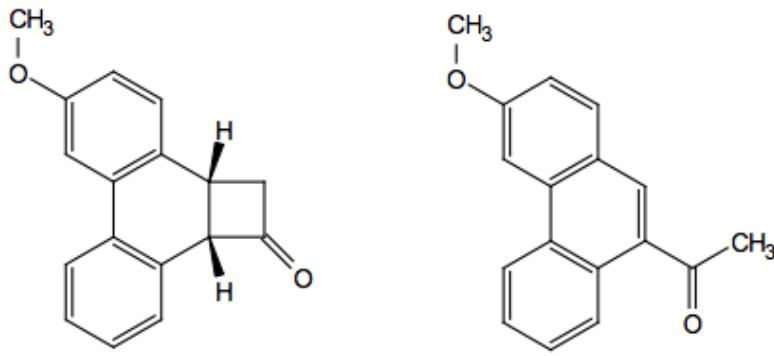

56 and S25, 10:1, ${ }^{13} \mathrm{C}\left\{{ }^{1} \mathrm{H}\right\}$ NMR (126 MHz, $\left.\mathrm{CDCl}_{3}\right)$

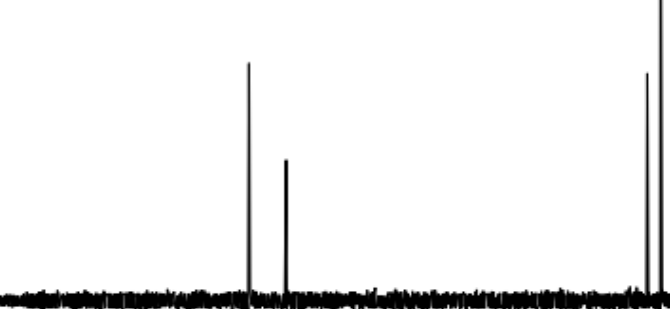

220

200

180

160

140

120

100

80

60

40

20

0 


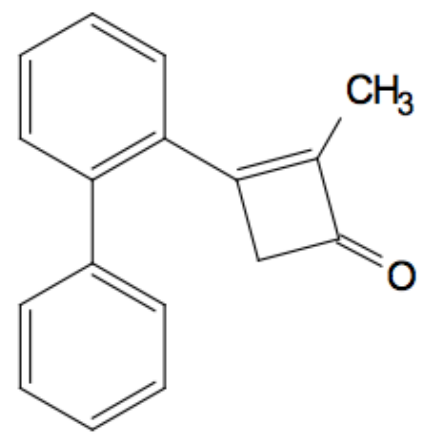

58, ${ }^{1} \mathrm{H}$ NMR $\left(500 \mathrm{MHz}, \mathrm{CDCl}_{3}\right)$

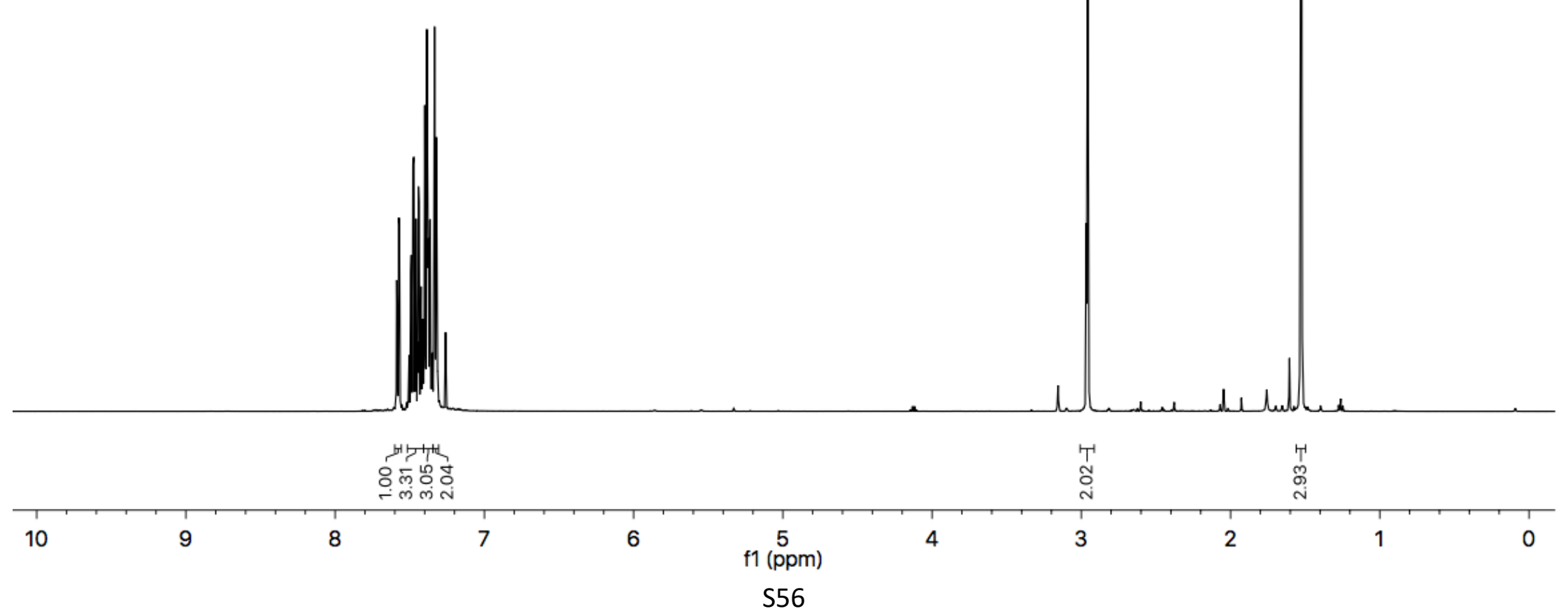




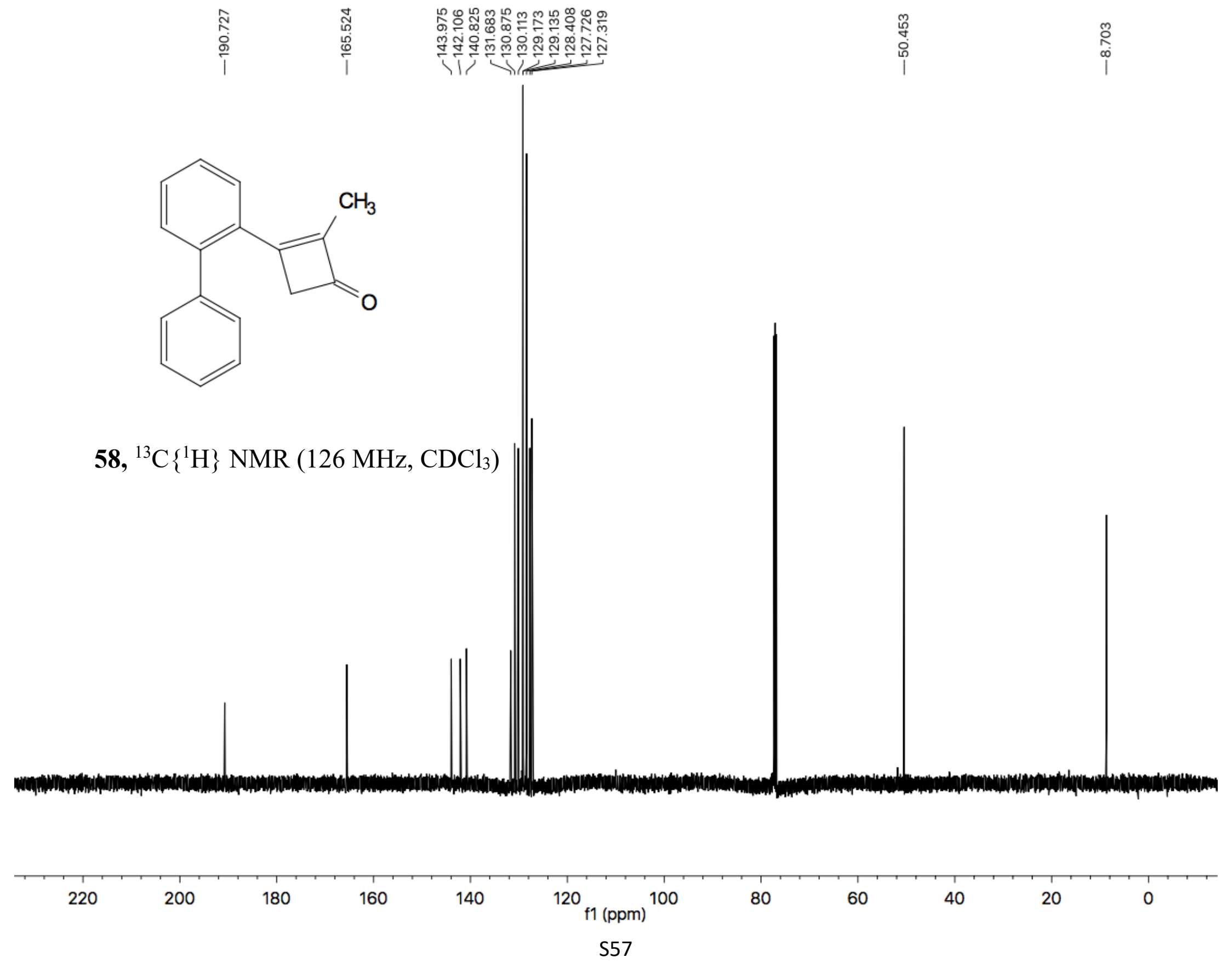




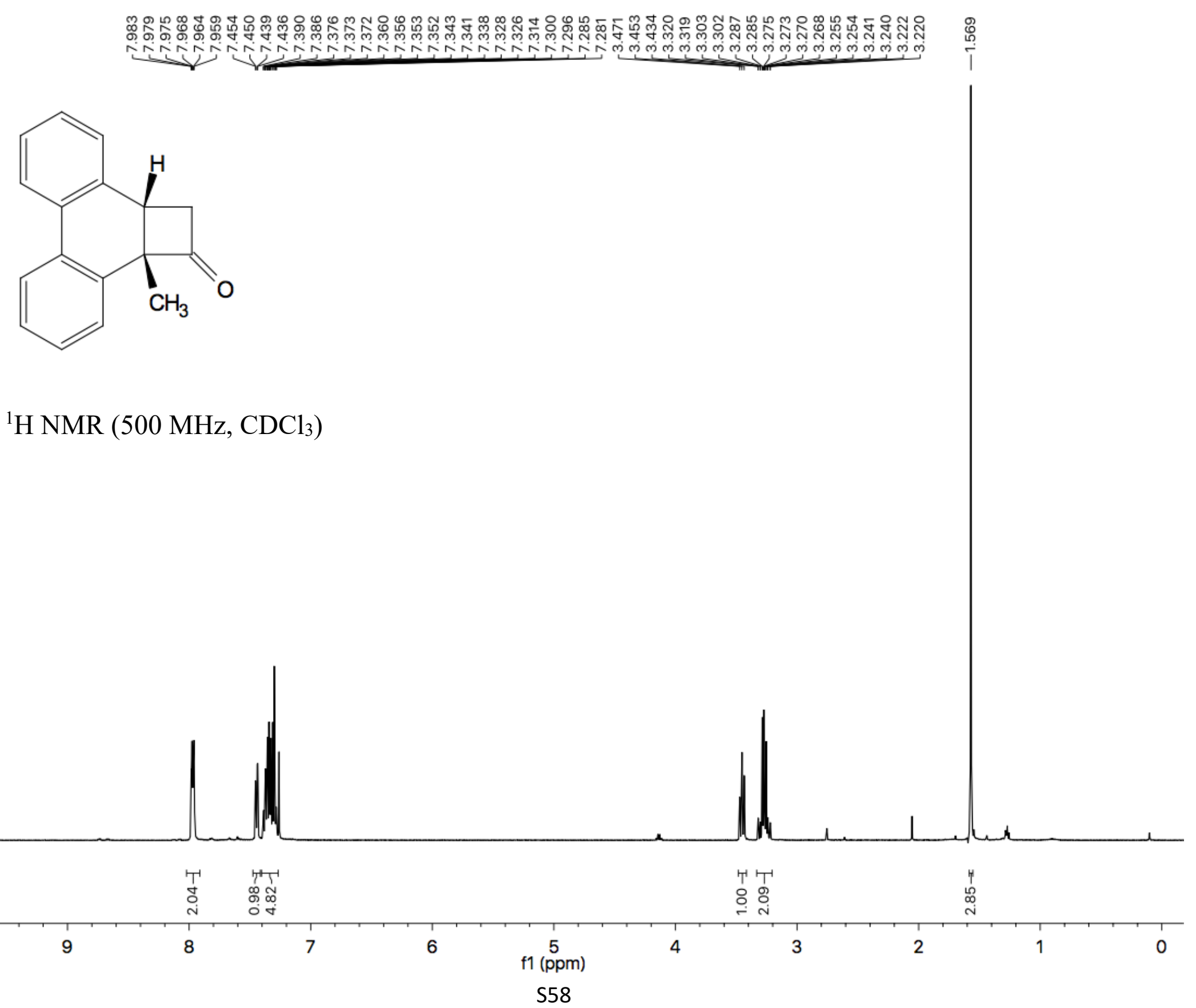




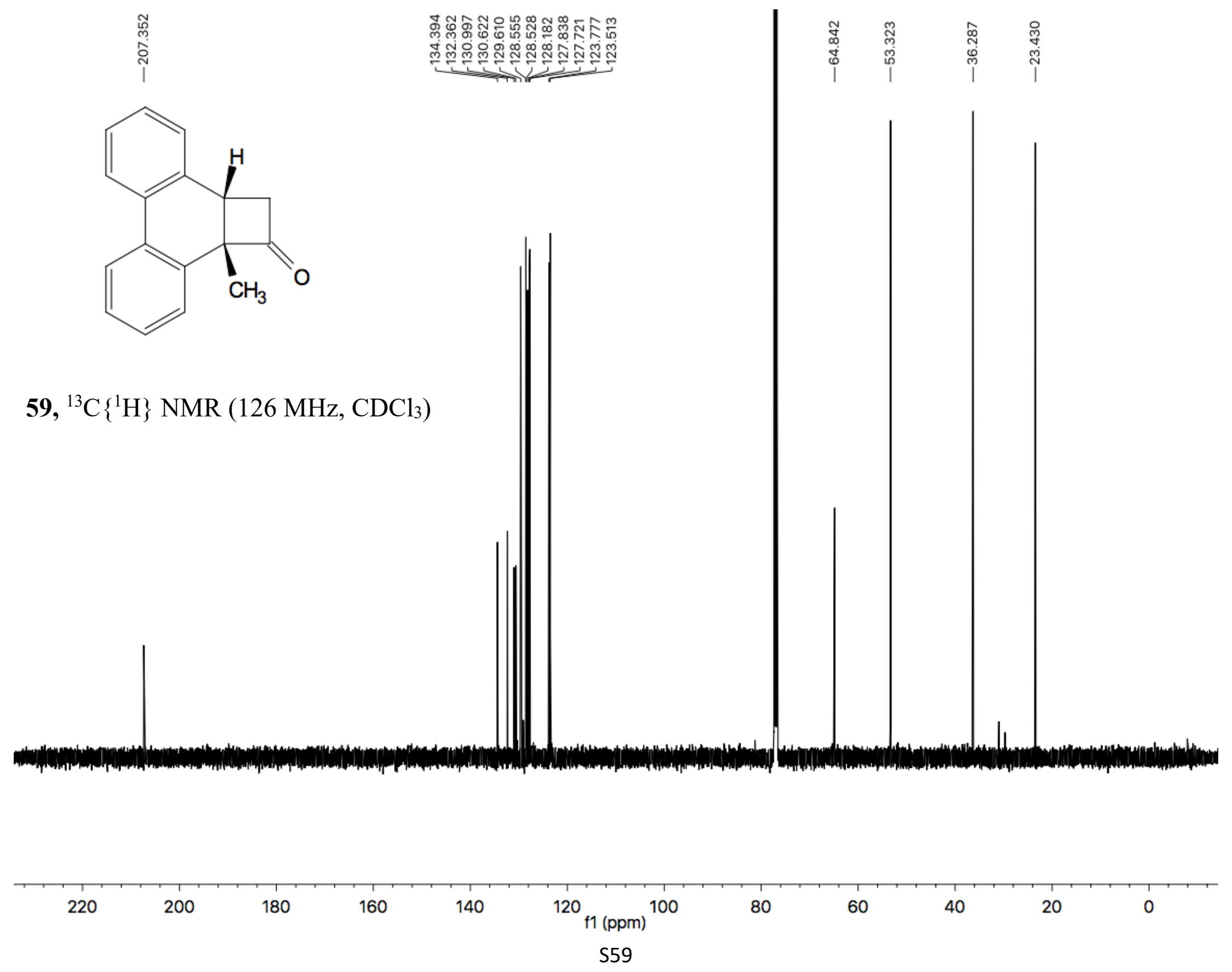




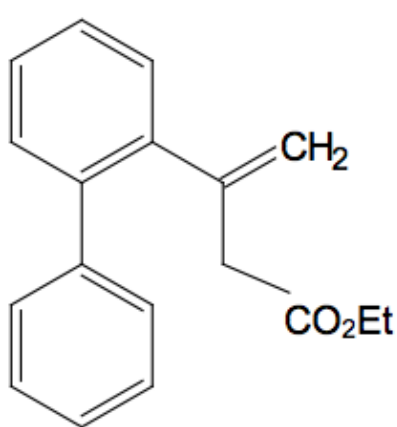

60, ${ }^{1} \mathrm{H}$ NMR $\left(500 \mathrm{MHz}, \mathrm{CDCl}_{3}\right)$

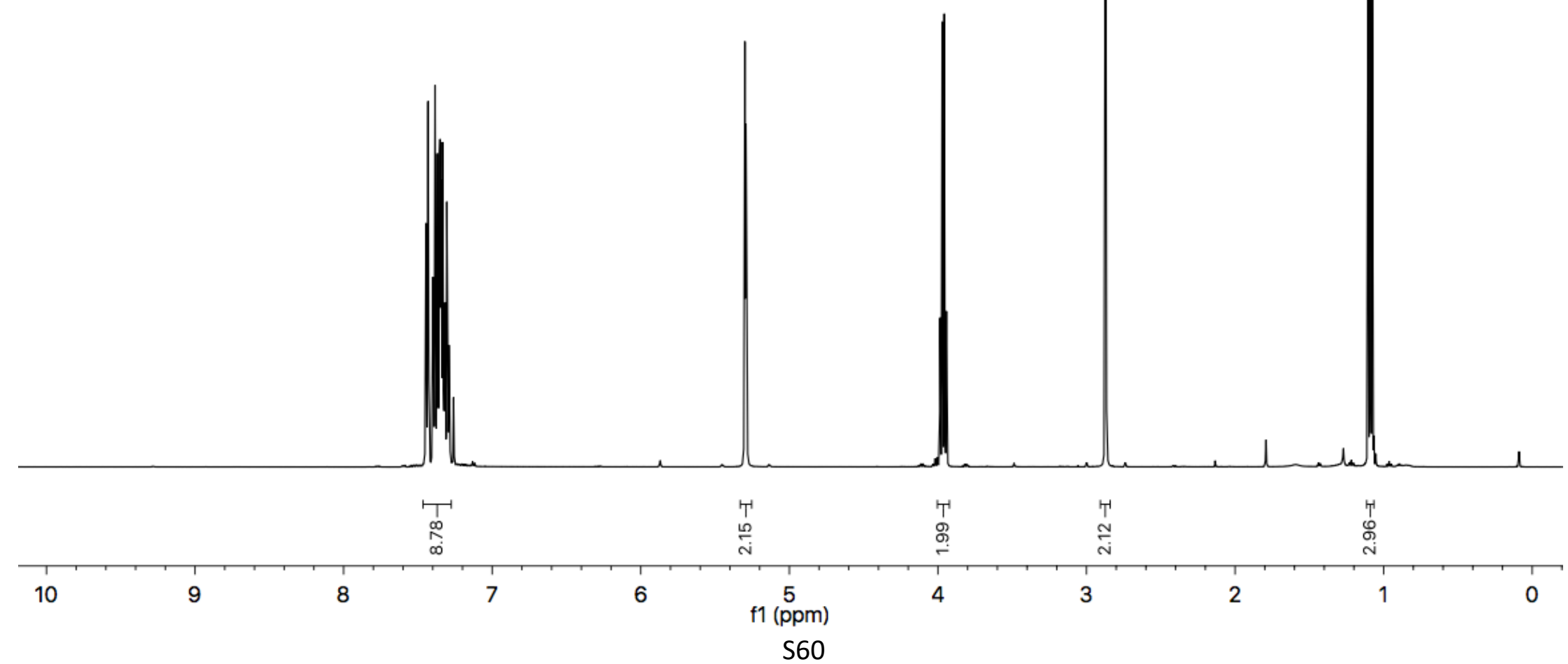



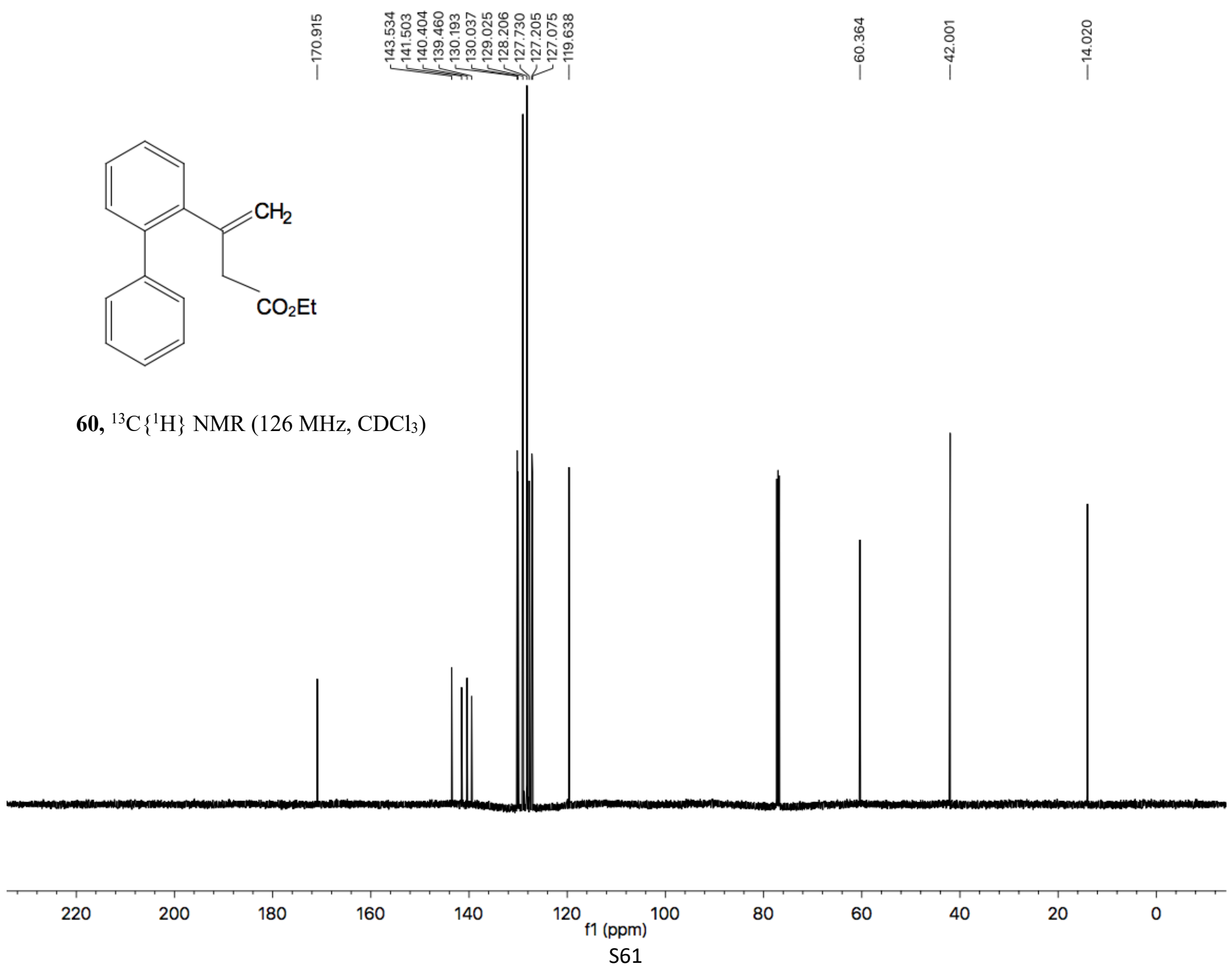


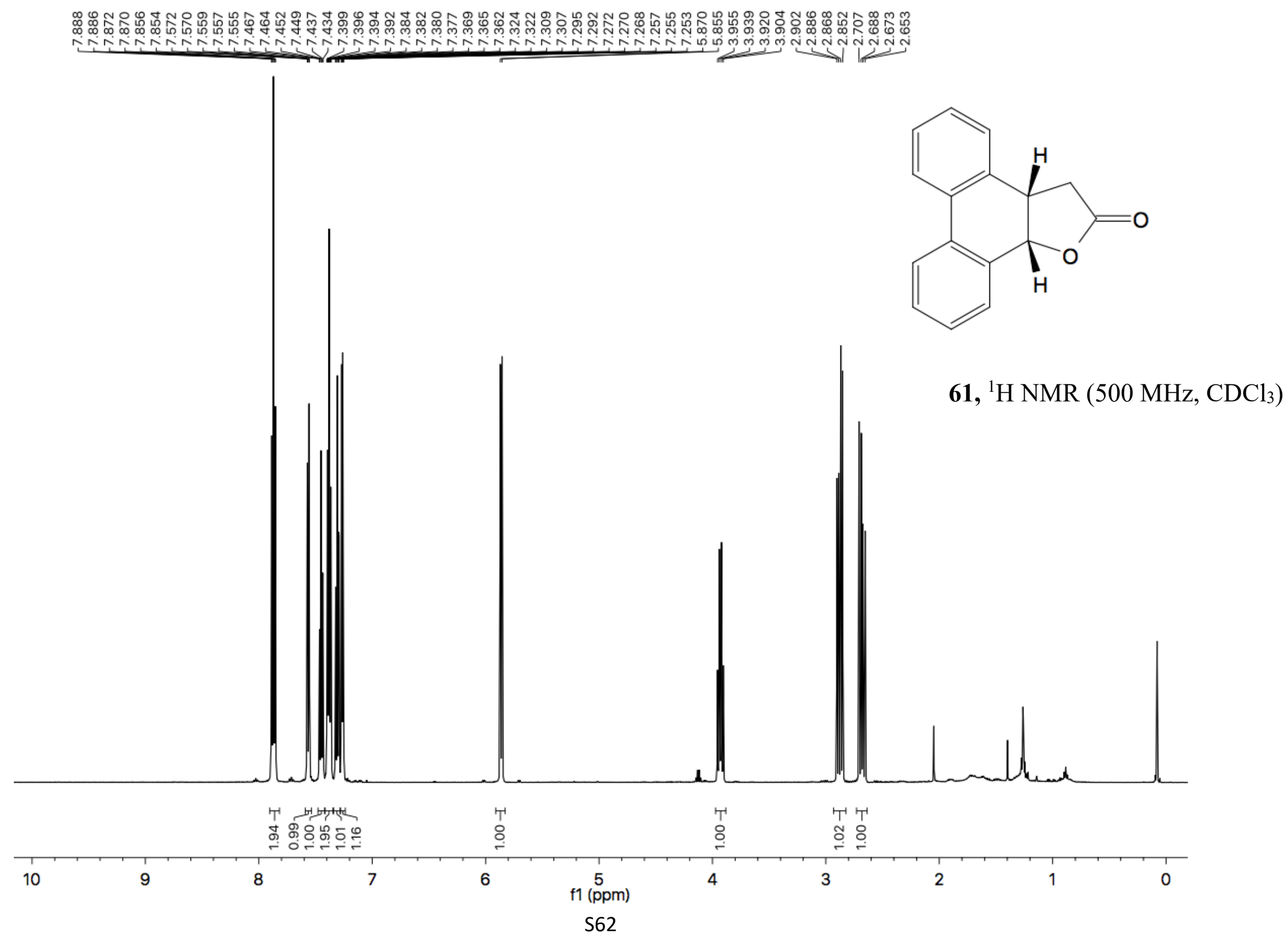




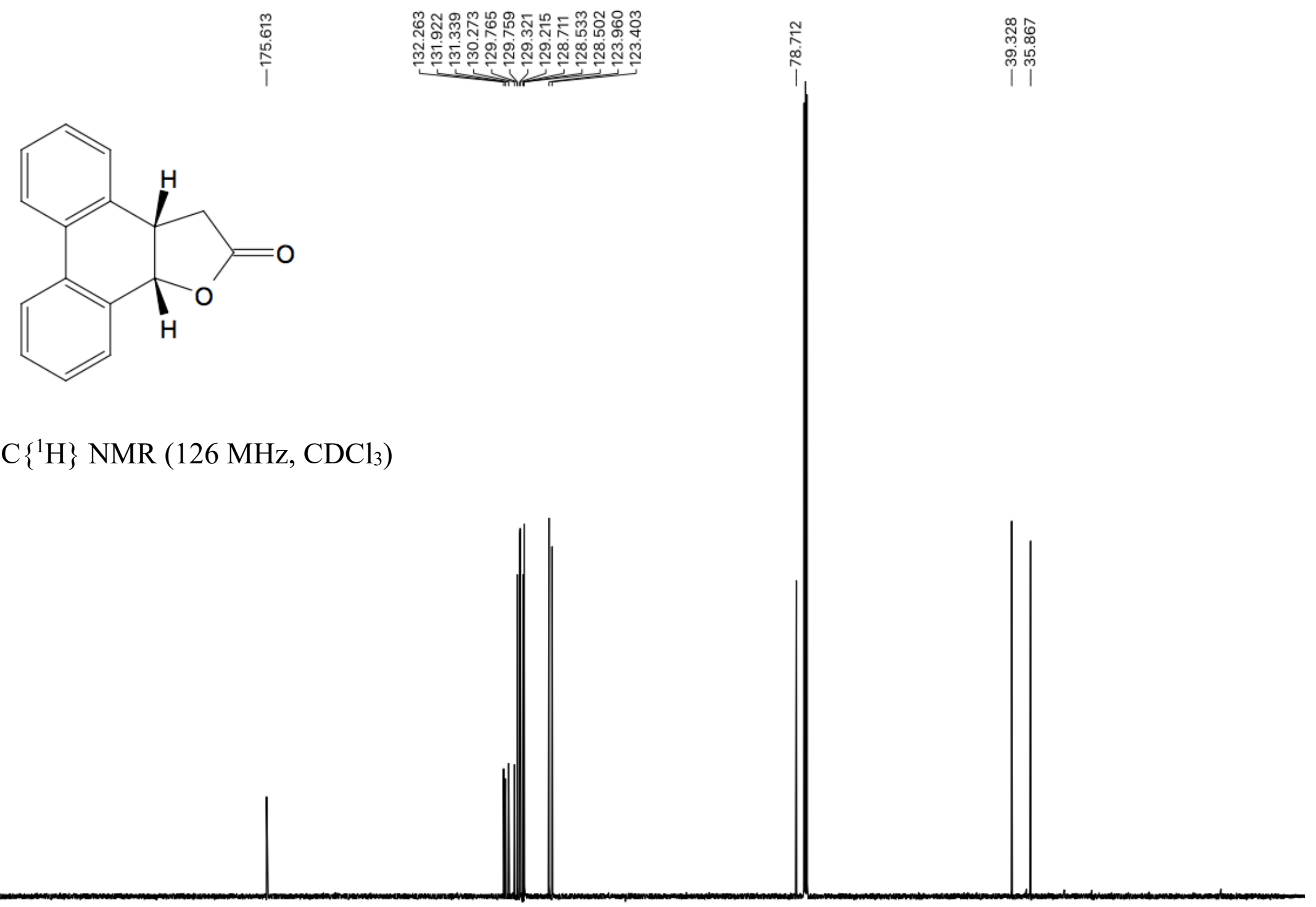




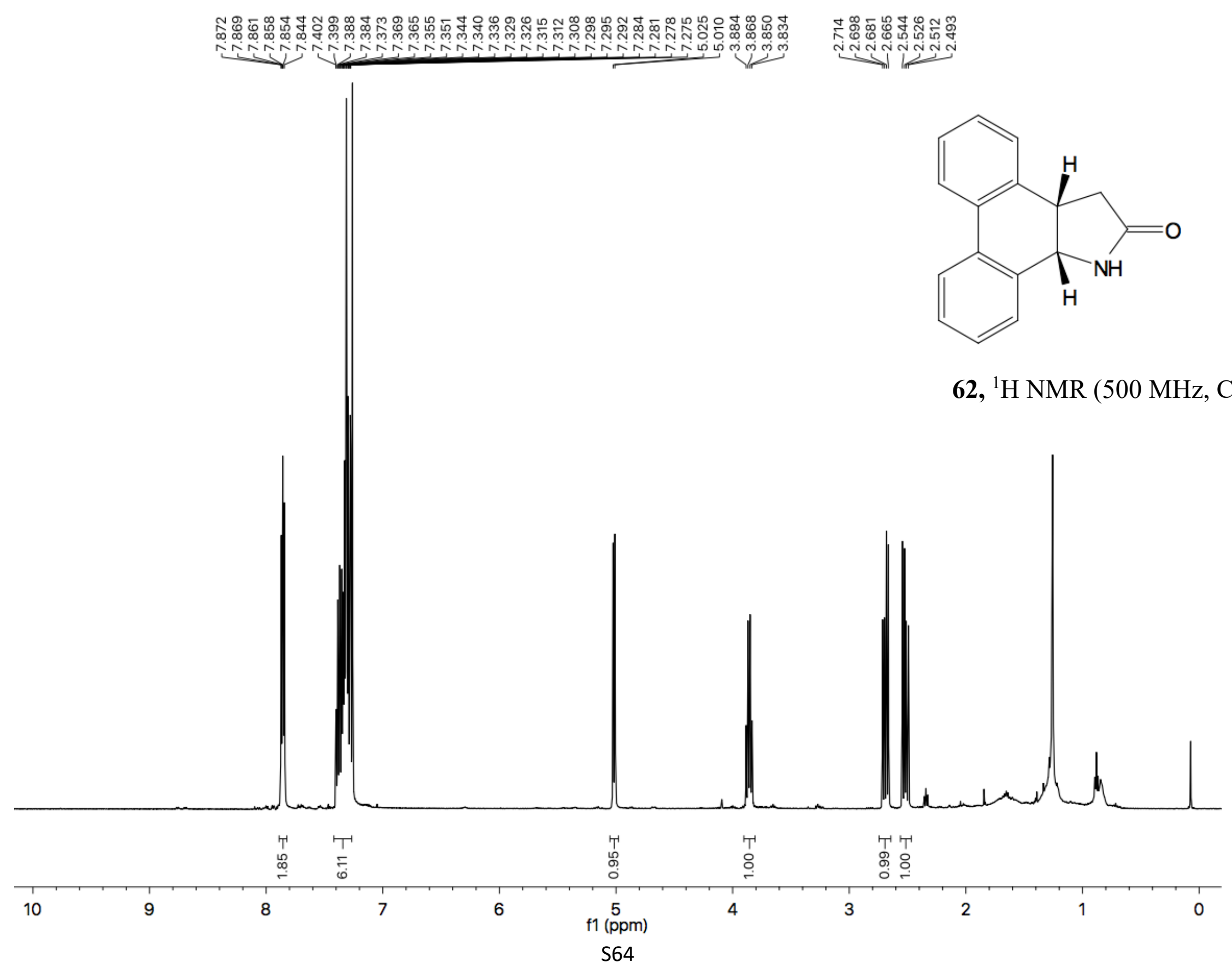




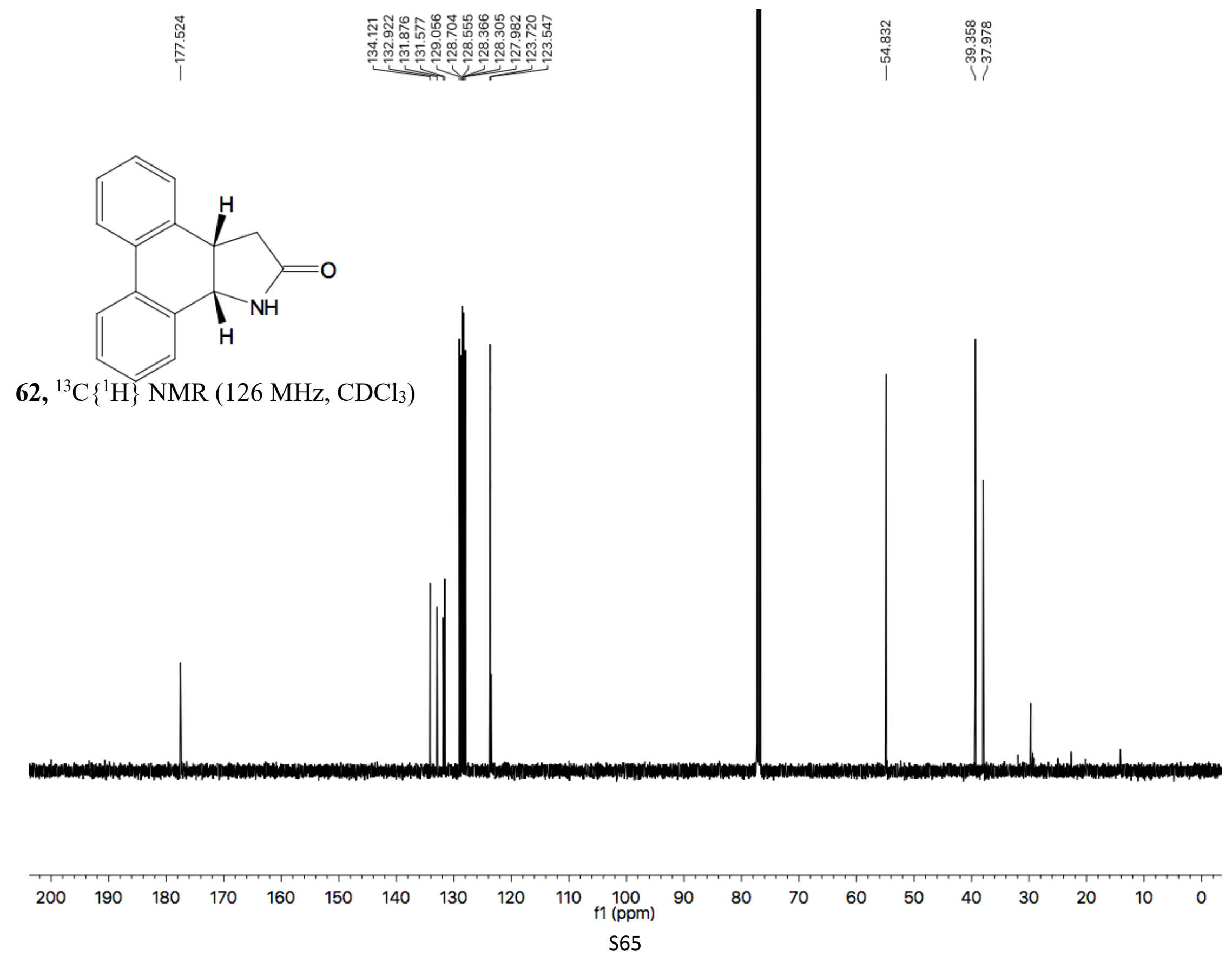




\section{Photochemical Reactor 350nm Lamp}

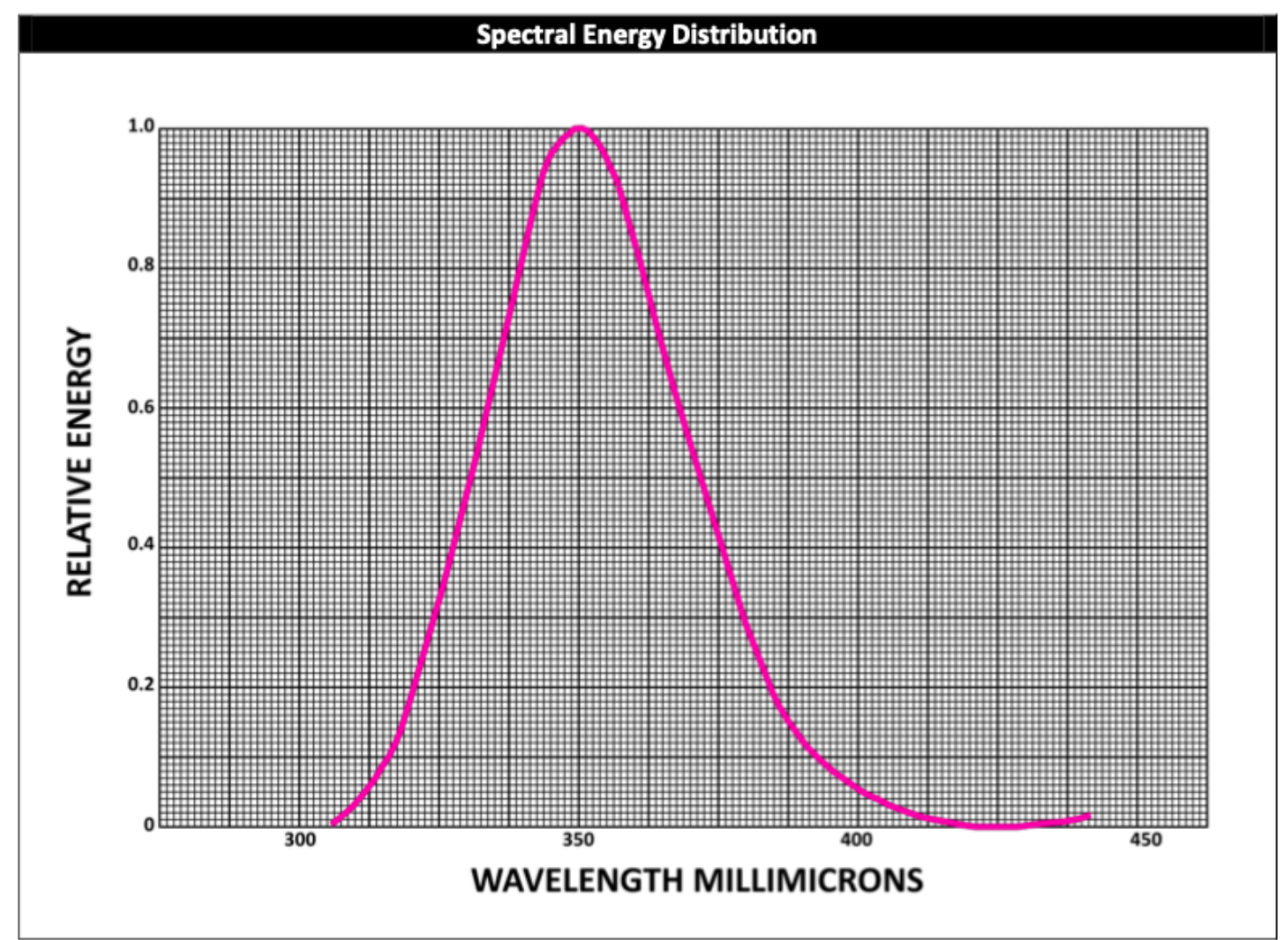

